\title{
Imageability and distributional typicality measures of nouns and verbs in contemporary English
}

\author{
CHRISTINE CHIARELLO, CONNIE SHEARS, and KEVIN LUND \\ University of California, Riverside, California
}

\begin{abstract}
Dissociations between noun and verb processing are not uncommon after brain injury; yet, precise psycholinguistic comparisons of nouns and verbs are hampered by the underrepresentation of verbs in published semantic word norms and by the absence of contemporary estimates for part-of-speech usage. We report herein imageability ratings and rating response times (RTs) for 1,197 words previously categorized as pure nouns, pure verbs, or words of balanced noun-verb usage on the basis of the Francis and Kučera (1982) norms. Nouns and verbs differed in rated imageability, and there was a stronger correspondence between imageability rating and RT for nouns than for verbs. For all word types, the image-rating-RT function implied that subjects employed an image generation process to assign ratings. We also report a new measure of noun-verb typicality that used the Hyperspace Analog to Language (HAL; Lund \& Burgess, 1996) context vectors (derived from a large sample of Usenet text) to compute the mean context distance between each word and all of the pure nouns and pure verbs. For a subset of the items, the resulting HAL noun-verb difference score was compared with part-ofspeech usage in a representative sample of the Usenet corpus. It is concluded that this score can be used to estimate the extent to which a given word occurs in typical noun or verb sentence contexts in informal contemporary English discourse. The item statistics given in Appendix B will enable experimenters to select representative examples of nouns and verbs or to compare typical with atypical nouns (or verbs), while holding constant or covarying rated imageability.
\end{abstract}

Word recognition is one of the most frequently studied phenomena in cognitive science. We now have available a rich empirical and theoretical base that has fostered inquiry into fundamental mechanisms of lexical access and retrieval (Forster, 1994; Seidenberg \& McClelland, 1989; Stone \& Van Orden, 1993). However, our knowledge of such mechanisms is heavily skewed toward the representation and processing of nouns, since most experiments either utilize nouns exclusively or select items without regard to part of speech.

Neuropsychological investigations, in contrast, document a powerful influence of part of speech on the processing of single words. Dissociations in the comprehension and production of open class (nouns, verbs, adjectives) and closed class (articles, auxiliaries, prepositions) items in aphasic patients are well known (Caplan, 1987). More recently, patients with selective deficits in verb retrieval, with sparing of nouns, have been the focus of intense investigation (Caramazza \& Hillis, 1991; Daniele, Guistolisi, Silveri, Colosimo, \& Gainotti, 1994); the reverse dissociation (greater impairment of noun than of verb

This research was supported by NSF Grant 97-29009 to C.C. and by NSF Presidential Faculty Fellow Award SBR-9453406 to C. Burgess. We thank Stella Liu, Ron Hasbrooke, and Nancy Quan for their assistance with this project and Curt Burgess, Natalie Kacinik, and Stella Liu for helpful comments on an earlier version of this manuscript. Correspondence concerning this article should be addressed to C. Chiarello, Department of Psychology, University of California, Riverside, CA 92521 (e-mail: christine.chiarello@ucr.edu). processing) has also been reported (Daniele et al., 1994; Zingeser \& Berndt, 1990). Neuroimaging (Warburton et al., 1996) and electrophysiological (Koenig \& Lehmann, 1996; Molfese, Burger-Judisch, Gill, Golinkoff, $\&$ Hirsch-Pasek, 1996) studies also support the idea of a neural dissociation between noun and verb processing mechanisms. Such data strongly imply that grammatical class is an important factor in the comprehension and production of individual words and highlight the need for targeted investigation of noun versus verb processing in neurologically intact individuals.

However, precise experimental contrasts of nouns and verbs are hampered by two methodological constraints on stimulus selection. First, although the noun-verb distinction is primarily a grammatical one, nouns and verbs, even if matched for frequency of occurrence and length, are likely to differ on semantic dimensions, such as imageability, that are known to influence lexical processing (Balota, Ferraro, \& Connor, 1991). A second methodological challenge for noun-verb experiments arises from the fluid nature of grammatical class assignment in English. Whereas some words are used exclusively as nouns or verbs, others (e.g., sleep) can represent either class, even without the addition of a derivational affix. Thus, this categorical contrast might be better conceptualized as a nouniness or verbiness continuum, which demands a measure that accurately reflects the extent to which a word is used in noun and verb contexts. In this report, we present (1) imageability ratings and rating response times (RTs) for a large set of words that includes a high proportion of 
verbs and (2) two new, continuous measures of nounverb distributional typicality that reflect statistical regularities present in contemporary discourse contexts. We begin by briefly discussing earlier work that is relevant to each measure.

\section{Imageability Ratings}

In order to be certain that noun-verb processing differences reflect grammatical (rather than partially correlated semantic) influences, it is necessary to match words for imageability (and/or other semantic dimensions). Unfortunately, verbs are notably underrepresented in most published semantic word norms (Paivio, Yuille, \& Madigan, 1968; Toglia \& Battig, 1978). Imageability ratings have been reported for the Toronto Word Pool, which includes verbs, adjectives, and adverbs, in addition to nouns (Friendly, Franklin, Hoffman, \& Rubin, 1982). However, since single-syllable words were not included in this corpus, no ratings are available for many of the most common verbs in English (e.g., see, think, sit, eat, grow, etc.). To address this problem, we report here imageability ratings for a large sample of nouns and verbs.

We also report the mean RTs for each word rating, in order to provide an additional index of ease of image generation. To our knowledge, there are no prior reports of RT measures for normative word-rating tasks. Word ratings are considered to be metalinguistic off-line tasks, and little is known about the on-line processes individuals use to assign such ratings. In the case of imageability ratings, it is presumed that the ratings reflect ease of mental image generation. If this is so, words receiving high imagery ratings should yield the fastest RTs. Furthermore, those receiving the lowest imagery ratings should produce the slowest responses, reflecting a difficult and time-consuming attempt to generate an image for an unimageable concept. Thus, RTs should decrease in a roughly linear manner as imageability ratings increase.

However, it is also possible that such ratings can be derived without an actual image generation attempt. Perhaps each word's semantic features are initially examined for the frequency of sensory-motor attributes. If many such attributes are found, a rapid high imagery rating could be given, whereas a low imagery rating could be quickly assigned if few or no such attributes are detected. But if a moderate number of sensory-motor attributes are found, a more time-consuming additional process would be undertaken, either to examine the nature of the features themselves or, perhaps, to attempt to generate an image. This account is consistent with feature comparison models that were developed to account for RT data in semantic verification tasks (Smith, Shoben, $\&$ Rips, 1974). If imagery ratings reflect a similar feature-based process, a curvilinear relation between ratings and RTs should be observed (with slowest responses for the intermediate ratings). Contrasting the RT-rating relationship for nouns and verbs will additionally suggest whether there are form class differences in how imageability decisions are made.

\section{Noun-Verb Usage Metrics}

To date, frequency data have been used to determine the extent to which words have predominant noun or verb usages. The Francis and Kučera (1982) norms, which tally frequency by part of speech (on the basis of human judgments of the word's role in published sentence contexts), have been used for this purpose (e.g., Berndt, Mitchum, Haendiges, \& Sandson, 1997; Zingeser \& Berndt, 1990). Although useful, these norms are now rather dated, and the corpus on which they are based is relatively small and may underrepresent lower frequency items (see Burgess \& Livesay, 1998). Furthermore, since only formal published texts (i.e., books, periodicals, newspapers) were sampled, the Francis and Kučera data will not reflect the greater flexibility in part-of-speech usage that occurs in more informal language contexts. Thus, it is likely that these conservative norms underestimate the extent to which many words can be used interchangeably as nouns and verbs in contemporary discourse, thereby limiting their utility as an index of psycholinguistic experience.

Friendly et al. (1982) took a different approach to estimating the frequency of grammatical class usage. Psychology undergraduates $(N=120)$ were given a list of words and, for each, were instructed to "mentally generate a sentence containing that item" and then to record the part of speech that the stimulus item represented in their sentence. Friendly et al. reported the mean percentage of noun usage for each word as derived from these data. Although this measure can reflect informal usages, there are several problems with this approach. First, data were only collected for words having dictionary definitions for more than one part of speech. Thus, there is no way to determine whether words that lexicographers have determined are unambiguous nouns or verbs are in fact used unambiguously in current discourse. Second, since the participants did not record the sentences they generated, there was no way to check the accuracy of their partof-speech judgments. Indeed, it is possible that some participants may not have actually generated sentences for all the items but, rather, may have made part-of-speech judgments based on viewing the word in isolation. Such judgments might then reflect students' ideas of what the part of speech is supposed to be, rather than how they actually use the word themselves. Third, even if the participants' judgments accurately reflected the sentences they generated, the resulting estimate is based on only $120 \mathrm{oc}-$ currences for each word, and it is unknown how this relates to the part-of-speech distribution actually encountered in the individual's language experience. Finally, because only the percentage of noun usage is reported, one cannot determine the frequency of verbs (or other parts of speech) generated in this sample.

In sum, although the Friendly et al. (1982) sentence generation task represents an innovative attempt to gather part-of-speech data without relying on the analysis of formal texts, it also highlights the difficulties of acquiring a representative sample of less formalized language and the 
limitations of relying on human decisions for each token in the sample. Ideally, to index noun-verb usage, one would like to have available a very large language sample that includes informal (i.e., conversational) exchanges, with part-of-speech usages estimated without requiring timeconsuming judgments. In this report, we utilize the Hyperspace Analog to Language (HAL) model (see Burgess, 1998) to computationally derive noun and verb context distances. As will be described in more detail below, this measure allows us to identify words that resemble nouns more than verbs in their distributional contexts (and vice versa). The noun-verb distance difference (NVDD) scores we report herein can be used to estimate the extent to which a word is used in noun versus verb contexts without relying on human judgments. Furthermore, because the HAL context vectors were derived from the Usenet corpus (which includes over 300 million word occurrences gathered from Usenet newgroups), this measure will reflect more contemporary conversational exchanges (Burgess, 1998; Lund \& Burgess, 1996).

Imageability ratings, RTs, and HAL NVDD scores were collected for 1,197 three- to six-letter words. The words were those that would be considered to be pure nouns, pure verbs, or balanced noun-verbs on the basis of the Francis and Kučera (1982) norms, since these represent word classes most likely to be used in psycholinguistic investigations. We examined the relation between imageability ratings and RTs and the suitability of the HAL measures for assessing the degree to which a word occurs in noun versus verb contexts. The normative data reported here should prove useful for future psycho- and neurolinguistic investigations of noun-verb processing differences.

\section{METHOD}

\section{Imageability Ratings}

Participants. The participants were 89 native English-speaking University of California, Riverside students ( 49 female; mean age $=$ 20.7 years). Each received payment $(\$ 5 / \mathrm{h})$ or course credit for participating. Twenty-two of the participants were tested in more than one session ( 21 received two sessions, I received three sessions), receiving a different stimulus list on each test day. An average of 8 days elapsed between test sessions.

Materials. All 1,197 stimulus words (three, four, five, or six letters in length) were taken from Francis and Kucera (1982). Pure verbs $(n=427)$ had verb frequencies of two or greater but no listings for any other part of speech. The resulting set of verbs represented nearly $50 \%$ of the pure verbs of the target length given in Francis and Kučera (verbs that the authors deemed obscure or unlikely to be known to the average college student were excluded). A set of 555 pure nouns was also selected, including words having noun frequencies of two or greater but no listings for any other part of speech. Since the Francis and Kučera norms contained over 3,200 such nouns, the authors selected a subset to span a range of frequencies and intuitive imageabilities. Finally, 215 balanced nounverbs were selected. These represented a nearly exhaustive list of words having similar frequencies for noun and verb usages (but none for any other part of speech). In this study, we used the Francis and Kučera frequencies that were summed over all the inflected forms of a given word. For each word, separate log frequencies were calculated for noun and for verb use; items with noun-verb log fre- quency differences of \pm 0.20 or less were considered to be relatively balanced in noun-verb usage (mean noun-verb difference of selected items $=0.005$ ).

Four experimental lists were created, each consisting of a unique set of 300 items (134-142 nouns, 105-113 verbs, 53-55 balanced words). Although it was our intention to gather data for 1,200 unique items, an error in stimulus list construction led to the elimination of three items from the final sample. A practice list consisting of another 10 items was also constructed.

Apparatus and Procedure. Power Macintosh 7500/100 computers (AppleVision 1710 Display) were used for stimulus presentation and recording of responses. The participants used the numeric keypad on the computer's keyboard to register their imageability ratings. The Psyscope software package was used to control experimental events (Cohen, MacWhinney, Flatt, \& Provost, 1993).

The participants were seated in individual testing rooms, approximately $57 \mathrm{~cm}$ from the computer display. They then received oral instructions from the experimenter and read a briefer set of instructions on the computer screen (the latter is provided in Appendix A). Imageability instructions were very similar to those employed by Toglia and Battig (1978), using a 7-point scale ( $1=$ not at all imageable; $7=$ highly imageable). The instructions emphasized the importance of using the entire range of ratings. The participants were also informed that they should try to create a mental image of the word, but not to spend a lot of time thinking about their response, since their "first impressions" were of greatest interest. They were told to register their rating with the numeric keypad and to press the keypad Enter key after typing their rating. The participants rested their fingers over the keypad in whatever position they felt was most comfortable.

The rating scale appeared at the top of the computer screen for each trial (see Appendix A). The stimulus word appeared in lowercase letters (Geneva Bold 18) in the center of the screen and remained visible until the participant responded. The message "Rating $=\ldots$ "also appeared four lines below the stimulus word; when a number was typed on the keypad, it appeared just after this message. RT was calculated as the time from the onset of the stimulus word until the Enter key was pressed. The screen was cleared once the Enter key was pressed, and the next trial was initiated after a 500 -msec interval.

Each session began with the set of 10 practice trials, followed by three blocks of 100 trials each. Short rest breaks were given after each trial block.

Each participant viewed one experimental list per session. Order of word presentation was independently randomized for each participant. Each of the four experimental lists was seen by 28 participants ( 14 females, 14 males).

\section{HAL Measures}

Before describing our method for determining noun and verb context distances, a brief review of how words are represented in the HAL model is in order (for more detailed accounts, see Burgess, 1998; Burgess, Livesay, \& Lund, 1998; Lund \& Burgess, 1996). The HAL model employs the Usenet corpus to derive a matrix of word co-occurrence values via a 10 -word window that moves across the text, so that lexical co-occurrences are weighted by the distances between words within the window. Using the 70,000 most frequently occurring items in the corpus, the model constructs a $70 \times 70 \mathrm{~K}$ co-occurrence matrix to represent co-occurrence (i.e., context) vectors for each of the 70,000 items. These context vectors can be thought of as the coordinates of points in high-dimensional space, where each word is represented by a single point. Words that occur in similar contexts will have similar vector representations and, thus, will occupy nearby locations in high-dimensional space. Burgess and colleagues have demonstrated that the distance between such word representations (henceforth referred to as the con- 
text distance) encodes both semantic and grammatical category information (Burgess \& Lund, 1997).

In particular, the HAL co-occurrence vectors are quite sensitive to grammatical class. Multidimensional scaling of vector representations produces clusters of items that segregate by part of speech, reflecting the fact that words from the same grammatical category tend to occur in similar sentential contexts (Burgess, 1998; Burgess \& Lund, 1997). Interestingly, Burgess and Lund found that words that could be used as both nouns and verbs tended to occupy locations between the noun and the verb clusters. But although context distances in the HAL model clearly represent grammatical class information, the model cannot explicitly tag words for part of speech. This led us to devise a similarity-based measure of noun and verb classification that made use of grammatical class information encoded in HAL's context distances.

The set of 555 pure nouns and 427 pure verbs, as classified by the Francis and Kučera norms were used to derive noun and verb context distances as follows. First, we computed the context distances between each of our 1,197 words and each of the Francis and Kučera pure nouns and pure verbs. Next, a HAL noun distance score was created for each word by averaging the distances between that word and all of the pure nouns. Verb distance scores were computed by averaging distances between each word and all of the pure verbs. This resulted in HAL noun distance and verb distance scores for each item that should reflect how contextually similar that word is to a relatively unambiguous set of nouns and verbs, respectively. However, because context distances encode a variety of information (including semantic dimensions and word frequency; see Lund \& Burgess, 1998), one cannot directly compare noun (or verb) distances across two different words. Hence we constructed a NVDD score (the difference between a word's noun and verb distances) to index the extent to which a given word was more typical in its contextual distribution to nouns or verbs. This difference score should subtract out other information about the word that is carried in the context vectors, leaving an estimate of noun versus verb use that can be compared across different words. On this measure, words that mainly occur in contexts that typify nouns will have a negative difference score, whereas words that mainly occur in contexts that typify verbs will have a positive difference score. We contend that this difference score indexes the distributional typicality of a word's use as a noun or a verb.

An inflected difference score was also computed as follows. First, all the possible inflected forms (both regular and irregular) were generated for each of the 1,197 words. Next, noun and verb distances were calculated for each form as described above. That is, the distance between each form and each of the uninflected nouns and verbs was computed. Because some inflected forms are ambiguous in noun-verb classification (e.g., building), we computed inflected-to-uninflected distances, rather than inflected-to-inflected distances. These distances were each weighted by the Usenet frequency for each form and then averaged across all forms of the word (inflected and uninflected). For example, the inflected verb (or noun) distances for daze would be the average of the frequencyweighted verb (or noun) distances computed for the forms daze, dazed, dazing, and dazes. Thus, the final inflected difference scores should indicate the extent to which a word, across all its possible inflected forms, typifies the contextual distribution of nouns or verbs.

To validate and further explore the HAL noun-verb measure, representative contexts from the Usenet corpus were sampled for a subset of 50 uninflected words. These words were selected to span the range of uninflected noun-verb difference scores for all three Francis-Kučera word classes, including both words for which the HAL measure agreed with the Francis-Kučera classification, and words for which these two indices disagreed. The sampling procedure for each word was as follows. First, all instances of the target word were identified in the Usenet corpus, and the context was delineated. The context for each instance was operationally defined as any text between two terminal punctuation marks (e.g., ".," "!!," "?") that included the target word. The computer then sampled every Nth context, where $N$ was defined as the total number of contexts divided by 100 . The first author coded each instance of the target word for part of speech. If the target word occurred more than once in a given context, only the first occurrence was coded. Any unusual uses for the target word (e.g., abbreviations, idioms) were noted.

A similar procedure was used to sample inflected contexts for 28 words. Here, all the contexts containing a given word or any of its inflected variants were identified, and the procedure described above was employed to select a representative sample of contexts that would encompass inflected as well as uninflected forms of a given word. These contexts were coded to provide an assessment of the inflected noun-verb difference measure.

Finally, frequencies for all 1,197 items were estimated from the Usenet corpus. Frequencies were summed across all inflected forms for each word, to better correspond to the summed Francis-Kučera frequencies employed to classify words as nouns, verbs, or balanced forms.

\section{RESULTS AND DISCUSSION}

The mean imageability rating and rating $\mathrm{RT}$ for each word are listed in Appendix B, along with the log summed Usenet frequency and the HAL context distance measures. Words with missing noun and verb distance values in Appendix B are not represented in the current HAL matrix. The means for each of our primary measures are given by Francis-Kučera word class in Table 1 . The correlations among these measures are provided in Table 2.

\section{Imageability Ratings}

Comparison with previous norms. A subset of our words (216 nouns, 80 verbs, 79 balanced) were also listed in the Toglia and Battig (1978) norms. There was good correspondence in imageability ratings between the norms $(r=.88)$ for these overlapping items, which was stronger for the Francis-Kučera nouns $(r=.88)$ and balanced forms $(r=.88)$ than for the verbs $(r=.75)$.

Table 1

Means (and Standard Deviations) of Imageability Ratings, Rating Reaction Times (RTs), Usenet Summed Log Frequency, and HAL Noun-Verb Distance Difference Scores, According to Word Class as Determined by the Francis and Kučera (1982) Norms

\begin{tabular}{|c|c|c|c|c|c|c|c|c|c|c|}
\hline \multirow{2}{*}{$\begin{array}{c}\text { Francis and Kučera } \\
\text { Word Class }\end{array}$} & \multicolumn{2}{|c|}{ Imageability Rating } & \multicolumn{2}{|c|}{ Rating RT } & \multicolumn{2}{|c|}{ Usenet Log Freq } & \multicolumn{2}{|c|}{ N-V Diff } & \multicolumn{2}{|c|}{ Inflected N-V Dif } \\
\hline & $M$ & $S D$ & $M$ & $S D$ & $M$ & $S D$ & $M$ & $\overline{S D}$ & $M$ & $S D$ \\
\hline$\overline{\mathrm{Pu}}$ & 5.3 & 1.46 & 230 & 5 & 3.7 & 073 & -100 & 36 & -90 & 34 \\
\hline Balanced noun-verb & 5.1 & 1.5 & 2,4 & 46 & 3.80 & 0. & -37 & 5 & -34 & 44 \\
\hline Pure verb & 3.96 & 1.74 & 2,686 & 412 & 3.71 & 0.85 & 105 & 59 & 33 & 50 \\
\hline
\end{tabular}


Table 2

Correlation Matrix for Word Measures

\begin{tabular}{|c|c|c|c|c|c|c|c|c|c|c|}
\hline & $\begin{array}{l}\text { Image } \\
\text { Rating }\end{array}$ & $\begin{array}{c}\text { Image } \\
\text { RT }\end{array}$ & $\begin{array}{c}\text { FK } \\
\text { Log Freq }\end{array}$ & $\begin{array}{l}\text { Usenset } \\
\text { Log Freq }\end{array}$ & $\begin{array}{c}\text { HAL } \\
\text { Noun } \\
\text { Distance }\end{array}$ & $\begin{array}{c}\text { HAL } \\
\text { Verb } \\
\text { Distance }\end{array}$ & NVDD & $\begin{array}{l}\text { HAL Infl } \\
\text { Noun } \\
\text { Distance }\end{array}$ & $\begin{array}{c}\text { HAL Infl } \\
\text { Verb } \\
\text { Distance }\end{array}$ & $\begin{array}{c}\text { Inflected } \\
\text { NVDD }\end{array}$ \\
\hline Image Rating & 1.00 & & & & & & & & & \\
\hline Image RT & -.68 & 1.00 & & & & & & & & \\
\hline FK Log Frequency & -.02 & -.02 & 1.00 & & & & & & & \\
\hline Usenet Log Freq & .06 & .03 & .81 & 1.00 & & & & & & \\
\hline HAL Noun Distance & -.36 & .20 & -.28 & -.33 & 1.00 & & & & & \\
\hline HAL Verb Distance & -.20 & -.20 & -.39 & -.39 & .34 & 1.00 & & & & \\
\hline NVDD & -.48 & .38 & .11 & .07 & .54 & -.61 & 1.00 & & & \\
\hline HAL Inflected Noun Distance & -.33 & .17 & -.36 & -.42 & .92 & .39 & .42 & 1.00 & & \\
\hline HAL Inflected Verb Distance & .09 & -.13 & -.43 & -.45 & .47 & .91 & -.42 & .60 & 1.00 & \\
\hline Inflected NVDD & -.47 & .38 & .09 & .05 & .48 & -.59 & .93 & .43 & -.47 & 1.00 \\
\hline
\end{tabular}

Note-All correlations in bold type are significant at . 01 or better. RT, response time; FK, Francis-Kučera; NVDD, noun-verb distance difference.

Likewise, there was an overall correlation of .92 between our imageability ratings and those reported in the Toronto norms of Friendly et al. (1982) for 192 overlapping items ( 87 nouns, 87 verbs, 18 balanced). The correlations were stronger for nouns $(r=.94)$ and balanced forms $(r=.92)$ than for verbs $(r=.71)$.

Thus, there is a good correspondence between the present imageability ratings and previously published norms, despite substantial differences in norming procedures (e.g., computerized vs. paper-and-pencil tasks) and populations. Words that are frequently used as nouns (pure nouns and balanced forms) show better agreement across norms than do the pure verbs. This may indicate greater variability in how verb, as compared with noun, concepts are imaged, consistent with the standard deviations, as reported in Table 1.

Ratings by frequency and Francis-Kučera grammatical class. As is noted in Table 2, there was no correlation of imageability rating and word frequency. This indicates that the participants' imageability ratings were not influenced in any regular way by differential familiarity with the stimulus words.

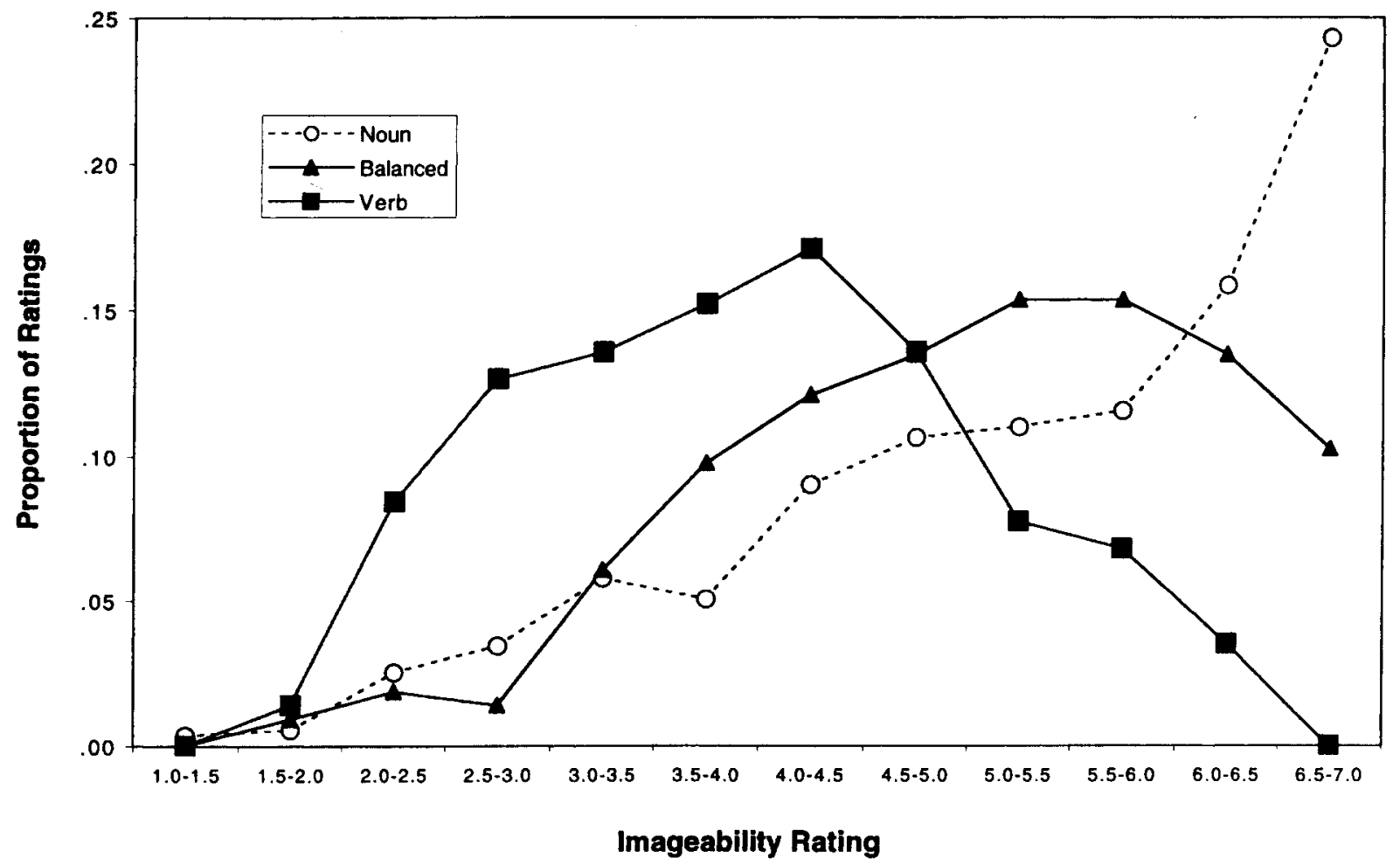

Figure 1. Proportion of imageability ratings given for nouns, balanced forms, and verbs (according to Francis \& Kučera, 1982 , classification). 
In general, nouns and balanced words were rated as more imageable than verbs. Figure 1 displays the distribution of imageability ratings for each Francis-Kučera word class. It is clear that the participants tended to reserve their highest imageability ratings for words with noun usages and that most nouns were rated as moderately to highly imageable. In contrast, pure verbs elicited much lower imageability ratings, but verb ratings were somewhat more evenly spread out over the entire range, as compared with noun ratings. The distribution of imageability ratings for the balanced forms was intermediate between these two patterns.

Imageability response times. There was no correlation between word frequency and imagery rating RTs (see Table 2). Since word frequency is a reliable predictor of response speed across a range of word recognition tasks (Balota \& Chumbley, 1984; Monsell, Doyle, \& Haggard, 1989), the absence of a correlation here is consistent with the idea that the RTs index the speed of postrecognition processes involved in assessing imageability, rather than word recognition latencies. This interpretation is supported by the overall negative correlation of these two measures $(r=-.68)$ : In general, the fastest imageability ratings were given to words rated most highly imageable. However, this association was much stronger for the pure nouns $(r=-.75)$ and balanced forms $(r=-.66)$ than for the pure verbs $(r=-.37)$. The scatter plots for each Francis-Kučera word class (see Figure 2) indicate that, especially for nouns and balanced forms, RTs increase as imagery ratings decrease up to the approximate midpoint of the rating scale and, thereafter, level off. Regression analyses with models for linear, quadratic, and cubic relations (Cohen \& Cohen, 1983) verified this departure from a linear trend. There was a significant linear trend for all Francis-Kučera word types [nouns, $F(1,554)=$ $791.8, p<.0001, r^{2}=.59$; balanced, $F(1,213)=177.5$, $p<.0001, r^{2}=.45$; verbs, $F(1,425)=70.6, p<.0001$, $\left.r^{2}=.14\right]$. The quadratic trend was also significant for all three word classes [nouns, $F(2,553)=567.4, p<.0001$, $r^{2}=.67$; balanced, $F(2,212)=107.2, p<.0001, r^{2}=$ $.50 ;$ verbs, $\left.F(2,424)=47.3, p<.001, r^{2}=.18\right]$. The cubic trend was not reliable for any word type.

These data are consistent with reliance on an image generation process, but one with an internally imposed response deadline. That is, within a certain time period, participants may attempt to generate an image and select an appropriate imageability rating as soon as an image becomes available. This would produce an image rating that corresponds to the ease and speed with which an image can be generated. However, the RT leveling for low image ratings implies that, if after some time ( $\sim 3 \mathrm{sec}$ ?), no image has been generated, no further image processing is attempted, and a low rating (1-3) is given. The data for the pure verbs, although qualitatively similar to those for nouns and balanced forms, show a much less consistent relation between image rating and RT (low $r^{2}$ values for both linear and quadratic trends). This may indicate a less consistent imaging process for verbal than for nominal concepts.

It should be noted, however, that our RT measures (amount of time to type the rating and hit the Enter key) were rather insensitive. It is likely that this increased both the mean and the variability of RTs. A better method for future studies would be to have participants speak aloud their ratings and to record vocal response latencies.

\section{HAL Noun-Verb Measures}

Our consideration of the HAL findings will be organized around four issues: (1) similarities and differences in noun-verb classification between Francis and Kučera (1982) and HAL; (2) comparison of HAL noun-verb difference scores to human coding of part-of-speech usages for a representative sampling of Usenet contexts; (3) comparison of the uninflected and the inflected noun-verb difference indices; and (4) the relation of the HAL nounverb difference measures to imageability and frequency.

Noun-verb classification: Francis-Kučera versus HAL. As is indicated in Figures 3 and 4, both the uninflected and the inflected HAL NVDD measures produced a good separation of the word types as determined by the Francis and Kučera (1982) norms, thereby providing some validation of the HAL measures. The Francis-Kučera pure nouns tended to have negative difference scores and the pure verbs tended to have positive difference scores, whereas balanced words had a more intermediate distribution (although somewhat more noun- than verblike).

However, this global consistency in classification is tempered by a nontrivial number of items for which the two measures fail to agree. Although, by definition, all pure forms had no usages for other parts of speech in the Francis-Kučera corpus, our noun-verb index suggests

Table 3

Examples of Words Classified Consistently (Bold) and Inconsistently by Francis and Kučera (1982) and the HAL Noun-Verb Difference Measure

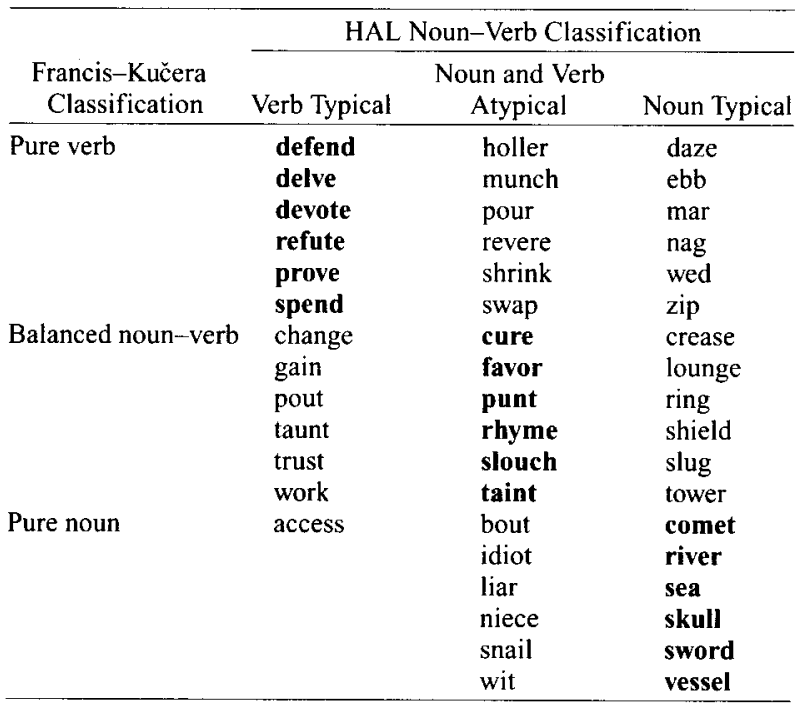



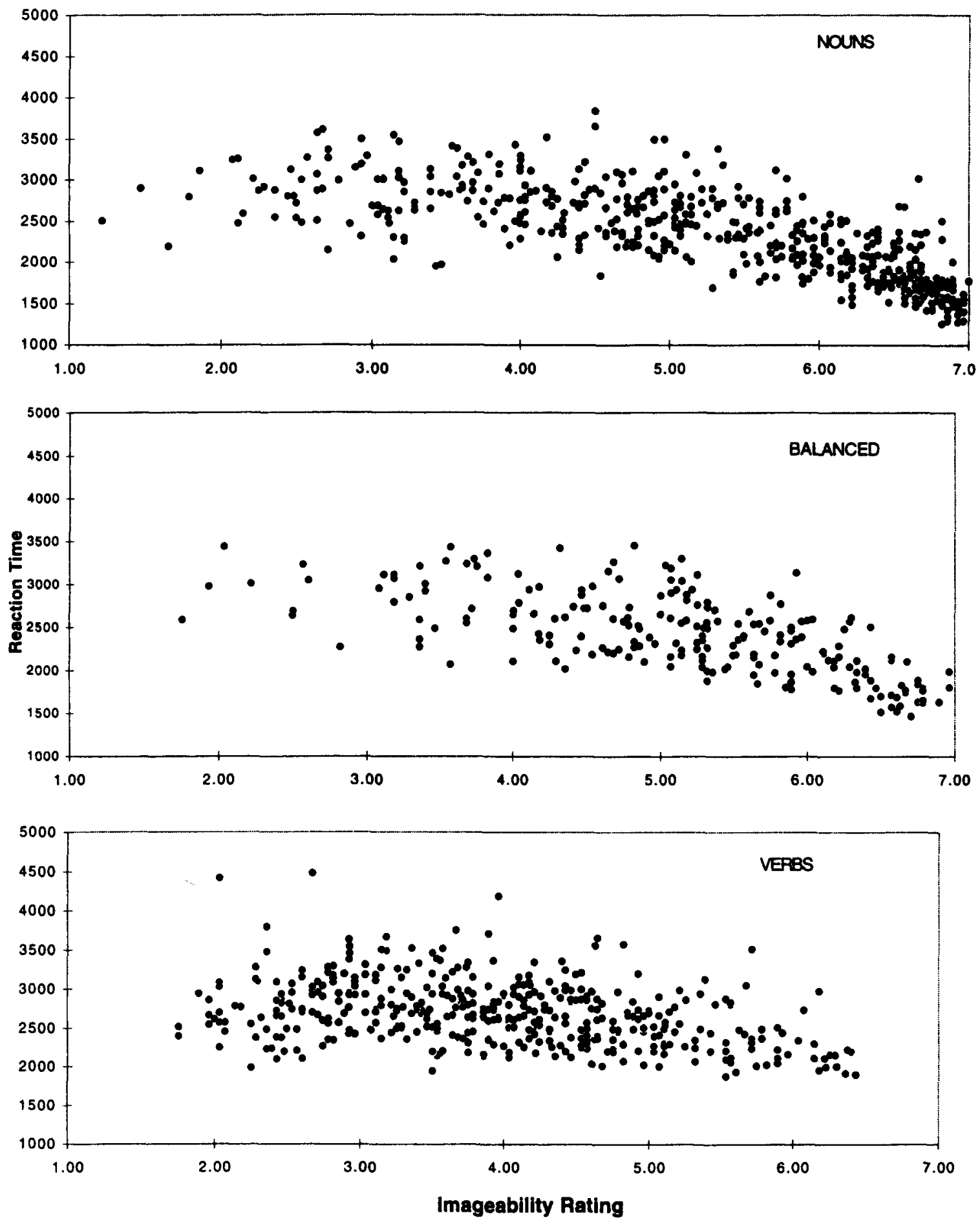

Figure 2. Scatter plots of imageability rating response time by mean imageability rating for nouns, balanced forms, and verbs (according to Francis $\&$ Kuxera, 1982, classification).

that some of these forms are much more nounlike (or verblike) than others. And it would appear to be better (from the perspective of the HAL model) to view a number of the putatively balanced words as rather typical nouns or verbs. Table 3 provides some examples of words classified consistently and inconsistently by both schemes. It should be noted, however, that because the HAL noun-verb difference score is a continuous measure, there is no point on the scale that can be identified as a categorical boundary between word classes.

There are a number of factors that could contribute to these discrepancies. (1) The Francis-Kučera classifica- 


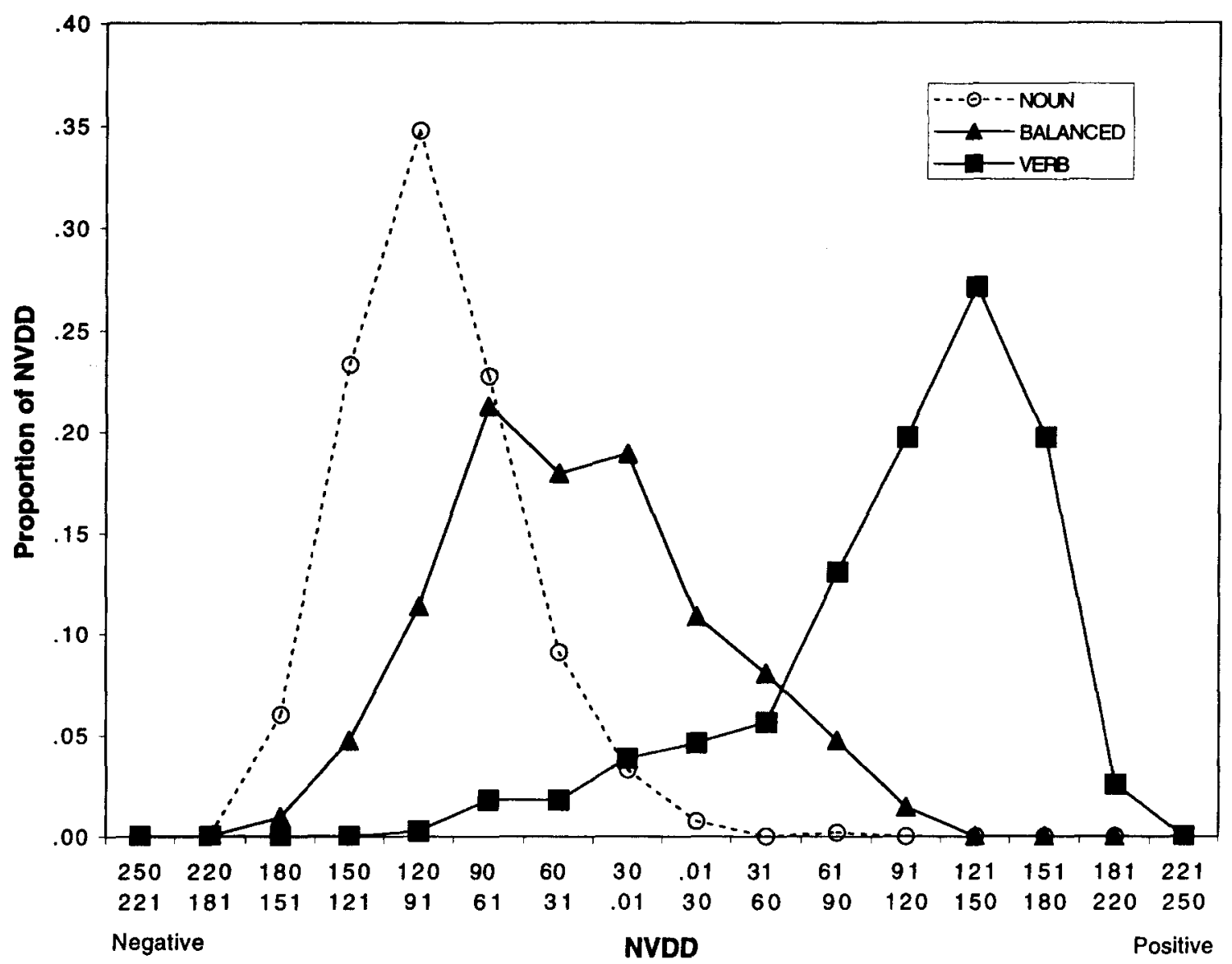

Figure 3. Proportion of noun-verb distance difference (NVDD) scores for words classified by Francis and Kučera (1982) as nouns, balanced forms, and verbs.

tion was based on direct counts of part-of-speech usages by human judges, whereas the HAL measures are based on computed similarity across context distances. We will consider the possibility that our difference score measures something other than (or in addition to) simple frequency of part-of-speech use. (2) The Francis-Kučera corpus was compiled from works published in 1961, 34 years prior to the assembly of the Usenet corpus (Burgess \& Livesay, 1998), and thus, some of the differences may reflect historical or generational changes in language use. (3) The Francis-Kučera corpus is based on formal texts, whereas the Usenet corpus includes much more informal and conversational exchanges. Thus, stylistic differences in language use would also be expected to contribute to the differing results. However, before evaluating such possibilities, we need to examine the extent to which the HAL difference measures reflect actual part-ofspeech usages within the Usenet corpus.

What does the HAL noun-verb difference index? Recall that our difference score measures the extent to which a word is more similar to a noun or a verb in the linguistic contexts in which it occurs. Words that nearly always occur in contexts that typify nouns should have large negative difference scores, whereas words that regularly occur in contexts that typify verbs should have large positive difference scores. Words with difference scores closer to zero are not likely to be typical of either nouns or verbs in the contexts in which they occur. If we are correct that this measure is an index of noun-verb distributional typicality, it should not always correspond to a simple count of the part-of-speech occurrences in the corpus (although we would expect a reasonably good correspondence among these measures). For example, one could imagine two words that are nearly always used as nouns, as based on a linguistic analysis of their sentence contexts, but which differ in the HAL measure because one occurs predominantly in contexts that typify other nouns, whereas the other occurs only in contexts that are very atypical of other nouns. If our noun-verb difference is best viewed as a typicality measure, this could account for some of the varying noun-verb classifications between HAL and Francis and Kučera (1982).

To determine the extent to which the difference score corresponds to noun versus verb usages in the Usenet corpus, consider the part-of-speech coding judgments for our sample of 50 words. As was described earlier, these 


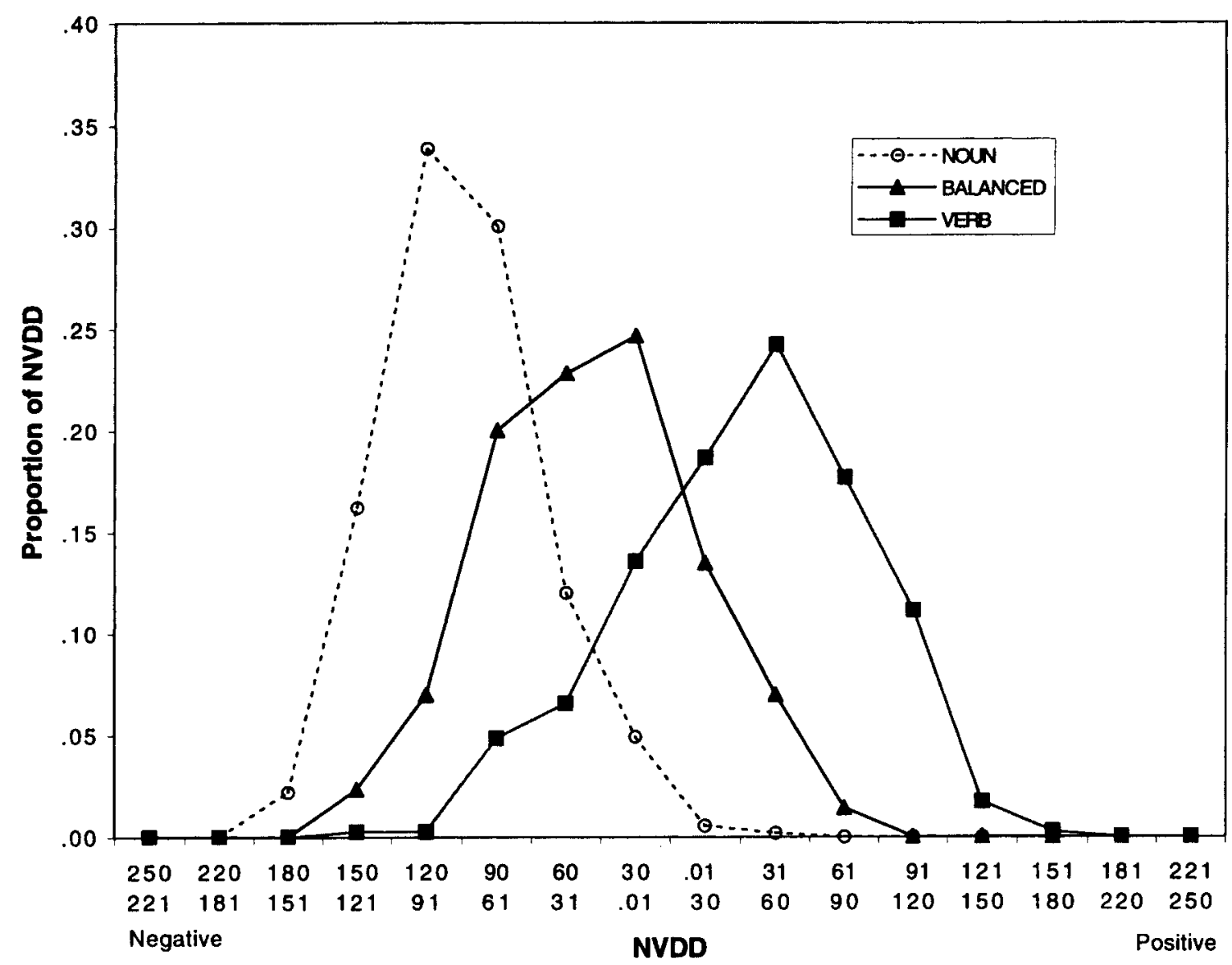

Figure 4. Proportion of inflected noun-verb distance difference (NVDD) scores for words classified by Francis and Kucera (1982) as nouns, balanced forms, and verbs.

words were selected to span a range of noun-verb difference scores and to include multiple examples of words from the three Francis-Kučera classes. Approximately half of the sample words had difference scores that "agreed with" the Francis-Kučera classification (e.g., sword, punish), whereas the others were chosen because their difference scores did not neatly correspond to the Francis-Kučera classification (e.g., zip, crease). Appendix $\mathrm{C}$ contains the part-of-speech data as classified by the first author for all 50 sample words and a description of the coding procedure.

Five categories (noun, adjective, preposition, adverb, verb) were needed to capture all the part-of-speech occurrences in the sample contexts, and the percentage of occurrence within each category for each sample word is given in Appendix C ( $3 \%$ of the sample contexts did not provide sufficient information to code part of speech, indicated by "?"). In general, words with large negative difference scores were mainly used as nouns in the Usenet corpus, and those with large positive difference scores were mainly used as verbs. To better compare the percentage of noun versus verb usage to HAL's noun-verb difference measure, for each sample word, the percent- age of usages classified as nouns was subtracted from the percentage classified as verbs (hence, negative differences will correspond to predominant noun uses). The correlation of the latter measure with the HAL nounverb difference was +.90 , indicating that over $80 \%$ of the variance in the difference scores could be accounted for by the extent to which the word was used as a noun or a verb in the Usenet corpus. This is an impressive correspondence, considering that approximately half of the sample words were chosen so as to be "oddities" from the perspective of the Francis and Kučera norms. And further inspection of Appendix C provides numerous examples of words for which the difference score, although discrepant from the Francis-Kučera classification, is an accurate reflection of noun versus verb usage in the Usenet corpus. For example, several words that were considered balanced on the basis of the Francis and Kučera norms were, in fact, predominantly used as nouns (e.g., crease, arch, slug) or verbs (e.g., work, gain, change) in the Usenet corpus and had corresponding typical noun or typical verb difference scores. Some of the more extreme examples of discrepant classifications appear to reflect stylistic or historical differences in part-of-speech usage 
(e.g., daze, access, swap) across the two corpora. In other cases, discrepancies could be traced to three-letter words that were used much more frequently as abbreviations for words of another part of speech [e.g., wed(nesday), mar(ch)] or entire phrases (cod vs. c.o.d.; note that, to be considered an instance of cod, the abbreviation "c.o.d." had to have been written as "cod" or "COD" in the corpus, since terminal punctuation marks signaled the end of a sentence context).

However, the HAL difference score did not always mirror the proportion of noun-verb occurrences in the corpus, and a consideration of the most extreme example among the sample words can illuminate why this sometimes occurred. The word extent is a pure noun according to the Francis-Kučera count and, indeed, is used as a noun in $99 \%$ of the sample Usenet contexts; yet, the noun-verb difference score $(+18)$ would appear to indicate that it does not occur in contexts typical of nouns or of verbs. In fact, over three quarters of this word's noun usages in the Usenet sample occurred within the expression to $X$ extent (e.g., to a large extent, to some extent, to the extent that, and so on). Note that, although extent functions as a noun within such phrases, it is never followed by a verb, and the phrase itself is generally used parenthetically. Because the majority of the occurrences of the word extent were within this single idiomatic expression, it is not typical of nouns in its contextual distribution. Hence, it is unlikely to be close to most nouns or verbs in high-dimensional context space, and the nounverb difference score appears to accurately reflect this fact.

Other words in the context sample also sometimes occurred within idiomatic or otherwise syntactically restricted expressions. The majority (89\%) of the noun usages of slouch occurred within the expression $X$ is no slouch. Similarly, although idiot was only used as a noun, the expression $X$ is an idiot accounted for $25 \%$ of its occurrences, and it was used parenthetically as an insult (e.g., idiot, the fans made the ballplayers rich) in another $15 \%$ of the contexts. The word care is used in the corpus as a verb nearly as often as it is used as a noun, but $30 \%$ of its noun uses occurred as take care $(o f)$. In each of these cases, the HAL difference score is much less nounlike than one would expect on the basis of a simple count of noun versus verb occurrences (see Appendix C). Since nouns that occur in an unusually restricted set of contexts will be less similar to most other nouns in their syntactic distribution, they are in this sense atypical nouns, and the noun-verb difference score seems to reflect this.

What about words that are neither nouns nor verbs? According to our analysis, such words should not appear in typical noun or verb contexts, and thus, difference scores close to zero would be expected. Although it was our intent to investigate only words with exclusive noun and/or verb uses, Appendix $\mathrm{C}$ contains two counterexamples. In only $12 \%$ of the contexts was bout used as a noun (e.g., his bout with chicken pox); fully $86 \%$ of the occurrences were reduced forms of the word about (e.g., tell me bout $i t$; bout time they started this newsgroup) and, hence, prepositions or adverbs. Likewise, although erect was originally coded as a pure verb, it had an adjective frequency of 8 (verb frequency $=26$ ) in Francis and Kučera (1982) that was overlooked when selecting our original set of pure verbs; yet, it only appeared as a verb in $9 \%$ of the sample Usenet contexts. Nearly all other occurrences represented adjective uses. The difference scores for bout $(-9)$ and erect $(+3)$ indicate that (from the perspective of the HAL model) such forms are not typical in their contextual distributions to either nouns or verbs. An exhaustive rechecking of the Francis and Kučera norms for all 1,197 stimulus words uncovered three other words with some adjective uses (ski, absent, worth) - the latter two items having predominant adjective uses and atypical difference scores (see Appendix B).

On the basis of the previous analysis, it can be inferred that a noun-verb difference score near zero should not be used as the sole criterion to identify words that are balanced in their use as nouns and verbs. Although Table 3 and Appendix $\mathrm{C}$ provide some examples of words with near-zero difference scores and approximately equal proportions of noun and verb uses (hush, punt), this is not always the case. As we have seen, noun-verb difference scores close to zero are more indicative of words that are neither typical nouns nor typical verbs.

In sum, an examination of the relation between the noun-verb difference score and judgments of part-ofspeech use in the Usenet corpus suggests a close correspondence. Words with very restricted syntactic distributions, even if exclusively used as a single part of speech, will nevertheless be contextually dissimilar to other words from that class, and the noun-verb difference is sensitive to this, as well as to actual part-of-speech usage. Thus, some discrepancies between the Francis-Kučera and the HAL noun-verb estimates may be traceable to the sensitivity of the latter to the typicality of a word's contextual distribution. In other cases, it was clear that disparities were attributable to generational and/or stylistic differences between the two corpora. The more informal style of discourse characteristic of the Usenet corpus does appear to engender more flexibility in part-ofspeech usage, and access to such contemporary information is a valuable resource.

Inflected noun-verb differences. As might be expected, overall, there was a strong correlation $(r=.93)$ between uninflected and inflected difference scores. This association was stronger for Francis-Kučera nouns ( $r=$ $.94)$ and balanced words $(r=.95)$ than for verbs $(r=$ .68 ). As is indicated by the means in Table 1 and by a comparison across Figures 3 and 4, there is greater overlap in the Francis-Kučera noun and verb distributions when inflected forms are included. This is primarily due to a shift away from high typical verb scores for inflected verbs. In contrast, the distributions for nouns and balanced forms are not altered when inflected forms are included.

A consideration of English inflectional morphology suggests why words with verb usages may become more 
ambiguous in grammatical class when inflected forms are included. The primary noun inflections, plural and possessive, will only rarely produce noun--verb ambiguities when added to a noun (e.g., oceans and ocean's are just as nounlike as ocean). However, some verb inflections - most notably, the progressive and the past tensewill produce forms that can also be used as nouns or adjectives (e.g., Everyone remembered the drowning; the drowned rat). Because the HAL model does not explicitly tag words for part of speech, all the contexts in which the inflected verb forms (drowning, drowns, drowned, as well as drown) occur will be included in the computation of noun and verb distances for such words. Thus, it is most likely that the less verblike inflected difference scores accurately reflect the wider contextual distribution of verbally inflected than of nominally inflected forms. Yet, despite this, the inflected index still provides a good separation of Francis-Kučera nouns and verbs, with balanced words showing an intermediate distribution (see Figure 4).

Appendix D contains the part of speech classification for the 28 words for which inflected contexts were sampled and a description of the coding procedure. Approximately half of the sample words were selected so as to have inflected difference scores that were discrepant with the Francis--Kučera classification. For each word, contexts were sampled (as described previously) for each inflected form of the word (the uninflected form was included as well). The percentages listed in Appendix D reflect the part-of-speech usages when averaged across all forms of the word. Six categories (noun, adjective, adjective/verb, noun-verb, interjection, verb) were needed to capture all the part-of-speech occurrences in the sample contexts.

Not surprisingly, when inflected forms are included, adjective usages for verbs and balanced forms are frequently noted. As was done for the uninflected difference measure, the percentage of noun uses for the sample words was subtracted from the percentage of verb uses and correlated with the inflected difference scores $(r=+.70)$. An inspection of Appendix D indicates that several Francis-Kučera verbs (elapse, tatter, bind) had adjective usages exceeding $25 \%$, usually coupled with relatively low noun usages, but negative inflected difference scores (indicating greater distributional similarity to nouns than to verbs). This suggested that verbs used as adjectives (e.g., tattered dress) occurred in contexts more similar to those of nouns than to those of verbs (nounnoun combinations are not infrequent-e.g., house dress). Indeed, when the proportion of adjective and noun usages was combined and subtracted from the proportion of verb usages, the correlation with inflected difference scores increased to .79 .

As was found for uninflected contexts, words with restricted sentential distributions tended to have atypical inflected difference scores, despite a very high proportion of use as a single part of speech. For example, apathy and deceit are nearly always used as nouns but have inflected difference scores ( -27 and -14 , respectively), indicating low noun typicality. However, unlike typical nouns, in the majority of the sample contexts, these words had no preceding modifiers (e.g., against a tide of apathy; deceit and outright disinformation). Because nouns generally take a variety of preceding modifiers, those that occur with few or no modifiers will not share as many contexts with other nouns and, in that sense, are not typical nouns.

In sum, the inflected noun-verb difference provides a reasonable measure of the extent to which a word, across all its inflected forms, is used primarily as a noun or a verb. As with the uninflected measure, this is best considered as an index of distributional typicality, rather than as an estimate of the actual part-of-speech usage in the corpus. The greater part-of-speech variability for inflected forms is appropriately reflected in the greater overlap of the Francis-Kučera word classes for the inflected, as compared with the uninflected, noun-verb difference (compare Figures 3 and 4). The inflected measure would be preferable whenever an experimenter is interested in the distributional behavior of a word that takes into account inflected, as well as uninflected, occurrences.

Relation of noun-verb difference to imageability and word frequency. As is indicated in Table 2, inflected and uninflected difference scores were negatively correlated with imageability ratings and positively correlated with imageability RTs. Thus, in general, more nounlike words had higher and faster imageability ratings than more verblike forms, similar to the pattern previously shown for the Francis-Kučera word classification (see Figure 1).

The HAL noun-verb indices, however, were not correlated with Usenet or Francis-Kučera frequency. Thus, although the noun and verb distances were negatively associated with frequency, relying on the difference score as our measure of noun-verb typicality effectively eliminates the known association of HAL's context vectors with word frequency (in general, less frequent words will have greater interword context distances than will higher frequency words). Lund and Burgess (1998) provide evidence that the techniques employed here (calculating difference scores between context distances across two sets of anchoring words-words that have little in common with each other except for the variable of interest) allow one to isolate a particular aspect of lexical knowledge from the highly distributed and overlapping context vectors in the HAL model. The absence of an association of frequency and the noun-verb difference supports their claim.

Finally, although word frequency measures were not the focus of our investigation, the correlation of FrancisKučera and Usenet frequencies may be of some interest. There was a strong overall association of these two measures $(r=.81)$, which was somewhat greater for FrancisKučera balanced words $(r=.84)$ or verbs $(r=.86)$ than for nouns $(r=.76)$. Burgess and Livesay (1998) previously reported a very high correlation between these 
two frequency estimates for nouns, but only for those of very high frequency $(r=.96)$; the two indices were very poorly correlated for moderate- and low-frequency nouns $(r s<.15)$. Because our sample included words of varying frequency and word class, the correlations reported here are of greater generality. Nevertheless, the $r^{2}$ value (.66) for the two measures may indicate that the Francis-Kučera norms are less sensitive indices of the frequency of word occurrences in contemporary informal discourse.

\section{GENERAL DISCUSSION}

In this report, we have presented several measures that can be used to assess both semantic and grammatical characteristics of individual nouns and verbs: imageability ratings, RTs, and two measures of distributional typicality. In general, words with noun usages were more readily imaged than verbs, as indexed by image ratings and RTs, and the RT distributions indicated that off-line image ratings reflect reliance on an image generation process, but one with an internally imposed response deadline. The uninflected and inflected measures of nounverb distributional typicality produced a good separation between words previously categorized as pure nouns or pure verbs (Francis \& Kučera, 1982) and also reflected the part-of-speech distribution in the Usenet corpus. We will now discuss the utility and limitations of these measures and suggest avenues for future research.

Investigators of word recognition traditionally have relied on normative word judgments about salient word characteristics (imageability, concreteness, familiarity, etc.) to select items for experimentation. Certainly, words that vary along the rated dimensions are often processed differently in various experimental contexts, implying that the information participants access for word-rating tasks also influences processing in other contexts. However, the word judgments themselves are often taken at face value, without attempting to discern how participants arrive at such decisions. The imageability RT data reported here suggest that words with equivalent mean ratings need not indicate that the words were imaged with equivalent consistency. The scatter for the imageabilityRT distributions suggested that the imagery process for verbal concepts is considerably less consistent than that for nominal concepts. Since the process participants use to determine imageability for verbs is less well understood, it would be unwise to assume that nouns and verbs "matched" for rated imageability are necessarily equivalent. Whether or not high- versus low-imagery verbs exhibit the same behavior in psycholingustic experiments as high- versus low-imagery nouns is an unsettled empirical question. The ratings reported here will be useful in undertaking such needed experimental investigations.

The grammatical categories of noun and verb represent rather idealized concepts that have proven invaluable for linguistic theory and scholarship. Nevertheless, it is essential to determine the extent to which a word is employed as a noun or a verb in contemporary language use. One approach to gathering such statistics requires human categorization of part-of-speech usage in a large corpus of contemporary text. The Francis and Kučera (1982) norms represent the most comprehensive attempt to do so. However, because this approach is extremely time consuming, only limited-sized corpora can be coded, and such norms are unlikely to be updated frequently. Thus, despite the massive effort needed to acquire such information, only a snapshot of a restricted set of texts at a limited point in time will result.

In this report, we presented a different approach. The HAL noun-verb indices described here provide a measure of distributional typicality - the extent to which a word is used in sentence contexts that typify nouns or verbs. The context vectors provided by the HAL model, which have been demonstrated to encode grammatical class information (Burgess \& Lund, 1997), were used to determine the mean context distance between an item and a large class of nouns and verbs. The difference between a word's noun and verb distances allows us to identify words that are closer to nouns than to verbs in highdimensional context space (and vice versa). Because there is no human coding of sentence contexts, these measures can be derived rather quickly from even massive corpora, limited only by available computational resources. The presently implemented model utilizes a $70 \times 70$ K matrix (Burgess, 1998; Burgess \& Lund, 1997), but larger matrices could be derived to represent a greater number of words. Although this computational approach provides benefits in speed and breadth of word codings, it is important to acknowledge some potential costs as well. The HAL model does not "interpret" text, and lexical items are treated exactly as they appear in the text stream. Hence, abbreviations, misspellings, and reduced word forms are not tagged and will be coded as instances of whatever word they resemble (i.e., there is no distinction between bout as an abstract noun and bout as a reduced form of about). However, it is arguable whether this is problematic. If an experimenter wishes to select words with predominant noun uses, strings with highfrequency non-noun uses in a person's language experience should be avoided, even if they represent abbreviations or slang. Hence a noun-verb difference score that appears aberrant may provide a "reality check" that a given form is frequently used in nonstandard ways.

Similarly, the qualitative characteristics of Usenet text should also be kept in mind. Whereas the Francis-Kučera corpus is based entirely on formal texts, the Internet exchanges that make up the Usenet corpus are extremely informal and may overrepresent the language use of subcultures that frequent the Internet. If an experimenter is interested in how a word is used in formal published texts, the noun-verb measures reported here would not be appropriate. However, the HAL methodology could be employed with any text corpus to create a new matrix that will reflect the distributional regularities of that corpus. Since new usages will appear in informal language con- 
texts long before they are accepted as standard English, this important component of an individual's psycholinguistic experience will be reflected in our noun-verb measures. Furthermore, if a word has a very large (positive or negative) difference score, it is very likely to occur nearly exclusively in typical verb or noun contexts, even when used informally.

But perhaps the most fundamental difference between the two approaches is their varying sensitivity to the typicality of a word's contextual distribution as a noun or a verb. Simple frequency counts, such as those reported by Francis and Kučera (1982), index only the number of times a word occurs as each part of speech. As we have seen, the HAL measures also reflect frequency of noun versus verb usages but, in addition, index the extent to which a word's contextual distribution is typical of nouns and verbs in the corpus. If a word occurs only in a very restricted set of sentence contexts, even if used exclusively as a single part of speech, its contextual distribution will be dissimilar to most other words of that grammatical class. Hence, it will have rather low distributional typicality, despite its high frequency as a single part of speech. Thus, it is not appropriate to view the noun-verb difference measures as distributional frequency counts per se. Whether or not this is advantageous depends on how the experimenter wishes to operationalize part-of-speech usage. But it is worth pointing out that human categorization across many different domains is characterized by graded membership-not all members of a category are equally good exemplars, and the best examplars are those that are similar to many other category members (Komatsu, 1992; Lakoff, 1987; Rosch \& Mervis, 1975). If grammatical categories are also structured according to a typicality gradient (Lakoff, 1987; Ross, 1973), HAL's noun-verb difference may provide a means to assess a word's noun-verb distributional typicality, while circumventing the need to gather normative typicality judgments.

We conclude that the noun-verb difference scores reported here provide a useful index of noun-verb distributional typicality in contemporary discourse. Since the HAL context distance measures reflect the statistical regularities present in the input corpus, additional research will be needed to assess just how distributional typicality might influence the performance of psycholinguistic tasks. For example, if participants are sensitive to the typicality of a word's occurrence in noun versus verb contexts, lexical and sentence acceptability decisions should be faster for typical than for atypical forms. In other domains, HAL's context distances have been successful at predicting human RTs in a variety of linguistic tasks (Burgess, 1998). But until this has been shown for nounverb distances, it is best to consider them as an index of the structure inherent in the linguistic input (i.e., informal contemporary discourse). At the very least, the item statistics reported here will enable experimenters to select representative examples of nouns and verbs, while holding constant or covarying rated imageability. Such information will facilitate further experimental inquiry into the neuro- and psycholinguistic bases of noun versus verb processing.

\section{REFERENCES}

Balota, D. A., \& Chumbley, J. I. (1984). Are lexical decisions a good measure of lexical access? The role of word frequency in the neglected decision stage. Journal of Experimental Psychology: Human Perception \& Performance, 10, 340-357.

Balota, D. A., Ferraro, F. R., \& Connor, L. T. (1991). On the early influence of meaning in word recognition: A review of the literature. In P. J. Schwanenflugel (Ed.), The psychology of word meanings (pp. 187-222). Hillsdale, NJ: Erlbaum.

Berndt, R. S., Mitchum, C. C., Haendiges, A. N., \& Sandson, J. (1997). Verb retrieval in aphasia: 1. Characterizing single word impairments. Brain \& Language, 56, 68-106.

BURGESs, C. (1998). From simple associations to the building blocks of language: Modeling meaning in memory with the HAL model. $B e$ havior Research Methods, Instruments, \& Computers, 30, 188-198.

Burgess, C., \& Livesay, K. (1998). The effect of corpus size in predicting reaction time in a basic word recognition task: Moving on from Kučera \& Francis. Behavior Research Methods, Instruments, and Computers, 30, 272-277.

Burgess, C., Livesay, K., \& Lund, K. (1998). Explorations in context space: Words, sentences, and discourse. Discourse Processes, 25 , 211-257.

Burgess, C.. \& LUND, K. (1997). Modeling parsing constraints with high-dimensional context space. Language \& Cognitive Processes, 12, 177-210.

CAPLAN, D. (1987). Neurolinguistics and linguistic aphasiology: An introduction. Cambridge: Cambridge University Press.

Caramazza, A., \& Hillis, A. E. (1991). Lexical organization of nouns and verbs in the brain. Nature, 349, 788-790.

COHEN, J., \& COHEN, P. (1983). Applied multiple regression/correlation analysis for the behavioral sciences. Hillsdale, $\mathrm{NJ}$ : Erlbaum.

Cohen, J., MacWhinney, B., Flatt, M., \& Provost, J. (1993). PsyScope: An interactive graphic system for designing and controlling experiments in the psychology laboratory using Macintosh computers. Behavioral Research Methods, Instruments, \& Computers, 25, 257-271.

Daniele, A., Guistolisi, L., Silveri, M. C., Colosimo, C., \& Gainотт1, G. (1994). Evidence for a possible neuroanatomical basis for lexical processing of nouns and verbs. Neuropsychologia, 32, 1325-1342.

ForSTER, K. I. (1994). Computational modeling and elementary process analysis in visual word recognition. Journal of Experimental Psychology: Human Perception \& Performance, 20, 1292-1310.

Francis, W. N., \& KuČERA, H. (1982). Frequency analysis of English usage: Lexicon and grammar. Boston: Houghton Mifflin.

Friendly, M., Franklin, P. E., Hoffman, D., \& Rubin, D. C. (1982). The Toronto Word Pool: Norms for imagery, concreteness, orthographic variables, and grammatical usage for 1,080 words. Behavior Research Methods \& Instrumentation, 14, 375-399.

Koenig, T., \& Lehmann, D. (1996). Microstates in language-related brain potential maps show noun-verb differences. Brain \& Language, 53, 169-182.

Komatsu, L. K. (1992). Recent views of conceptual structure. Psychological Bulletin, 112, 500-526.

LAKOFF, G. (1987). Women, fire, and dangerous things: What categories reveal about the mind. Chicago: University of Chicago Press.

LuND, K., \& Burgess, C. (1996). Producing high-dimensional semantic spaces from lexical co-occurrence. Behavior Research Methods, Instruments, \& Computers, 28, 203-208.

LUND, K., \& BURGESS, C. (1998, November). What 's in a context representation, and how do we know? Paper presented at the meeting of the Society for Computers in Psychology, Dallas.

Molfese, D. L.. Burger-Judisch, L. M., Gill, L. A., Golinkoff, R. M., \& Hirsch-PASEK, K. A. (1996). Electrophysiological correlates of noun-verb processing in adults. Brain \& Language, 54, 388413. 
Monsell, S., Doyle, M. C., \& Haggard, P. N. (1989). Effects of frequency on visual word recognition tasks: Where are they? Journal of Experimental Psychology: General, 118, 43-71.

Paivio, A. V., Yullle, J. C., \& Madigan, S. A. (1968). Concreteness, imagery, and meaningfulness values for 925 nouns. Journal of Experimental Psychology Monographs, 76 (I, Pt. 2, Suppl.).

Rosch, E., \& Mervis, C. B. (1975). Family resemblances: Studies in the internal structure of categories. Cognitive Psychology, 7, 573-605.

Ross, J. R. (1973). Nouniness. In O. Fujimura (Ed.), Three dimensions of linguistic theory (pp. 138-257). Tokyo: TEC Company Ltd.

SeidenberG, M. S., \& MCClelland, J. L. (1989). A distributed, developmental model of word recognition and naming. Psychological Review, 96, 523-568.
Smith, E. E., Shoben, E. J., \& RiPs, L. J. (1974). Structure and process in semantic memory: A featural model for semantic decisions. Psychological Review, 81, 214-241.

Stone, G. O., \& VAN ORden, G. C. (1993). Strategic control of processing in word recognition. Journal of Experimental Psychology: Human Perception \& Performance, 19, 744-774.

Toglia, M. P., \& BATTIG, W. F. (1978). Handbook of semantic word norms. Hillsdale, NJ: Erlbaum.

Warburton, E., Wise, R. J. S., Price, C. J., Weiller, C., Hadar, U., Ramsay, S., \& Frackowiak, R. S. J. (1996). Noun and verb retrieval by normal subjects: Studies with PET. Brain, 119, 159-179.

ZINGESER, L. B., \& BERNDT, R. S. (1990). Retrieval of nouns and verbs in agrammatism and anomia. Brain \& Language, 39, 14-32.

\section{APPENDIX A \\ Instructions for Imageability Ratings}

In this study we are examining how people rate words. The purpose is to select words to be used in a later experiment.

You will see a word on the computer screen such as:

splash.

We will ask you to rate how imageable you think the word is using the scale below. When a word is highly imageable, it will quickly and easily arouse a mental image (i.e., a mental picture, sound, or other sensory experience). When a word is not imageable, it is difficult if not impossible to create a mental image of what the word represents in your mind. Use the scale below to rate how easily you can bring to mind a mental image of each word you are presented with. If a word easily and quickly arouses a sensory experience or mental image, it would be given a high imageability rating. If a word is impossible to image, or you are able to create an image of it only after a long delay, then it should be given a low imageability rating.

So please rate how imageable you think the following words are using this scale:

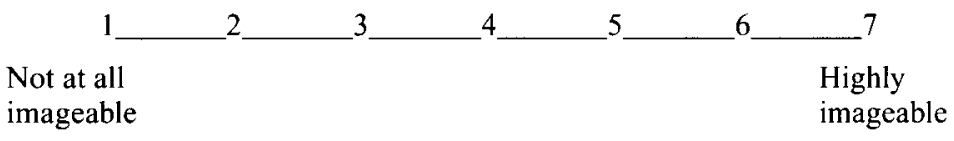

APPENDIX B

Imagery and Distributional Typicality Scores by Item

\begin{tabular}{|c|c|c|c|c|c|c|c|c|c|c|c|c|}
\hline \multirow[b]{2}{*}{ Word } & \multirow{2}{*}{$\begin{array}{c}\text { FK } \\
\text { Code }\end{array}$} & \multicolumn{2}{|c|}{ Image Rate } & \multicolumn{2}{|c|}{ Image RT } & \multicolumn{3}{|c|}{ HAL Uninflected $\dagger$} & \multicolumn{3}{|c|}{ HAL Inflected $\ddagger$} & \multirow{2}{*}{$\begin{array}{c}\text { Usenet } \\
\text { Log Frequency }\end{array}$} \\
\hline & & $M$ & $S D$ & $M$ & $S D$ & NDist & VDist & NVDD & NDist & VDist & NVDD & \\
\hline absent & $V^{*}$ & 4.57 & 1.91 & 2,566 & 1,628 & 573 & 570 & 3 & 573 & 570 & 3 & 3.48 \\
\hline absorb & $\mathrm{V}$ & 4.18 & 1.85 & 2,732 & 1,598 & 610 & 487 & 123 & 598 & 562 & 36 & 3.86 \\
\hline accept & V & 3.70 & 2.02 & 2,809 & 1,931 & 629 & 456 & 173 & 613 & 513 & 100 & 4.98 \\
\hline access & $\mathrm{N}$ & 3.07 & 1.61 & 3,022 & 1,688 & 590 & 529 & 61 & 594 & 538 & 56 & 5.27 \\
\hline accord & $\mathrm{B}$ & 2.57 & 2.32 & 3,232 & 1,531 & 494 & 610 & -116 & 505 & 544 & -39 & 4.84 \\
\hline $\operatorname{accost}$ & $\mathrm{V}$ & 2.61 & 1.40 & 2,706 & 1,548 & & & & 757 & 728 & 29 & 2.30 \\
\hline accuse & $\mathrm{V}$ & 4.04 & 1.95 & 2,800 & 1,962 & 639 & 472 & 167 & 582 & 546 & 36 & 4.20 \\
\hline acquit & V & 3.23 & 1.95 & 2,653 & 1,644 & & & & 719 & 689 & 30 & 2.85 \\
\hline act & B & 4.79 & 1.93 & 2,526 & 1,299 & 487 & 503 & -16 & 494 & 512 & -18 & 5.05 \\
\hline action & $\mathrm{N}$ & 3.86 & 2.10 & 3,075 & 1,478 & 459 & 557 & -98 & 481 & 559 & -78 & 5.03 \\
\hline adapt & V & 3.21 & 1.69 & 2,799 & 2,874 & 647 & 481 & 166 & 619 & 540 & 79 & 3.87 \\
\hline add & V & 5.43 & 1.67 & 2,197 & 1,216 & 577 & 449 & 128 & 563 & 490 & 73 & 5.33 \\
\hline adhere & V & 2.82 & 1.72 & 2,341 & 1,263 & 672 & 513 & 159 & 713 & 625 & 88 & 3.54 \\
\hline adjust & V & 3.74 & 1.87 & 2,327 & 963 & 602 & 444 & 158 & 577 & 493 & 84 & 4.20 \\
\hline admire & V & 4.36 & 1.73 & 2,982 & 2,225 & 646 & 523 & 123 & 648 & 568 & 80 & 3.73 \\
\hline admit & V & 3.75 & 1.71 & 2,982 & 1,632 & 653 & 500 & 153 & 628 & 518 & 110 & 4.61 \\
\hline adopt & V & 4.79 & 1.79 & 2,456 & 1,103 & 627 & 464 & 163 & 578 & 528 & 50 & 4.24 \\
\hline
\end{tabular}


APPENDIX B (Continued)

\begin{tabular}{|c|c|c|c|c|c|c|c|c|c|c|c|c|}
\hline \multirow[b]{2}{*}{ Word } & \multirow{2}{*}{$\begin{array}{l}\text { FK } \\
\text { Code }\end{array}$} & \multicolumn{2}{|c|}{ Image Rate } & \multicolumn{2}{|c|}{ Image RT } & \multicolumn{3}{|c|}{ HAL Uninflected $\dagger$} & \multicolumn{3}{|c|}{ HAL Inflected $\ddagger$} & \multirow{2}{*}{$\begin{array}{c}\text { Usenet } \\
\text { Log Frequency }\end{array}$} \\
\hline & & $M$ & $S D$ & $M$ & $S D$ & NDist & VDist & NVDD & NDist & VDist & NVDD & \\
\hline adore & V & 4.96 & 1.79 & 2,455 & 928 & 659 & 578 & 81 & 678 & 618 & 60 & 3.21 \\
\hline adorn & V & 2.86 & 1.88 & 2,583 & 3,249 & & & & 645 & 718 & -73 & 2.58 \\
\hline affair & $\mathrm{N}$ & 4.64 & 1.91 & 2,182 & 966 & 529 & 663 & -134 & 571 & 673 & -102 & 4.25 \\
\hline affirm & $\mathrm{V}$ & 2.86 & 1.92 & 2,563 & 1,055 & 655 & 510 & 145 & 697 & 665 & 32 & 3.35 \\
\hline afford & V & 4.00 & 2.04 & 2,267 & 1,013 & 701 & 593 & 108 & 698 & 598 & 100 & 4.30 \\
\hline agent & $\mathrm{N}$ & 5.07 & 1.68 & 2,384 & 1,584 & 477 & 562 & -85 & 505 & 578 & -73 & 4.58 \\
\hline agree & $\mathrm{V}$ & 3.43 & 1.97 & 2,682 & 1,450 & 666 & 563 & 103 & 642 & 558 & 84 & 5.12 \\
\hline ail & $\mathrm{V}$ & 2.48 & 1.58 & 2,194 & 1,167 & 678 & 718 & -40 & 679 & 684 & -5 & 2.72 \\
\hline aim & B & 4.36 & 1.97 & 2,621 & 1,083 & 485 & 509 & -24 & 520 & 554 & -34 & 4.30 \\
\hline alarm & $\mathrm{B}$ & 6.29 & 1.24 & 2,572 & 1,250 & 481 & 563 & -82 & 532 & 586 & -54 & 3.96 \\
\hline album & $N$ & 6.14 & 1.60 & 1,827 & 613 & 505 & 620 & -115 & 515 & 621 & -106 & 4.72 \\
\hline alcove & $\mathbf{N}$ & 3.71 & 2.16 & 2,540 & 1,197 & 651 & 766 & -115 & 651 & 766 & -115 & 2.42 \\
\hline align & V & 3.70 & 1.68 & 2,918 & 1,352 & 591 & 487 & 104 & 592 & 565 & 27 & 3.57 \\
\hline allege & $\mathrm{V}$ & 2.39 & 1.40 & 2,237 & 1,047 & 715 & 670 & 45 & 544 & 612 & -68 & 3.96 \\
\hline alley & $\mathrm{N}$ & 6.07 & 1.61 & 1,873 & 928 & 519 & 643 & -124 & 534 & 653 & -119 & 3.51 \\
\hline allot & V & 2.36 & 1.45 & 2,227 & 1,565 & 735 & 684 & 51 & 686 & 684 & 2 & 2.98 \\
\hline allow & V & 2.43 & 1.48 & 2,724 & 1,701 & 589 & 470 & 119 & 578 & 533 & 45 & 5.26 \\
\hline allude & $\mathrm{V}$ & 2.93 & 1.90 & 2,429 & 1,190 & 693 & 597 & 96 & 652 & 633 & 19 & 3.20 \\
\hline alter & $\mathrm{V}$ & 4.57 & 2.08 & 2,299 & 1,220 & 552 & 471 & 81 & 557 & 524 & 33 & 4.20 \\
\hline amass & V & 2.71 & 1.76 & 2,958 & 2,433 & 713 & 612 & 101 & 693 & 646 & 47 & 2.72 \\
\hline amaze & $\mathrm{V}$ & 4.54 & 1.67 & 3,212 & 2,530 & 768 & 626 & 142 & 589 & 623 & -34 & 4.51 \\
\hline amble & $\mathrm{V}$ & 2.04 & 1.37 & 3,087 & 1,587 & & & & & & & 1.74 \\
\hline ambush & B & 5.52 & 1.48 & 2,182 & 760 & 701 & 824 & -123 & 711 & 816 & -105 & 3.33 \\
\hline amend & $\mathrm{V}$ & 2.96 & 1.67 & 3,143 & 1,830 & 621 & 542 & 79 & 700 & 708 & -8 & 3.83 \\
\hline amuse & V & 4.68 & 1.98 & 2,818 & 1,918 & 657 & 495 & 162 & 639 & 602 & 37 & 3.94 \\
\hline anchor & B & 6.75 & 0.52 & 1,839 & 879 & 475 & 545 & -70 & 505 & 569 & -64 & 3.62 \\
\hline angel & $\mathrm{N}$ & 6.79 & 0.57 & 1.555 & 453 & 634 & 745 & -111 & 592 & 702 & -110 & 4.41 \\
\hline annoy & V & 4.57 & 1.71 & 2,908 & 3,104 & 709 & 584 & 125 & 618 & 576 & 42 & 4.35 \\
\hline answer & B & 4.61 & 2.02 & 2,266 & 856 & 550 & 497 & 53 & 557 & 519 & 38 & 5.25 \\
\hline apathy & $N$ & 2.36 & 1.95 & 2,545 & 1,410 & 551 & 578 & -27 & 551 & 578 & -27 & 3.01 \\
\hline appall & V & 3.50 & 1.84 & 3,461 & 2,160 & & & & 645 & 648 & -3 & 3.30 \\
\hline appear & V & 3.64 & 2.00 & 3.216 & 2,418 & 576 & 493 & 83 & 555 & 546 & 9 & 5.06 \\
\hline append & V & 2.04 & 1.48 & 2,255 & 1,004 & 601 & 533 & 68 & 606 & 587 & 19 & 3.72 \\
\hline apply & V & 2.57 & 1.67 & 2,486 & 1,114 & 601 & 471 & 130 & 576 & 517 & 59 & 4.73 \\
\hline arch & B & 6.39 & 1.20 & 1,952 & 630 & 515 & 652 & -137 & 573 & 673 & -100 & 3.75 \\
\hline area & $\mathrm{N}$ & 4.00 & 2.00 & 3,300 & 1,768 & 521 & 644 & -123 & 541 & 647 & -106 & 5.34 \\
\hline arena & $N$ & 6.36 & 1.13 & 2,221 & 2,059 & 536 & 685 & -149 & 551 & 693 & -142 & 4.08 \\
\hline argue & V & 4.46 & 1.64 & 2.988 & 1.548 & 663 & 482 & 181 & 641 & 522 & 119 & 4.58 \\
\hline arise & V & 3.96 & 1.99 & 2,842 & 1,456 & 636 & 581 & 55 & 628 & 640 & -12 & 4.10 \\
\hline aroma & $\mathrm{N}$ & 5.18 & 1.91 & 3,084 & 3,447 & 537 & 619 & -82 & 537 & 619 & -82 & 2.90 \\
\hline arouse & V & 4.79 & 2.02 & 2,473 & 1,767 & 706 & 573 & 133 & 661 & 615 & 46 & 3.44 \\
\hline arrive & V & 4.11 & 1.66 & 2,637 & 1,054 & 610 & 496 & 114 & 594 & 562 & 32 & 4.48 \\
\hline arrow & $\mathrm{N}$ & 6.68 & 0.98 & 1.543 & 514 & 524 & 640 & -116 & 514 & 627 & -113 & 4.01 \\
\hline arson & $N$ & 4.11 & 1.93 & 2.868 & 1,509 & 675 & 743 & -68 & 675 & 743 & -68 & 2.88 \\
\hline art & $\mathrm{N}$ & 5.71 & 1.30 & 2,631 & 1,772 & 460 & 582 & -122 & 470 & 596 & -126 & 4.93 \\
\hline artery & $\mathrm{N}$ & 5.79 & 1.45 & 2,656 & 1,599 & 596 & 722 & -126 & 615 & 704 & -89 & 2.96 \\
\hline artist & $\mathrm{N}$ & 6.39 & 1.13 & 1,648 & 513 & 471 & 590 & -119 & 496 & 591 & -95 & 4.54 \\
\hline ascend & V & 3.93 & 2.14 & 2,287 & 1,007 & 583 & 543 & 40 & 593 & 597 & -4 & 3.34 \\
\hline ash & $N$ & 6.32 & 1.42 & 1,847 & 806 & 500 & 607 & -107 & 624 & 691 & -67 & 3.93 \\
\hline ask & V & 3.39 & 1.83 & 2,778 & 1,692 & 602 & 459 & 143 & 582 & 500 & 82 & 5.50 \\
\hline aspect & $\mathrm{N}$ & 1.21 & 0.42 & 2,501 & 1,172 & 514 & 616 & -102 & 551 & 624 & -73 & 4.58 \\
\hline aspire & V & 3.36 & 2.18 & 2,683 & 1,342 & 684 & 548 & 136 & 630 & 583 & 47 & 3.20 \\
\hline assert & V & 2.43 & 1.57 & 2,657 & 1,742 & 623 & 453 & 170 & 609 & 532 & 77 & 3.90 \\
\hline assess & V & 2.68 & 1.87 & 2,982 & 1,602 & 649 & 511 & 138 & 661 & 602 & 59 & 3.70 \\
\hline asset & $\mathrm{N}$ & 3.75 & 1.90 & 2,737 & 1,151 & 543 & 602 & -59 & 540 & 602 & -62 & 4.06 \\
\hline assign & V & 3.50 & 1.86 & 1,946 & 850 & 624 & 476 & 148 & 572 & 539 & 33 & 4.29 \\
\hline assume & V & 2.54 & 1.62 & 3,069 & 2,015 & 600 & 483 & 117 & 571 & 510 & 61 & 4.93 \\
\hline assure & V & 2.82 & 1.61 & 3,294 & 2,711 & 649 & 527 & 122 & 639 & 558 & 81 & 4.15 \\
\hline atlas & $\mathrm{N}$ & 6.36 & 0.91 & 2,240 & 1,777 & 503 & 611 & -108 & 503 & 611 & -108 & 3.73 \\
\hline atom & $\mathrm{N}$ & 5.54 & 1.71 & 2,350 & 1,262 & 517 & 664 & -147 & 532 & 650 & -118 & 3.76 \\
\hline attach & V & 4.43 & 1.62 & 3,041 & 1,440 & 598 & 464 & 134 & 531 & 533 & -2 & 4.47 \\
\hline attack & B & 5.64 & 1.66 & 2,153 & 879 & 468 & 487 & -19 & 491 & 502 & -11 & 4.90 \\
\hline attain & V & 3.29 & 1.94 & 2,505 & 1,421 & 679 & 518 & 161 & 671 & 588 & 83 & 3.67 \\
\hline
\end{tabular}


APPENDIX B (Continued)

\begin{tabular}{|c|c|c|c|c|c|c|c|c|c|c|c|c|}
\hline \multirow[b]{2}{*}{ Word } & \multirow{2}{*}{$\begin{array}{c}\text { FK } \\
\text { Code }\end{array}$} & \multicolumn{2}{|c|}{ Image Rate } & \multicolumn{2}{|c|}{ Image RT } & \multicolumn{3}{|c|}{ HAL Uninflected $\dagger$} & \multicolumn{3}{|c|}{ HAL Inflected $\ddagger$} & \multirow{2}{*}{$\begin{array}{c}\text { Usenet } \\
\text { Log Frequency }\end{array}$} \\
\hline & & $M$ & $S D$ & $M$ & $S D$ & NDist & VDist & NVDD & NDist & VDist & NVDD & \\
\hline attend & $\mathrm{V}$ & 3.41 & 1.58 & 3,330 & 2,514 & 641 & 475 & 166 & 609 & 531 & 78 & 4.40 \\
\hline aunt & $\mathrm{N}$ & 6.50 & 1.00 & 2,170 & 1,080 & 567 & 578 & -11 & 594 & 605 & -11 & 3.54 \\
\hline auto & $\mathrm{N}$ & 5.96 & 1.88 & 2,156 & 1,593 & 477 & 564 & -87 & 484 & 568 & -84 & 4.22 \\
\hline autumn & $N$ & 6.14 & 1.11 & 2,464 & 1,334 & 609 & 752 & -143 & 609 & 752 & -143 & 3.50 \\
\hline avenge & $\mathrm{V}$ & 2.43 & 1.32 & 3,094 & 1,319 & 711 & 606 & 105 & 682 & 662 & 20 & 2.67 \\
\hline avenue & $\mathrm{N}$ & 5.54 & 1.79 & 2,412 & 1,391 & 759 & 840 & -81 & 751 & 829 & -78 & 4.33 \\
\hline avert & V & 2.54 & 1.53 & 2,741 & 1,448 & 728 & 693 & 35 & 726 & 695 & 31 & 3.18 \\
\hline avoid & $\mathrm{V}$ & 4.04 & 2.13 & 2,120 & 1,066 & 600 & 453 & 147 & 597 & 477 & 120 & 4.76 \\
\hline await & V & 3.89 & 1.55 & 2,366 & 812 & 630 & 534 & 96 & 624 & 615 & 9 & 3.83 \\
\hline awaken & V & 5.57 & 1.67 & 2,055 & 1,068 & 617 & 514 & 103 & 610 & 637 & -27 & 3.62 \\
\hline awe & B & 4.29 & 1.82 & 2,604 & 1,277 & 509 & 586 & -77 & 529 & 595 & -66 & 3.47 \\
\hline awning & $\mathrm{N}$ & 5.11 & 2.01 & 2,466 & 916 & & & & & & & 1.18 \\
\hline bacon & $\mathrm{N}$ & 6.89 & 0.31 & 1,555 & 885 & 514 & 598 & -84 & 514 & 598 & -84 & 3.50 \\
\hline badge & $\mathrm{N}$ & 6.43 & 1.20 & 1,777 & 917 & 499 & 594 & -95 & 522 & 603 & -81 & 3.48 \\
\hline baffle & V & 3.75 & 1.73 & 3,335 & 2,254 & 583 & 605 & -22 & 645 & 636 & 9 & 3.21 \\
\hline ballad & $\mathrm{N}$ & 4.52 & 2.10 & 2,412 & 1,358 & 505 & 671 & -166 & 528 & 664 & -136 & 3.20 \\
\hline ballet & $\mathrm{N}$ & 6.50 & 1.11 & 2,070 & 1,068 & 473 & 584 & -111 & 473 & 584 & -111 & 3.22 \\
\hline ban & B & 3.71 & 2.31 & 2,718 & 1,361 & 511 & 504 & 7 & 549 & 541 & 8 & 4.36 \\
\hline banana & $\mathrm{N}$ & 6.81 & 0.96 & 1,558 & 541 & 496 & 590 & -94 & 505 & 582 & -77 & 3.63 \\
\hline banish & V & 3.54 & 1.79 & 2,553 & 1,210 & 686 & 545 & 141 & 660 & 649 & 11 & 3.12 \\
\hline banner & $\mathrm{N}$ & 6.32 & 1.39 & 1,808 & 728 & 504 & 609 & -105 & 521 & 612 & -91 & 3.59 \\
\hline barley & $\mathrm{N}$ & 4.96 & 2.25 & 2,189 & 1,354 & 550 & 633 & -83 & 550 & 633 & -83 & 3.08 \\
\hline barn & $\mathrm{N}$ & 6.93 & 0.38 & 1,278 & 333 & 506 & 639 & -133 & 522 & 648 & -126 & 3.46 \\
\hline basin & $\mathrm{N}$ & 4.93 & 2.07 & 2,039 & 924 & 597 & 740 & -143 & 606 & 742 & -136 & 3.38 \\
\hline basis & $\mathrm{N}$ & 1.64 & 0.95 & 2,191 & 953 & 601 & 682 & -81 & 601 & 682 & -81 & 4.68 \\
\hline baste & V & 4.29 & 1.88 & 2,797 & 2,480 & & & & 768 & 836 & -68 & 2.72 \\
\hline batch & $\mathrm{N}$ & 4.00 & 2.09 & 3,111 & 1,893 & 503 & 572 & -69 & 517 & 580 & -63 & 4.07 \\
\hline bath & $\mathrm{N}$ & 6.48 & 1.16 & 1,696 & 918 & 475 & 598 & -123 & 490 & 600 & -110 & 3.83 \\
\hline bathe & V & 5.57 & 1.73 & 2,806 & 1,291 & 679 & 512 & 167 & 614 & 593 & 21 & 3.43 \\
\hline baton & $\mathrm{N}$ & 5.75 & 1.71 & 2,067 & 947 & 708 & 823 & -115 & 708 & 823 & -115 & 3.23 \\
\hline bauble & $N$ & 3.11 & 2.18 & 2,539 & 1,464 & & & & & & & 1.71 \\
\hline bawl & V & 3.50 & 1.95 & 3,193 & 1,100 & & & & & & & 2.38 \\
\hline beast & $\mathrm{N}$ & 6.46 & 0.88 & 1,908 & 861 & 537 & 704 & -167 & 568 & 723 & -155 & 4.30 \\
\hline beauty & $N$ & 5.36 & 1.68 & 3,185 & 3,028 & 445 & 560 & -115 & 456 & 569 & -113 & 4.13 \\
\hline beckon & V & 3.75 & 2.05 & 2,309 & 1,098 & & & & 756 & 825 & -69 & 2.68 \\
\hline become & V & 2.75 & 1.62 & 2,266 & 1,224 & 578 & 448 & 130 & 563 & 506 & 57 & 5.16 \\
\hline bee & $\mathrm{N}$ & 6.96 & 0.19 & 1,294 & 357 & 464 & 569 & -105 & 590 & 694 & -104 & 3.95 \\
\hline beet & $\mathrm{N}$ & 5.46 & 2.01 & 2,780 & 2,978 & 603 & 650 & -47 & 620 & 672 & -52 & 2.76 \\
\hline beg & V & 5.54 & 1.62 & 2,094 & 965 & 608 & 506 & 102 & 602 & 546 & 56 & 4.00 \\
\hline begin & V & 3.54 & 1.73 & 3,386 & 1,936 & 585 & 504 & 81 & 565 & 568 & -3 & 5.08 \\
\hline behave & V & 3.86 & 1.84 & 2,747 & 2,618 & 652 & 476 & 176 & 629 & 521 & 108 & 3.99 \\
\hline belief & $\mathbf{N}$ & 3.64 & 1.75 & 2,743 & 2,108 & 490 & 548 & -58 & 537 & 560 & -23 & 4.53 \\
\hline bell & $\mathrm{N}$ & 6.71 & 0.81 & 1,635 & 699 & 470 & 606 & -136 & 477 & 604 & -127 & 4.45 \\
\hline belly & $\mathrm{N}$ & 6.18 & 1.44 & 1,836 & 1,275 & 555 & 639 & -84 & 564 & 645 & -81 & 3.80 \\
\hline belong & V & 2.79 & 1.83 & 2,617 & 1,180 & 656 & 562 & 94 & 625 & 581 & 44 & 4.44 \\
\hline berate & V & 1.96 & 1.53 & 2,542 & 2,229 & 743 & 569 & 174 & 710 & 613 & 97 & 2.56 \\
\hline betray & V & 3.79 & 1.89 & 3,151 & 2,534 & 674 & 511 & 163 & 634 & 595 & 39 & 3.47 \\
\hline beware & V & 4.39 & 2.04 & 2,275 & 905 & 564 & 578 & -14 & 564 & 578 & -14 & 3.75 \\
\hline bib & $\mathrm{N}$ & 5.93 & 1.76 & 1,796 & 800 & 596 & 712 & -116 & 596 & 712 & -116 & 2.89 \\
\hline bicker & V & 4.21 & 2.02 & 2,422 & 1,812 & 728 & 649 & 79 & 596 & 607 & -11 & 3.03 \\
\hline jind & V & 3.71 & 1.74 & 2,867 & 1,265 & 570 & 581 & -11 & 539 & 583 & -44 & 4.46 \\
\hline blade & $\mathrm{N}$ & 6.67 & 0.68 & 1,638 & 730 & 446 & 602 & -156 & 465 & 601 & -136 & 4.16 \\
\hline bleed & $\mathrm{V}$ & 6.39 & 0.99 & 2,198 & 1,700 & 565 & 474 & 91 & 542 & 538 & 4 & 3.91 \\
\hline blend & B & 5.54 & 1.57 & 2,547 & 1,889 & 531 & 560 & -29 & 553 & 583 & -30 & 3.75 \\
\hline bless & V & 4.41 & 1.85 & 3,356 & 2,470 & 633 & 606 & 27 & 595 & 648 & -53 & 4.22 \\
\hline blight & B & 2.21 & 1.57 & 3,013 & 1,740 & 861 & 944 & -83 & 861 & 944 & -83 & 3.29 \\
\hline liss & $\mathrm{N}$ & 3.21 & 1.71 & 2,967 & 3,177 & 517 & 583 & -66 & 517 & 583 & -66 & 3.35 \\
\hline 00 & $\mathrm{~N}$ & 5.61 & 1.59 & 2,597 & 1,017 & 536 & 661 & -125 & 560 & 660 & -100 & 3.20 \\
\hline loom & B & 5.82 & 1.39 & 2,341 & 1,051 & 572 & 652 & -80 & 569 & 643 & -74 & 3.71 \\
\hline lot & B & 5.14 & 1.51 & 3,301 & 4,695 & 566 & 622 & -56 & 656 & 698 & -42 & 2.94 \\
\hline blouse & $\mathrm{N}$ & 6.54 & 1.04 & 1,787 & 1,126 & 658 & 741 & -83 & 664 & 741 & -77 & 3.28 \\
\hline blurt & V & 4.25 & 1.90 & 2,571 & 1,992 & 795 & 644 & 151 & 757 & 690 & 67 & 2.71 \\
\hline bo & B & 6.00 & 1.47 & 2,582 & 1,934 & 482 & 621 & -139 & 495 & 608 & -113 & 4.06 \\
\hline
\end{tabular}


APPENDIX B (Continued)

\begin{tabular}{|c|c|c|c|c|c|c|c|c|c|c|c|c|}
\hline \multirow[b]{2}{*}{ Word } & \multirow{2}{*}{$\begin{array}{c}\text { FK } \\
\text { Code }\end{array}$} & \multicolumn{2}{|c|}{ Image Rate } & \multicolumn{2}{|c|}{ Image RT } & \multicolumn{3}{|c|}{ HAL Uninflected $\dagger$} & \multicolumn{3}{|c|}{ HAL Inflected $\ddagger$} & \multirow{2}{*}{$\begin{array}{c}\text { Usenet } \\
\text { Log Frequency }\end{array}$} \\
\hline & & $M$ & $S D$ & $M$ & $S D$ & NDist & VDist & NVDD & NDist & VDist & NVDD & \\
\hline bone & $\mathrm{N}$ & 6.46 & 1.17 & 1,916 & 1,203 & 661 & 792 & -131 & 596 & 718 & -122 & 4.37 \\
\hline bonus & $\mathrm{N}$ & 4.21 & 1.83 & 2,684 & 1,650 & 520 & 613 & -93 & 536 & 616 & -80 & 4.23 \\
\hline boost & $\mathrm{B}$ & 4.04 & 2.06 & 3,126 & 1,634 & 566 & 514 & 52 & 586 & 557 & 29 & 3.80 \\
\hline booth & $N$ & 6.14 & 1.15 & 2,013 & 859 & 484 & 606 & -122 & 504 & 618 & -114 & 3.73 \\
\hline booty & $\mathrm{N}$ & 5.54 & 1.88 & 2,780 & 1,324 & 599 & 665 & -66 & 621 & 674 & -53 & 2.75 \\
\hline borrow & V & 4.82 & 1.83 & 2,298 & 1,072 & 651 & 484 & 167 & 593 & 528 & 65 & 4.02 \\
\hline bound & B & 4.00 & 1.66 & 2,105 & 853 & 520 & 532 & -12 & 538 & 559 & -21 & 4.23 \\
\hline bounty & $\mathrm{N}$ & 3.57 & 1.77 & 3,383 & 2,889 & 502 & 630 & -128 & 525 & 643 & -118 & 3.28 \\
\hline bout & $\mathrm{N}$ & 3.21 & 1.79 & 2,252 & 1,209 & 583 & 592 & -9 & 583 & 595 & -12 & 3.79 \\
\hline breath & $\mathrm{N}$ & 5.89 & 1.47 & 2,440 & 1,773 & 541 & 593 & -52 & 546 & 596 & -50 & 4.18 \\
\hline brew. & B & 4.96 & 1.29 & 2,311 & 979 & 490 & 525 & -35 & 512 & 565 & -53 & 3.89 \\
\hline bride & $\mathrm{N}$ & 6.89 & 0.31 & 1,798 & 719 & 489 & 620 & -131 & 506 & 626 & -120 & 3.67 \\
\hline bring & V & 2.68 & 1.54 & 2,696 & 1,449 & 566 & 404 & 162 & 546 & 473 & 73 & 5.09 \\
\hline brood & B & 3.36 & 2.18 & 2,272 & 1,740 & 570 & 572 & -2 & 584 & 599 & -15 & 3.03 \\
\hline broth & $\mathrm{N}$ & 4.96 & 2.15 & 2,569 & 1,436 & 589 & 680 & -91 & 589 & 680 & -91 & 2.89 \\
\hline brow & $\mathrm{N}$ & 5.26 & 1.79 & 2,314 & 938 & 591 & 677 & -86 & 607 & 688 & -81 & 2.99 \\
\hline bruise & B & 6.29 & 1.01 & 2,044 & 925 & 625 & 614 & 11 & 615 & 618 & -3 & 3.35 \\
\hline brush & B & 6.68 & 0.55 & 2,101 & 680 & 501 & 520 & -19 & 541 & 556 & -15 & 3.99 \\
\hline bucket & $\mathrm{N}$ & 6.68 & 0.67 & 1,803 & 894 & 505 & 638 & -133 & 509 & 628 & -119 & 3.61 \\
\hline buckle & B & 6.43 & 1.03 & 1,886 & 1,062 & 531 & 584 & -53 & 577 & 623 & -46 & 3.42 \\
\hline bug & $\mathrm{B}$ & 6.57 & 0.79 & 1,572 & 698 & 513 & 578 & -65 & 520 & 571 & -51 & 4.72 \\
\hline bugle & $\mathrm{N}$ & 5.54 & 1.75 & 2,360 & 882 & 577 & 672 & -95 & 596 & 672 & -76 & 2.73 \\
\hline bulb & $N$ & 6.32 & 1.02 & 2,072 & 1,245 & 559 & 653 & -94 & 545 & 625 & -80 & 3.73 \\
\hline bulge & B & 5.07 & 2.00 & 2,164 & 1,069 & 568 & 673 & -105 & 589 & 670 & -81 & 3.31 \\
\hline bullet & $\mathrm{N}$ & 6.89 & 0.32 & 1,797 & 617 & 452 & 582 & -130 & 460 & 567 & -107 & 4.12 \\
\hline bury & V & 5.21 & 1.77 & 2,551 & 1,226 & 590 & 471 & 119 & 555 & 541 & 14 & 3.47 \\
\hline bustle & B & 3.57 & 2.18 & 2,071 & 1,070 & & & & 690 & 805 & -115 & 2.58 \\
\hline butler & $\mathrm{N}$ & 6.43 & 1.17 & 1,874 & 1,055 & 571 & 651 & -80 & 571 & 651 & -80 & 3.56 \\
\hline buzz & B & 5.14 & 1.96 & 2,552 & 1,161 & 475 & 557 & -82 & 507 & 578 & -71 & 3.71 \\
\hline $\mathrm{cab}$ & $\mathrm{N}$ & 6.61 & 0.99 & 1,813 & 1,016 & 466 & 587 & -121 & 478 & 594 & -116 & 3.60 \\
\hline cadet & $N$ & 5.33 & 1.86 & 2,286 & 1,153 & 521 & 603 & -82 & 524 & 606 & -82 & 3.32 \\
\hline camel & $\mathrm{N}$ & 6.75 & 0.70 & 1,454 & 370 & 683 & 808 & -125 & 674 & 789 & -115 & 3.61 \\
\hline campus & $N$ & 6.43 & 1.03 & 1,830 & 691 & 519 & 632 & -113 & 538 & 645 & -107 & 4.18 \\
\hline cancel & V & 3.93 & 1.86 & 2,839 & 1,709 & 588 & 472 & 116 & 603 & 565 & 38 & 4.76 \\
\hline cancer & $\mathrm{N}$ & 4.86 & 2.12 & 2,470 & 1,077 & 499 & 570 & -71 & 506 & 575 & -69 & 4.28 \\
\hline canyon & $\mathrm{N}$ & 6.57 & 0.69 & 1,798 & 1,227 & 497 & 640 & -143 & 508 & 646 & -138 & 3.66 \\
\hline cape & $\mathrm{N}$ & 6.04 & 1.50 & 2,315 & 1,767 & 507 & 644 & -137 & 510 & 645 & -135 & 3.75 \\
\hline care & $\mathrm{B}$ & 4.64 & 2.26 & 2,217 & 1,172 & 587 & 503 & 84 & 591 & 517 & 74 & 5.09 \\
\hline carrot & $\mathrm{N}$ & 6.68 & 0.82 & 1,662 & 818 & 491 & 616 & -125 & 535 & 628 & -93 & 3.44 \\
\hline carry & V & 5.32 & 1.79 & 2,060 & 796 & 580 & 426 & 154 & 549 & 487 & 62 & 4.71 \\
\hline carve & V & 5.54 & 1.43 & 2,874 & 1,761 & 629 & 501 & 128 & 570 & 572 & -2 & 3.50 \\
\hline casino & $\mathrm{N}$ & 6.68 & 0.86 & 1,746 & 941 & 532 & 634 & -102 & 584 & 675 & -91 & 3.86 \\
\hline cast & $\mathrm{B}$ & 5.32 & 1.83 & 2,558 & 1,021 & 467 & 491 & -24 & 471 & 506 & -35 & 4.52 \\
\hline cater & $\mathrm{V}$ & 4.89 & 1.73 & 2,648 & 1,823 & 670 & 537 & 133 & 649 & 616 & 33 & 3.52 \\
\hline cattle & $\mathrm{N}$ & 6.75 & 0.52 & 1,666 & 576 & 492 & 575 & -83 & 492 & 575 & -83 & 3.58 \\
\hline cavern & $\mathrm{N}$ & 5.86 & 1.88 & 2,254 & 1,298 & 559 & 695 & -136 & 740 & 868 & -128 & 3.43 \\
\hline cavity & $\mathrm{N}$ & 6.07 & 1.36 & 2,585 & 1,374 & 552 & 696 & -144 & 565 & 681 & -116 & 3.17 \\
\hline cavort & V & 2.07 & 1.63 & 2,571 & 1,287 & & & & & & & 2.04 \\
\hline cease & V & 3.48 & 1.72 & 2,737 & 1,300 & 596 & 491 & 105 & 614 & 556 & 58 & 3.85 \\
\hline cell & $\mathrm{N}$ & 5.71 & 1.46 & 2,236 & 874 & 455 & 588 & -133 & 589 & 673 & -84 & 4.65 \\
\hline cereal & $\mathrm{N}$ & 6.61 & 0.92 & 1,907 & 1,619 & 504 & 578 & -74 & 535 & 607 & -72 & 3.59 \\
\hline chalk & B & 6.61 & 1.23 & 1,523 & 779 & 498 & 532 & -34 & 498 & 532 & -34 & 3.22 \\
\hline change & $\mathrm{B}$ & 3.54 & 1.95 & 3,268 & 1,738 & 538 & 432 & 106 & 531 & 475 & 56 & 5.47 \\
\hline chase & B & 5.64 & 1.62 & 1,945 & 785 & 479 & 524 & -45 & 506 & 539 & -33 & 4.14 \\
\hline chef & $\mathrm{N}$ & 6.54 & 0.88 & 2,365 & 2,064 & 499 & 610 & -111 & 523 & 622 & -99 & 3.24 \\
\hline chess & $\mathrm{N}$ & 6.68 & 0.72 & 1,947 & 710 & 481 & 576 & -95 & 481 & 576 & -95 & 4.05 \\
\hline chest & $\mathrm{N}$ & 6.64 & 0.68 & 1,873 & 808 & 574 & 660 & -86 & 576 & 660 & -84 & 4.13 \\
\hline chew & V & 5.89 & 1.03 & 2,220 & 892 & 596 & 457 & 139 & 589 & 523 & 66 & 3.77 \\
\hline child & $\mathrm{N}$ & 6.61 & 1.20 & 1,972 & 2,167 & 464 & 541 & -77 & 494 & 534 & -40 & 5.24 \\
\hline chime & B & 5.75 & 1.55 & 2,875 & 1,971 & 596 & 631 & -35 & 597 & 648 & -51 & 3.29 \\
\hline chive & $\mathrm{N}$ & 4.96 & 2.05 & 2,886 & 1,462 & & & & & & & 2.03 \\
\hline choir & $\mathrm{N}$ & 6.39 & 1.40 & 2,265 & 1,387 & 489 & 611 & -122 & 503 & 619 & -116 & 3.37 \\
\hline choke & V & 5.89 & 1.31 & 2,102 & 813 & 489 & 507 & -18 & 538 & 554 & -16 & 3.76 \\
\hline
\end{tabular}


APPENDIX B (Continued)

\begin{tabular}{|c|c|c|c|c|c|c|c|c|c|c|c|c|}
\hline \multirow[b]{2}{*}{ Word } & \multirow{2}{*}{$\begin{array}{c}\text { FK } \\
\text { Code }\end{array}$} & \multicolumn{2}{|c|}{ Image Rate } & \multicolumn{2}{|c|}{ Image RT } & \multicolumn{3}{|c|}{ HAL Uninflected $†$} & \multicolumn{3}{|c|}{ HAL Inflected $\$$} & \multirow{2}{*}{$\begin{array}{c}\text { Usenet } \\
\text { Log Frequency }\end{array}$} \\
\hline & & $M$ & $S D$ & $M$ & $S D$ & NDist & VDist & NVDD & NDist & VDist & NVDD & \\
\hline choose & $\mathrm{V}$ & 3.67 & 1.69 & 3,758 & 2,017 & 596 & 447 & 149 & 579 & 486 & 93 & 4.95 \\
\hline chore & $\mathrm{N}$ & 5.14 & 1.90 & 2,461 & 1,502 & 656 & 703 & -47 & 659 & 690 & -31 & 3.18 \\
\hline church & $\mathrm{N}$ & 6.67 & 0.88 & 1,511 & 598 & 471 & 583 & -112 & 480 & 587 & -107 & 4.75 \\
\hline cider & $\mathrm{N}$ & 5.61 & 1.57 & 2,002 & 884 & 556 & 604 & -48 & 556 & 604 & -48 & 2.82 \\
\hline cigar & $\mathrm{N}$ & 6.86 & 0.45 & 1,689 & 1,116 & 588 & 668 & -80 & 587 & 660 & -73 & 3.23 \\
\hline cinema & $\mathrm{N}$ & 6.36 & 1.50 & 1,761 & 801 & 494 & 639 & -145 & 509 & 649 & -140 & 3.55 \\
\hline circus & $\mathrm{N}$ & 6.81 & 0.48 & 1,711 & 1,048 & 476 & 636 & -160 & 494 & 643 & -149 & 3.56 \\
\hline cite & V & 2.93 & 1.82 & 3,635 & 2,591 & 592 & 499 & 93 & 567 & 557 & 10 & 4.25 \\
\hline city & $\mathrm{N}$ & 6.57 & 1.20 & 1,620 & 1,148 & 494 & 651 & -157 & 501 & 648 & -147 & 5.08 \\
\hline claim & B & 3.18 & 1.52 & 3,114 & 1,693 & 567 & 486 & 81 & 549 & 509 & 40 & 5.08 \\
\hline clan & $\mathrm{N}$ & 4.71 & 2.21 & 2,241 & 1,033 & 451 & 581 & -130 & 469 & 591 & -122 & 3.73 \\
\hline clang & B & 4.82 & 1.93 & 2,333 & 1,354 & 783 & 798 & -15 & 783 & 798 & -15 & 2.44 \\
\hline clause & $\mathrm{N}$ & 2.79 & 1.57 & 2,991 & 1,007 & 527 & 636 & -109 & 537 & 639 & -102 & 3.89 \\
\hline claw & B & 6.21 & 1.23 & 2,159 & 1,374 & 525 & 617 & -92 & 561 & 630 & -69 & 3.73 \\
\hline clay & $\mathrm{N}$ & 6.14 & 1.15 & 1,857 & 1,005 & 670 & 787 & -117 & 670 & 787 & -117 & 4.03 \\
\hline clench & V & 4.63 & 1.84 & 2,357 & 1,708 & 689 & 600 & 89 & 695 & 701 & -6 & 3.11 \\
\hline client & $\mathrm{N}$ & 4.61 & 2.02 & 2,480 & 1,425 & 523 & 603 & -80 & 564 & 613 & -49 & 5.02 \\
\hline cliff & $\mathrm{N}$ & 6.75 & 0.59 & 1,629 & 989 & 474 & 593 & -119 & 501 & 614 & -113 & 3.82 \\
\hline cling & $\mathrm{V}$ & 4.75 & 1.55 & 2,483 & 1,297 & 634 & 494 & 140 & 635 & 580 & 55 & 3.45 \\
\hline clinic & $\mathrm{N}$ & 5.86 & 1.33 & 2,084 & 947 & 505 & 628 & -123 & 521 & 620 & -99 & 3.82 \\
\hline clot & B & 5.14 & 1.58 & 2,234 & 1,220 & 626 & 690 & -64 & 675 & 718 & -43 & 2.82 \\
\hline cloth & $\mathrm{N}$ & 6.44 & 0.97 & 2,064 & 1,316 & 778 & 860 & -82 & 773 & 853 & -80 & 4.06 \\
\hline clothe & V & 5.63 & 1.84 & 2,477 & 1,109 & 694 & 616 & 78 & 525 & 562 & -37 & 4.41 \\
\hline coax & V & 2.54 & 1.57 & 2,961 & 1,500 & 503 & 565 & -62 & 539 & 591 & -52 & 3.40 \\
\hline cocoa & $\mathrm{N}$ & 5.96 & 1.43 & 2,288 & 1,857 & 557 & 667 & -110 & 557 & 667 & -110 & 3.16 \\
\hline $\operatorname{cod}$ & $\mathrm{N}$ & 4.18 & 2.37 & 2,718 & 1,385 & 679 & 661 & 18 & 688 & 670 & 18 & 4.07 \\
\hline coddle & $\mathrm{V}$ & 2.57 & 1.83 & 2,209 & 1,063 & & & & & & & 1,84 \\
\hline coffin & $\mathrm{N}$ & 6.64 & 1.06 & 2,353 & 2,128 & 669 & 820 & -151 & 669 & 811 & -142 & 3.59 \\
\hline colony & $N$ & 5.21 & 1.60 & 2,888 & 2,011 & 469 & 619 & -150 & 494 & 621 & -127 & 3.87 \\
\hline column & $\mathrm{N}$ & 6.07 & 1.12 & 2,141 & 985 & 476 & 623 & -147 & 486 & 619 & -133 & 4.35 \\
\hline comb & B & 6.75 & 0.44 & 1,883 & 746 & 585 & 623 & -38 & 635 & 665 & -30 & 3.47 \\
\hline come & V & 3.57 & 1.91 & 2,936 & 1,520 & 554 & 438 & 116 & 541 & 500 & 41 & 5.72 \\
\hline comedy & $\mathrm{N}$ & 4.79 & 1.95 & 2,677 & 1,687 & 462 & 582 & -120 & 471 & 586 & -115 & 3.87 \\
\hline comet & $\mathrm{N}$ & 6.68 & 0.86 & 2,211 & 1,307 & 513 & 686 & -173 & 528 & 685 & -157 & 3.65 \\
\hline comma & $\mathrm{N}$ & 5.50 & 1.82 & 2,713 & 1,324 & 538 & 626 & -88 & 563 & 632 & -69 & 3.38 \\
\hline compel & V & 2.79 & 1.85 & 2,347 & 1,800 & 679 & 580 & 99 & 630 & 600 & 30 & 3.87 \\
\hline comply & V & 3.43 & 1.79 & 2,726 & 1,772 & 691 & 525 & 166 & 682 & 567 & 115 & 3.66 \\
\hline concur & V & 2.46 & 1.45 & 2,875 & 1,608 & 696 & 644 & 52 & 708 & 698 & 10 & 3.26 \\
\hline confer & V & 2.29 & 1.46 & 3,282 & 2,397 & 650 & 580 & 70 & 667 & 649 & 18 & 3.15 \\
\hline convey & V & 2.52 & 1.42 & 2,815 & 1,438 & 640 & 512 & 128 & 643 & 571 & 72 & 3.66 \\
\hline cookie & $\mathrm{N}$ & 6.93 & 0.26 & 1,382 & 470 & 465 & 590 & -125 & 484 & 568 & -84 & 3.74 \\
\hline cope & V & 2.46 & 1.32 & 2,934 & 1,663 & 646 & 492 & 154 & 626 & 516 & 110 & 3.70 \\
\hline corn & $\mathrm{N}$ & 6.79 & 0.79 & 1,720 & 1,568 & 467 & 572 & -105 & 467 & 572 & -105 & 3.70 \\
\hline corpse & $\mathrm{N}$ & 6.50 & 0.84 & 1,815 & 720 & 495 & 619 & -124 & 516 & 621 & -105 & 3.52 \\
\hline county & $\mathrm{N}$ & 4.63 & 1.94 & 2,375 & 856 & 515 & 642 & -127 & 522 & 647 & -125 & 4.42 \\
\hline coupon & $\mathbf{N}$ & 6.57 & 1.14 & 1,796 & 986 & 583 & 686 & -103 & 583 & 650 & -67 & 3.66 \\
\hline cousin & $\mathrm{N}$ & 5.89 & 1.81 & 2,458 & 1,664 & 552 & 612 & -60 & 571 & 616 & -45 & 3.83 \\
\hline coward & $\mathrm{N}$ & 5.07 & 1.86 & 2,667 & 1,793 & 621 & 632 & -11 & 616 & 631 & -15 & 3.36 \\
\hline crab & $\mathrm{N}$ & 6.89 & 0.31 & 1,732 & 1,734 & 486 & 619 & -133 & 516 & 620 & -104 & 3.14 \\
\hline craft & $\mathrm{N}$ & 4.79 & 1.73 & 2,203 & 908 & 455 & 560 & -105 & 509 & 591 & -82 & 4.02 \\
\hline cram & V & 4.46 & 1.99 & 2,846 & 1,289 & 687 & 629 & 58 & 661 & 634 & 27 & 3.34 \\
\hline crave & $\mathrm{V}$ & 4.61 & 1.95 & 2,750 & 1,917 & 682 & 589 & 93 & 635 & 604 & 31 & 3.23 \\
\hline crease & B & 5.18 & 1.72 & 2,580 & 1,611 & 617 & 761 & -144 & 707 & 800 & -93 & 3.56 \\
\hline create & $\mathrm{V}$ & 3.18 & 1.96 & 3,486 & 1,904 & 596 & 435 & 161 & 562 & 499 & 63 & 5.22 \\
\hline creek & $\mathrm{N}$ & 5.96 & 1.64 & 1,995 & 968 & 580 & 699 & -119 & 583 & 702 & -119 & 3.94 \\
\hline crime & $\mathrm{N}$ & 5.75 & 1.48 & 2,199 & 2,071 & 470 & 561 & -91 & 494 & 569 & -75 & 4.67 \\
\hline crisis & $N$ & 4.89 & 1.83 & 2,309 & 947 & 478 & 614 & -136 & 486 & 617 & -131 & 4.16 \\
\hline critic & $\mathrm{N}$ & 4.64 & 1.91 & 2,766 & 1,726 & 504 & 597 & -93 & 512 & 566 & -54 & 3.90 \\
\hline croak & B & 5.32 & 1.74 & 2,263 & 991 & 734 & 659 & 75 & 734 & 659 & 75 & 2.27 \\
\hline crunch & B & 5.50 & 1.45 & 2,288 & 1,048 & 499 & 557 & -58 & 555 & 598 & -43 & 3.42 \\
\hline crutch & $\mathrm{N}$ & 5.43 & 1.97 & 1,881 & 810 & 621 & 694 & -73 & 635 & 690 & -55 & 2.95 \\
\hline cult & $\mathrm{N}$ & 4.39 & 2.15 & 2,710 & 1,366 & 464 & 585 & -121 & 482 & 593 & -111 & 4.12 \\
\hline cure & B & 4.46 & 1.95 & 2,934 & 1,704 & 504 & 503 & 1 & 531 & 527 & 4 & 4.11 \\
\hline
\end{tabular}


APPENDIX B (Continued)

\begin{tabular}{|c|c|c|c|c|c|c|c|c|c|c|c|c|}
\hline \multirow[b]{2}{*}{ Word } & \multirow{2}{*}{$\begin{array}{c}\text { FK } \\
\text { Code }\end{array}$} & \multicolumn{2}{|c|}{ Image Rate } & \multicolumn{2}{|c|}{ Image RT } & \multicolumn{3}{|c|}{ HAL Uninflected $\dagger$} & \multicolumn{3}{|c|}{ HAL Inflected $\ddagger$} & \multirow{2}{*}{$\begin{array}{c}\text { Usenet } \\
\text { Log Frequency }\end{array}$} \\
\hline & & $M$ & $S D$ & $M$ & $S D$ & NDist & VDist & NVDD & NDist & VDist & NVDD & \\
\hline dabble & $\bar{V}$ & 3.54 & 1.97 & 2,142 & 934 & 727 & 584 & 143 & 783 & 719 & 64 & 2.65 \\
\hline daisy & $\mathrm{N}$ & 6.79 & 0.57 & 1,754 & 972 & 508 & 575 & -67 & 536 & 606 & -70 & 3.21 \\
\hline dance & B & 6.57 & 0.92 & 1,714 & 555 & 456 & 519 & -63 & 480 & 547 & -67 & 4.64 \\
\hline danger & $\mathrm{N}$ & 4.00 & 2.31 & 2,756 & 1,531 & 512 & 593 & -81 & 524 & 600 & -76 & 4.19 \\
\hline dash & B & 5.07 & 1.86 & 3,185 & 1,727 & 460 & 551 & -91 & 498 & 570 & -72 & 3.70 \\
\hline day & $\mathrm{N}$ & 5.11 & 2.10 & 3,309 & 2,936 & 484 & 597 & -113 & 512 & 617 & -105 & 5.60 \\
\hline daze & V & 4.61 & 1.55 & 2,975 & 1,828 & 614 & 726 & -112 & 587 & 664 & -77 & 3.12 \\
\hline deal & B & 4.86 & 2.09 & 2,486 & 1,590 & 560 & 507 & 53 & 559 & 525 & 34 & 5.11 \\
\hline death & $\mathrm{N}$ & 6.14 & 1.35 & 2,239 & 1,232 & 459 & 540 & -81 & 467 & 547 & -80 & 4.93 \\
\hline debt & $N$ & 4.57 & 1.93 & 2,315 & 1,213 & 518 & 598 & -80 & 546 & 615 & -69 & 4.22 \\
\hline decay & B & 4.93 & 1.70 & 2,384 & 1,164 & 565 & 587 & -22 & 578 & 613 & -35 & 3.69 \\
\hline deceit & $\mathrm{N}$ & 2.36 & 1.57 & 2,877 & 1,740 & 684 & 698 & -14 & 684 & 698 & -14 & 2.96 \\
\hline decide & V & 2.46 & 1.53 & 2,822 & 1,312 & 625 & 460 & 165 & 594 & 516 & 78 & 4.99 \\
\hline deduce & V & 3.11 & 1.85 & 2,565 & 1,469 & 709 & 560 & 149 & 701 & 597 & 104 & 3.15 \\
\hline deduct & V & 3.26 & 1.93 & 2,524 & 1,167 & 705 & 554 & 151 & 702 & 607 & 95 & 3.27 \\
\hline defeat & B & 4.54 & 1.93 & 2,980 & 2,342 & 542 & 466 & 76 & 549 & 519 & 30 & 4.17 \\
\hline defend & $\mathrm{V}$ & 4.50 & 1.60 & 3,191 & 2,547 & 649 & 458 & 191 & 609 & 488 & 121 & 4.40 \\
\hline defer & V & 1.96 & 1.69 & 2,666 & 1,291 & 693 & 523 & 170 & 648 & 573 & 75 & 3.18 \\
\hline define & $\mathrm{V}$ & 3.04 & 1.62 & 2,691 & 1,287 & 598 & 459 & 139 & 570 & 531 & 39 & 4.78 \\
\hline defy & $\mathrm{V}$ & 2.82 & 1.76 & 3,094 & 1,789 & 651 & 526 & 125 & 654 & 592 & 62 & 3.31 \\
\hline delude & V & 2.82 & 1.61 & 3,174 & 6,388 & 731 & 578 & 153 & 678 & 619 & 59 & 3.21 \\
\hline delve & V & 2.07 & 1.65 & 2,457 & 1,443 & 737 & 547 & 190 & 745 & 623 & 122 & 3.03 \\
\hline demand & B & 4.19 & 1.88 & 2,352 & 1,309 & 507 & 498 & 9 & 517 & 516 & 1 & 4.64 \\
\hline demon & $\mathrm{N}$ & 6.21 & 1.23 & 1,994 & 830 & 538 & 689 & -151 & 529 & 652 & -123 & 4.10 \\
\hline denote & V & 2.46 & 1.50 & 2,648 & 1,426 & 647 & 584 & 63 & 661 & 696 & -35 & 3.50 \\
\hline deny & V & 3.39 & 1.89 & 2,446 & 953 & 634 & 452 & 182 & 601 & 511 & 90 & 4.48 \\
\hline depart & V & 4.26 & 1.85 & 2,907 & 2,069 & 568 & 491 & 77 & 575 & 575 & 0 & 3.57 \\
\hline depend & V & 3.14 & 1.72 & 3,273 & 2,955 & 595 & 514 & 81 & 579 & 572 & 7 & 4.84 \\
\hline depict & V & 2.04 & 1.23 & 3,036 & 1,377 & 640 & 554 & 86 & 620 & 658 & -38 & 3.59 \\
\hline depth & $\mathrm{N}$ & 3.57 & 1.50 & 3,041 & 1,262 & 493 & 580 & -87 & 505 & 589 & -84 & 4.18 \\
\hline derive & V & 2.75 & 1.71 & 2,597 & 1,267 & 631 & 478 & 153 & 578 & 594 & -16 & 4.21 \\
\hline design & B & 5.29 & 1.49 & 2,159 & 936 & 532 & 597 & -65 & 540 & 595 & -55 & 5.24 \\
\hline desire & B & 4.68 & 1.98 & 2,201 & 1,090 & 519 & 522 & -3 & 554 & 562 & -8 & 4.69 \\
\hline desk & $N$ & 6.71 & 0.85 & 1,796 & 1,108 & 540 & 650 & -110 & 544 & 651 & -107 & 4.16 \\
\hline detach & V & 4.54 & 1.77 & 2,363 & 948 & 626 & 556 & 70 & 580 & 577 & 3 & 3.25 \\
\hline detain & V & 3.61 & 1.79 & 2,645 & 1,440 & 781 & 665 & 116 & 684 & 663 & 21 & 3.36 \\
\hline detect & V & 3.71 & 1.78 & 2,773 & 1,456 & 624 & 483 & 141 & 614 & 549 & 65 & 4.25 \\
\hline detest & V & 4.14 & 1.90 & 2,657 & 1,847 & 700 & 614 & 86 & 700 & 614 & 86 & 2.67 \\
\hline device & $N$ & 4.25 & 1.90 & 2,428 & 1,248 & 479 & 591 & -112 & 498 & 584 & -86 & 4.87 \\
\hline devise & V & 2.96 & 1.60 & 2,923 & 1,662 & 656 & 501 & 155 & 636 & 596 & 40 & 3.47 \\
\hline devote & V & 3.04 & 1.76 & 3,182 & 2,163 & 672 & 489 & 183 & 590 & 618 & -28 & 4.08 \\
\hline devour & V & 5.14 & 1.58 & 2,705 & 1,476 & 694 & 562 & 132 & 875 & 913 & -38 & 3.44 \\
\hline dew & $\mathrm{N}$ & 5.96 & 1.37 & 1,876 & 698 & 512 & 613 & -101 & 512 & 613 & -101 & 3.12 \\
\hline diary & $\mathrm{N}$ & 6.46 & 0.96 & 1,893 & 700 & 480 & 616 & -136 & 511 & 635 & -124 & 3.55 \\
\hline differ & V & 3.57 & 2.06 & 3,515 & 3,194 & 608 & 516 & 92 & 593 & 557 & 36 & 4.11 \\
\hline dilate & V & 3.36 & 2.04 & 3,526 & 2,137 & & & & 702 & 692 & 10 & 2.70 \\
\hline dine & V & 5.21 & 0.96 & 2,984 & 1,725 & 652 & 610 & 42 & 538 & 613 & -75 & 3.53 \\
\hline dinner & $N$ & 6.68 & 0.77 & 1,877 & 1,153 & 537 & 548 & -11 & 541 & 552 & -11 & 4.14 \\
\hline $\operatorname{dip}$ & B & 6.21 & 1.20 & 2,282 & 1,132 & 474 & 516 & -42 & 508 & 542 & -34 & 3.87 \\
\hline dirt & $\mathrm{N}$ & 6.61 & 0.99 & 1,941 & 1,683 & 455 & 541 & -86 & 455 & 541 & -86 & 3.88 \\
\hline distil & V & 3.14 & 1.76 & 3,504 & 2,736 & & & & 584 & 592 & -8 & 3.01 \\
\hline divert & $\mathrm{V}$ & 3.56 & 1.95 & 2,174 & 955 & 665 & 537 & 128 & 665 & 600 & 65 & 3.36 \\
\hline donate & V & 3.46 & 1.71 & 3,023 & 1,709 & 681 & 505 & 176 & 648 & 563 & 85 & 3.79 \\
\hline donor & $\mathrm{N}$ & 4.79 & 1.50 & 2,315 & 926 & 545 & 637 & -92 & 572 & 642 & -70 & 3.44 \\
\hline door & $\mathrm{N}$ & 6.86 & 0.36 & 1,560 & 554 & 528 & 628 & -100 & 521 & 618 & -97 & 4.82 \\
\hline dough & $\mathrm{N}$ & 6.39 & 1.07 & 2,364 & 1,655 & 511 & 600 & -89 & 511 & 600 & -89 & 3.53 \\
\hline doze & V & 5.00 & 1.41 & 2,717 & 1,353 & 635 & 649 & -14 & 673 & 672 & 1 & 2.76 \\
\hline dragon & $\mathrm{N}$ & 6.64 & 0.73 & 1,460 & 676 & 599 & 732 & -133 & 584 & 714 & -130 & 4.55 \\
\hline drain & B & 6.14 & 1.04 & 2,122 & 928 & 707 & 787 & -80 & 680 & 748 & -68 & 4.27 \\
\hline drama & $\mathrm{N}$ & 4.57 & 1.85 & 2,648 & 1,550 & 473 & 595 & -122 & 492 & 608 & -116 & 3.72 \\
\hline dress & B & 6.67 & 1.00 & 1,743 & 560 & 493 & 520 & -27 & 518 & 540 & -22 & 4.39 \\
\hline drift & B & 5.29 & 1.44 & 2,401 & 1,256 & 532 & 572 & -40 & 563 & 591 & -28 & 3.76 \\
\hline drill & B & 5.89 & 1.31 & 1,778 & 612 & 492 & 570 & -78 & 509 & 571 & -62 & 3.99 \\
\hline
\end{tabular}


APPENDIX B (Continued)

\begin{tabular}{|c|c|c|c|c|c|c|c|c|c|c|c|c|}
\hline \multirow[b]{2}{*}{ Word } & \multirow{2}{*}{$\begin{array}{l}\text { FK } \\
\text { Code }\end{array}$} & \multicolumn{2}{|c|}{ Image Rate } & \multicolumn{2}{|c|}{ Image RT } & \multicolumn{3}{|c|}{ HAL Uninflected $\dagger$} & \multicolumn{3}{|c|}{ HAL Inflected $\ddagger$} & \multirow{2}{*}{$\begin{array}{c}\text { Usenet } \\
\text { Log Frequency }\end{array}$} \\
\hline & & $M$ & $S D$ & $M$ & $S D$ & NDist & VDist & NVDD & NDist & VDist & NVDD & \\
\hline drink & $\mathrm{B}$ & 6.75 & 0.59 & 1,629 & 669 & 529 & 450 & 79 & 534 & 499 & 35 & 4.66 \\
\hline droop & V & 4.75 & 1.84 & 2,350 & 1,442 & 690 & 678 & 12 & 690 & 678 & 12 & 2.07 \\
\hline drown & V & 5.89 & 1.40 & 2,506 & 1,372 & 649 & 527 & 122 & 629 & 648 & -19 & 3.72 \\
\hline duct & $\mathrm{N}$ & 4.39 & 2.11 & 3,133 & 2,166 & 523 & 601 & -78 & 548 & 622 & -74 & 3.17 \\
\hline duet & $N$ & 5.44 & 1.50 & 2,486 & 1,439 & 509 & 615 & -106 & 538 & 635 & -97 & 3.12 \\
\hline dune & $\mathrm{N}$ & 4.14 & 2.09 & 2,373 & 1,017 & 518 & 639 & -121 & 534 & 657 & -123 & 3.43 \\
\hline dusk & $\mathrm{N}$ & 5.86 & 1.56 & 2,440 & 1,235 & 586 & 661 & -75 & 586 & 661 & -75 & 2.90 \\
\hline duty & $\mathrm{N}$ & 4.00 & 1.76 & 2,468 & 1,488 & 553 & 605 & -52 & 569 & 622 & -53 & 4.38 \\
\hline dwarf & B & 6.46 & 1.20 & 1,793 & 902 & 513 & 639 & -126 & 531 & 646 & -115 & 3.83 \\
\hline dwell & $\mathrm{V}$ & 4.04 & 2.05 & 2,181 & 962 & 655 & 513 & 142 & 641 & 592 & 49 & 3.45 \\
\hline eagle & $\mathrm{N}$ & 6.86 & 0.59 & 1,780 & 1,152 & 460 & 593 & -133 & 481 & 613 & -132 & 4.00 \\
\hline earn & V & 3.93 & 1.92 & 2,736 & 1,600 & 647 & 498 & 149 & 614 & 541 & 73 & 4.38 \\
\hline ease & B & 2.50 & 1.45 & 2,693 & 1,165 & 532 & 513 & 19 & 550 & 534 & 16 & 4.06 \\
\hline easel & $\mathrm{N}$ & 5.46 & 1.95 & 2,297 & 1,395 & 634 & 724 & -90 & 634 & 724 & -90 & 2.35 \\
\hline eat & V & 6.36 & 0.87 & 1,912 & 704 & 601 & 427 & 174 & 579 & 476 & 103 & 4.83 \\
\hline ebb & V & 1.75 & 1.43 & 2,398 & 2,064 & 587 & 675 & -88 & 635 & 706 & -71 & 2.85 \\
\hline echo & B & 5.18 & 1.68 & 2,816 & 1,293 & 750 & 802 & -52 & 729 & 780 & -51 & 4.52 \\
\hline edit & V & 4.57 & 1.97 & 2,397 & 888 & 570 & 477 & 93 & 550 & 521 & 29 & 4.66 \\
\hline eject & V & 5.89 & 1.45 & 2,040 & 843 & 599 & 518 & 81 & 609 & 573 & 36 & 3.44 \\
\hline elapse & V & 2.93 & 2.06 & 2,761 & 1,373 & & & & 619 & 705 & -86 & 3.05 \\
\hline elude & V & 2.89 & 1.47 & 2,683 & 1,585 & 710 & 586 & 124 & 704 & 679 & 25 & 3.01 \\
\hline embark & V & 3.64 & 2.09 & 2,405 & 1,335 & 753 & 594 & 159 & 721 & 652 & 69 & 3.09 \\
\hline emerge & V & 4.19 & 1.64 & 3,055 & 1,736 & 604 & 520 & 84 & 582 & 622 & -40 & 4.06 \\
\hline emit & $\mathrm{V}$ & 3.50 & 1.97 & 2,185 & 877 & 628 & 539 & 89 & 626 & 628 & -2 & 3.51 \\
\hline empire & $\mathrm{N}$ & 5.07 & 1.90 & 2,710 & 2,156 & 506 & 659 & -153 & 566 & 704 & -138 & 4.37 \\
\hline enable & V & 2.93 & 1.78 & 2,944 & 1,727 & 601 & 489 & 112 & 609 & 568 & 41 & 4.45 \\
\hline enact & V & 2.68 & 1.70 & 2,920 & 1,890 & 695 & 590 & 105 & 689 & 673 & 16 & 3.59 \\
\hline endure & V & 3.43 & 1.91 & 2,825 & 1,681 & 674 & 506 & 168 & 684 & 633 & 51 & 3.62 \\
\hline energy & $\mathrm{N}$ & 4.00 & 1.81 & 3,248 & 2,168 & 489 & 588 & -99 & 492 & 588 & -96 & 4.78 \\
\hline engage & V & 4.11 & 1.85 & 2,312 & 952 & 610 & 443 & 167 & 592 & 519 & 73 & 4.27 \\
\hline engine & $\mathrm{N}$ & 6.56 & 0.85 & 1,843 & 785 & 459 & 603 & -144 & 466 & 598 & -132 & 4.70 \\
\hline engulf & V & 4.57 & 1.83 & 2,859 & 2,051 & 742 & 650 & 92 & 689 & 692 & -3 & 2.78 \\
\hline enjoy & V & 4.07 & 2.05 & 3,022 & 1,621 & 603 & 470 & 133 & 609 & 504 & 105 & 4.85 \\
\hline enlist & V & 3.50 & 1.88 & 2,197 & 1,499 & 722 & 555 & 167 & 612 & 572 & 40 & 3.19 \\
\hline enroll & V & 4.11 & 1.71 & 3,152 & 5,377 & 739 & 603 & 136 & 692 & 624 & 68 & 3.51 \\
\hline enter & V & 4.36 & 1.97 & 2,639 & 1,554 & 569 & 458 & 111 & 564 & 504 & 60 & 4.81 \\
\hline enzyme & $N$ & 4.00 & 2.13 & 2,575 & 1,974 & 584 & 673 & -89 & 587 & 660 & -73 & 3.40 \\
\hline equip & V & 3.50 & 1.58 & 2,509 & 1,299 & 662 & 618 & 44 & 579 & 591 & -12 & 3.90 \\
\hline era & $\mathrm{N}$ & 3.39 & 1.62 & 2,651 & 1,555 & 516 & 657 & -141 & 516 & 657 & -141 & 4.18 \\
\hline erase & V & 5.93 & 1.33 & 2,436 & 1,726 & 625 & 478 & 147 & 629 & 533 & 96 & 3.79 \\
\hline erect & $\mathrm{Va}$ & 4.89 & 1.66 & 2,485 & 1,010 & 598 & 595 & 3 & 609 & 617 & -8 & 3.55 \\
\hline erode & V & 4.54 & 1.99 & 2,476 & 1,029 & 720 & 596 & 124 & 706 & 689 & 17 & 3.04 \\
\hline err & V & 2.30 & 1.32 & 3,106 & 2,406 & 621 & 572 & 49 & 640 & 597 & 43 & 3.62 \\
\hline errand & $\mathrm{N}$ & 3.18 & 1.81 & 3,463 & 1,430 & 606 & 680 & -74 & 664 & 680 & -16 & 2.77 \\
\hline erupt & V & 5.79 & 1.57 & 2,361 & 2,055 & 640 & 584 & 56 & 645 & 682 & -37 & 3.19 \\
\hline estate & $\mathrm{N}$ & 5.29 & 1.78 & 2,780 & 2,190 & 557 & 650 & -93 & 561 & 652 & -91 & 4.01 \\
\hline evade & V & 3.56 & 1.91 & 3,365 & 3,668 & 683 & 530 & 153 & 684 & 592 & 92 & 3.19 \\
\hline event & $\mathrm{N}$ & 4.04 & 2.15 & 2,756 & 1,607 & 482 & 609 & -127 & 491 & 592 & -101 & 4.92 \\
\hline evict & V & 4.21 & 2.11 & 2,522 & 841 & 811 & 714 & 97 & 803 & 726 & 77 & 2.64 \\
\hline evolve & V & 3.86 & 1.99 & 2,143 & 753 & 648 & 502 & 146 & 600 & 567 & 33 & 4.05 \\
\hline exalt & V & 2.18 & 1.39 & 2,769 & 1,720 & & & & 631 & 648 & -17 & 2.99 \\
\hline exceed & V & 3.21 & 1.85 & 2,992 & 1,586 & 643 & 551 & 92 & 632 & 613 & 19 & 4.03 \\
\hline excel & V & 4.43 & 2.08 & 2,193 & 895 & 567 & 588 & -21 & 576 & 594 & -18 & 4.12 \\
\hline excite & V & 4.96 & 1.86 & 2,490 & 1,732 & 659 & 519 & 140 & 599 & 584 & 15 & 4.38 \\
\hline exert & V & 2.61 & 1.47 & 2,744 & 1,229 & 647 & 513 & 134 & 643 & 589 & 54 & 3.32 \\
\hline exhale & V & 5.43 & 1.85 & 2,432 & 1,326 & 618 & 604 & 14 & 618 & 604 & 14 & 2.75 \\
\hline exist & V & 3.04 & 1.84 & 2,930 & 1,490 & 655 & 575 & 80 & 611 & 585 & 26 & 5.07 \\
\hline expand & V & 4.43 & 1.97 & 2,649 & 1,277 & 627 & 483 & 144 & 587 & 542 & 45 & 4.47 \\
\hline expel & V & 3.59 & 1.62 & 3,138 & 3,324 & 704 & 594 & 110 & 641 & 628 & 13 & 3.37 \\
\hline expire & V & 3.74 & 1.97 & 3,278 & 1,395 & 621 & 547 & 74 & 617 & 616 & 1 & 3.89 \\
\hline extend & V & 3.89 & 1.87 & 3,714 & 3,316 & 613 & 457 & 156 & 529 & 533 & -4 & 4.55 \\
\hline extent & $\mathrm{N}$ & 2.54 & 1.88 & 2,997 & 1,679 & 590 & 572 & 18 & 590 & 573 & 17 & 4.18 \\
\hline fabric & $\mathrm{N}$ & 5.89 & 1.26 & 2,344 & 1,218 & 477 & 584 & -107 & 490 & 589 & -99 & 3.87 \\
\hline
\end{tabular}


APPENDIX B (Continued)

\begin{tabular}{|c|c|c|c|c|c|c|c|c|c|c|c|c|}
\hline \multirow[b]{2}{*}{ Word } & \multirow{2}{*}{$\begin{array}{c}\text { FK } \\
\text { Code }\end{array}$} & \multicolumn{2}{|c|}{ Image Rate } & \multicolumn{2}{|c|}{ Image RT } & \multicolumn{3}{|c|}{ HAL Uninflected $\uparrow$} & \multicolumn{3}{|c|}{ HAL Inflected $\ddagger$} & \multirow{2}{*}{$\begin{array}{c}\text { Usenet } \\
\text { Log Frequency }\end{array}$} \\
\hline & & $M$ & $S D$ & $M$ & $S D$ & NDist & VDist & NVDD & NDist & VDist & NVDD & \\
\hline facet & $\mathrm{N}$ & 4.29 & 2.26 & 2,338 & 1,389 & 638 & 687 & -49 & 662 & 707 & -45 & 3.32 \\
\hline fact & $\mathrm{N}$ & 3.46 & 2.15 & 2,845 & 1,730 & 502 & 568 & -66 & 505 & 565 & -60 & 5.34 \\
\hline fad & $\mathrm{N}$ & 3.85 & 1.92 & 2,722 & 1,116 & 577 & 664 & -87 & 588 & 663 & -75 & 3.13 \\
\hline fail & V & 3.04 & 1.62 & 3,309 & 1,411 & 582 & 459 & 123 & 554 & 526 & 28 & 4.82 \\
\hline fairy & $\mathrm{N}$ & 6.18 & 1.47 & 2,125 & 1,103 & 473 & 589 & -116 & 496 & 600 & -104 & 3.45 \\
\hline faith & $\mathrm{N}$ & 2.68 & 1.74 & 3,609 & 2,167 & 519 & 577 & -58 & 524 & 581 & -57 & 4.48 \\
\hline falcon & $\mathrm{N}$ & 6.21 & 1.55 & 1,574 & 772 & 574 & 715 & -141 & 574 & 712 & -138 & 3.96 \\
\hline falter & V & 2.04 & 1.10 & 2,701 & 1,172 & 714 & 626 & 88 & 714 & 626 & 88 & 2.28 \\
\hline fame & $\mathrm{N}$ & 4.89 & 2.04 & 2,489 & 1,284 & 545 & 622 & -77 & 545 & 622 & -77 & 3.78 \\
\hline family & $\mathrm{N}$ & 6.43 & 1.07 & 1,711 & 495 & 447 & 556 & -109 & 468 & 562 & -94 & 5.03 \\
\hline famine & $N$ & 4.89 & 1.95 & 2,797 & 2,230 & 541 & 625 & -84 & 586 & 659 & -73 & 3.10 \\
\hline fasten & V & 5.18 & 1.54 & 2,770 & 1,421 & 665 & 549 & 116 & 634 & 612 & 22 & 3.13 \\
\hline fate & $\mathrm{N}$ & 3.21 & $2.4 \mathrm{I}$ & 2,857 & 1,600 & 476 & 583 & -107 & 483 & 587 & -104 & 3.96 \\
\hline favor & B & 4.00 & 1.56 & 2,652 & 1,731 & 573 & 574 & -1 & 573 & 575 & -2 & 4.39 \\
\hline feat & $\mathrm{N}$ & 3.04 & 1.93 & 2,689 & 1,533 & 575 & 668 & -93 & 592 & 667 & $-7 \overline{5}$ & 3.31 \\
\hline fender & $\mathrm{N}$ & 5.89 & 1.71 & 2,479 & 1,380 & 494 & 601 & -107 & 509 & 612 & -103 & 3.48 \\
\hline fern & $\mathrm{N}$ & 6.14 & 1.53 & 1,545 & 429 & 595 & 689 & -94 & 603 & 693 & -90 & 2.89 \\
\hline fervor & $\mathrm{N}$ & 2.50 & 1.71 & 2,536 & 1,311 & 611 & 679 & -68 & 611 & 679 & -68 & 2.64 \\
\hline fetch & V & 5.82 & 1.72 & 2,022 & 818 & 576 & 486 & 90 & 599 & 546 & 53 & 3.69 \\
\hline fever & $\mathrm{N}$ & 5.50 & 1.71 & 2,090 & 884 & 549 & 659 & -110 & 549 & 659 & -110 & 3.62 \\
\hline fiber & $N$ & 4.18 & 2.16 & 2,898 & 1,403 & 504 & 596 & -92 & 514 & 603 & -89 & 3.90 \\
\hline fig & $N$ & 5.14 & 2.03 & 2,005 & 903 & 504 & 622 & -118 & 517 & 624 & -107 & 3.43 \\
\hline file & B & 6.33 & 1.04 & 1,981 & 1,242 & 505 & 596 & -91 & 516 & 581 & -65 & 5.71 \\
\hline filter & B & 5.46 & 1.50 & 2,044 & 1,067 & 468 & 540 & -72 & 487 & 548 & -61 & 4.48 \\
\hline fish & B & 6.89 & 0.42 & 1,629 & 807 & 435 & 534 & -99 & 455 & 540 & -85 & 4.62 \\
\hline flare & $B$ & 5.68 & 1.61 & 2,546 & 1,756 & 792 & 884 & -92 & 746 & 831 & -85 & 3.77 \\
\hline flash & B & 6.57 & 0.79 & 2,118 & 1,564 & 480 & 602 & -122 & 490 & 597 & -107 & 4.37 \\
\hline flask & $\mathrm{N}$ & 5.29 & 2.09 & 1,687 & 537 & 608 & 754 & -146 & 608 & 754 & -146 & 2.91 \\
\hline flaunt & V & 4.64 & 1.83 & 2,394 & 1,594 & 708 & 551 & 157 & 698 & 590 & 108 & 2.72 \\
\hline flea & $\mathrm{N}$ & 6.21 & 1.29 & 1,670 & 606 & 496 & 579 & -83 & 534 & 580 & -46 & 3.79 \\
\hline flee & V & 5.11 & 1.73 & 2,492 & 1,780 & 633 & 513 & 120 & 618 & 610 & 8 & 3.70 \\
\hline flight & $\mathrm{N}$ & 5.61 & 1.42 & 2,398 & 1,309 & 441 & 578 & -137 & 458 & 581 & -123 & 4.55 \\
\hline flow & B & 5.25 & 1.48 & 3,109 & 2,145 & 493 & 544 & -51 & 507 & 562 & -55 & 4.45 \\
\hline flu & $\mathrm{N}$ & 4.79 & 1.66 & 2,761 & 1,312 & 540 & 637 & -97 & 540 & 637 & -97 & 3.18 \\
\hline focus & $B$ & 3.75 & 1.97 & 3,207 & 1,965 & 484 & 476 & 8 & 511 & 517 & -6 & 4.64 \\
\hline foe & $\mathrm{N}$ & 4.39 & 2.01 & 2,284 & 1,286 & 512 & 600 & -88 & 548 & 622 & -74 & 3.33 \\
\hline follow & V & 5.04 & 1.67 & 2,520 & 1,545 & 574 & 429 & 145 & 573 & 601 & -28 & 5.55 \\
\hline folly & $\mathrm{N}$ & 2.07 & 1.36 & 3,245 & 2,126 & 562 & 632 & -70 & 579 & 652 & -73 & 3.19 \\
\hline forbid & V & 2.93 & 1.65 & 2,921 & 1,493 & 600 & 526 & 74 & 574 & 597 & -23 & 4.04 \\
\hline forget & V & 4.36 & 1.85 & 2,136 & 832 & 604 & 507 & 97 & 614 & 542 & 72 & 4.89 \\
\hline found & V & 4.07 & 1.65 & 2,606 & 1,362 & 574 & 529 & 45 & 576 & 538 & 38 & 5.33 \\
\hline fraud & $\mathrm{N}$ & 4.29 & 1.96 & 2,510 & 1,924 & 522 & 578 & -56 & 530 & 584 & -54 & 3.91 \\
\hline frenzy & $\mathrm{N}$ & 4.00 & 2.13 & 2,553 & 1,135 & 555 & 706 & -151 & 555 & 706 & -151 & 3.32 \\
\hline fright & $\mathrm{N}$ & 5.50 & 1.43 & 2,701 & 1,295 & 580 & 655 & -75 & 580 & 655 & -75 & 2.78 \\
\hline frog & $\mathrm{N}$ & 6.89 & 0.42 & 1,667 & 1,060 & 476 & 601 & -125 & 495 & 601 & -106 & 3.67 \\
\hline frolic & B & 4.25 & 2.17 & 2,302 & 932 & 743 & 703 & 40 & 743 & 703 & 40 & 2.24 \\
\hline fury & $\mathrm{N}$ & 4.64 & 2.26 & 2,523 & 1,171 & 599 & 723 & -124 & 603 & 723 & -120 & 3.60 \\
\hline fuse & B & 5.11 & 1.99 & 2,937 & 2,317 & 503 & 563 & -60 & 530 & 588 & -58 & 3.55 \\
\hline fusion & $\mathrm{N}$ & 3.93 & 2.14 & 2,775 & 1,549 & 501 & 656 & -155 & 501 & 656 & -155 & 3.94 \\
\hline gadget & $\mathrm{N}$ & 4.96 & 1.77 & 3,495 & 3,244 & 497 & 600 & -103 & 520 & 600 & -80 & 3.40 \\
\hline gaiety & $\mathrm{N}$ & 3.14 & 2.19 & 2,301 & 869 & & & & & & & 1.83 \\
\hline gain & B & 3.18 & 1.98 & 3,069 & 1,892 & 547 & 442 & 105 & 544 & 490 & 54 & 4.63 \\
\hline galley & $\mathrm{N}$ & 4.21 & 2.04 & 2,350 & 979 & 569 & 699 & -130 & 569 & 699 & -130 & 2.67 \\
\hline gallon & $\mathrm{N}$ & 6.14 & 1.27 & 2,516 & 1,332 & 611 & 732 & -121 & 600 & 704 & -104 & 3.75 \\
\hline gallop & B & 6.18 & 1.06 & 2,106 & 8,76 & 594 & 682 & -88 & 616 & 700 & -84 & 2.63 \\
\hline garlic & $\mathrm{N}$ & 6.68 & 0.82 & 1,838 & 1,075 & 546 & 660 & -114 & 546 & 660 & -114 & 3.62 \\
\hline gasp & B & 4.54 & 1.95 & 2,181 & 882 & 541 & 543 & -2 & 639 & 639 & 0 & 3.78 \\
\hline gather & V & 4.18 & 1.72 & 3,119 & 1,731 & 580 & 454 & 126 & 535 & 549 & -14 & 4.34 \\
\hline gem & $\mathrm{N}$ & 6.54 & 0.69 & 1,897 & 1,213 & 492 & 594 & -102 & 516 & 618 & -102 & 3.73 \\
\hline genius & $\mathrm{N}$ & 4.75 & 1.80 & 3,106 & 3,089 & 491 & 589 & -98 & 501 & 593 & -92 & 3.85 \\
\hline germ & $\mathrm{N}$ & 4.70 & 1.96 & 2,193 & 796 & 549 & 664 & -115 & 569 & 652 & -83 & 3.03 \\
\hline get & V & 3.46 & 1.95 & 2,515 & 1,175 & 614 & 439 & 175 & 600 & 476 & 124 & 6.19 \\
\hline gift & $\mathrm{N}$ & 6.68 & 0.55 & 2,337 & 3,178 & 495 & 582 & -87 & 514 & 577 & -63 & 4.23 \\
\hline
\end{tabular}


APPENDIX B (Continued)

\begin{tabular}{|c|c|c|c|c|c|c|c|c|c|c|c|c|}
\hline \multirow[b]{2}{*}{ Word } & \multirow{2}{*}{$\begin{array}{c}\text { FK } \\
\text { Code }\end{array}$} & \multicolumn{2}{|c|}{ Image Rate } & \multicolumn{2}{|c|}{ Image RT } & \multicolumn{3}{|c|}{ HAL Uninflected $\dagger$} & \multicolumn{3}{|c|}{ HAL Inflected $\ddagger$} & \multirow{2}{*}{$\begin{array}{c}\text { Usenet } \\
\text { Log Frequency }\end{array}$} \\
\hline & & $M$ & $S D$ & $M$ & $S D$ & NDist & VDist & NVDD & NDist & VDist & NVDD & \\
\hline giggle & B & 6.11 & 1.19 & 2,199 & 1,417 & 597 & 562 & 35 & 648 & 628 & 20 & 3.66 \\
\hline glance & B & 5.61 & 1.62 & 2,687 & 3,061 & 598 & 624 & -26 & 633 & 645 & -12 & 3.82 \\
\hline gland & $\mathrm{N}$ & 4.50 & 1.88 & 3,647 & 3,027 & 588 & 686 & -98 & 591 & 678 & -87 & 3.14 \\
\hline glaze & B & 5.11 & 1.66 & 2,315 & 1,227 & 556 & 608 & -52 & 596 & 642 & -46 & 3.05 \\
\hline glide & V & 5.39 & 1.29 & 3,126 & 2,356 & 534 & 555 & -21 & 557 & 586 & -29 & 3.37 \\
\hline gloat & V & 3.96 & 1.93 & 2,618 & 1,131 & 695 & 549 & 146 & 659 & 588 & 71 & 2.76 \\
\hline gloom & $\mathrm{N}$ & 4.89 & 1.93 & 3,493 & 7,502 & 769 & 856 & -87 & 769 & 856 & -87 & 3.50 \\
\hline gloss & B & 4.68 & 2.04 & 3,261 & 2,534 & 563 & 559 & 4 & 593 & 582 & 11 & 3.09 \\
\hline glow & B & 5.96 & 1.26 & 2,384 & 1,550 & 482 & 564 & -82 & 512 & 593 & -81 & 3.71 \\
\hline glut & B & 2.04 & 1.35 & 3,444 & 2,591 & 594 & 662 & -68 & 594 & 662 & -68 & 2.79 \\
\hline gnaw & V & 4.57 & 1.87 & 2,228 & 885 & 722 & 605 & 117 & 737 & 698 & 39 & 2.73 \\
\hline goal & $\mathrm{N}$ & 3.68 & 2.34 & 3,212 & 1,967 & 501 & 578 & -77 & 513 & 575 & -62 & 4.61 \\
\hline goat & $\mathrm{N}$ & 6.64 & 1.19 & 1,631 & 756 & 557 & 661 & -104 & 555 & 645 & -90 & 3.59 \\
\hline gobble & V & 4.96 & 1.88 & 2,020 & 869 & 699 & 611 & 88 & 699 & 611 & 88 & 2.53 \\
\hline gouge & V & 4.32 & 2.07 & 2,461 & 1,670 & 658 & 595 & 63 & 683 & 651 & 32 & 2.85 \\
\hline govern & V & 4.64 & 1.93 & 2,743 & 2,310 & 653 & 580 & 73 & 604 & 639 & -35 & 3.85 \\
\hline gram & $\mathrm{N}$ & 3.52 & 2.05 & 2,823 & 1,569 & 527 & 645 & -118 & 595 & 686 & -91 & 3.66 \\
\hline grape & $\mathrm{N}$ & 6.21 & 1.64 & 1,484 & 500 & 505 & 602 & -97 & 505 & 599 & -94 & 3.47 \\
\hline gravy & $\mathrm{N}$ & 6.59 & 1.31 & 1,665 & 891 & 520 & 603 & -83 & 520 & 603 & -83 & 2.97 \\
\hline graze & V & 4.68 & 1.91 & 2,009 & 713 & 675 & 579 & 96 & 595 & 609 & -14 & 3.19 \\
\hline greed & $\mathrm{N}$ & 4.43 & 2.01 & 2,812 & 1,575 & 563 & 660 & -97 & 563 & 660 & -97 & 3.63 \\
\hline greet & $\mathrm{V}$ & 5.11 & 1.89 & 2,294 & 781 & 674 & 521 & 153 & 588 & 582 & 6 & 3.66 \\
\hline grief & $\mathrm{N}$ & 4.36 & 1.81 & 2,719 & 1,672 & 539 & 574 & -35 & 539 & 574 & -35 & 3.59 \\
\hline grieve & V & 4.75 & 2.01 & 2,227 & 1,165 & 656 & 560 & 96 & 636 & 584 & 52 & 2.99 \\
\hline grind & V & 5.04 & 1.79 & 2,194 & 1,393 & 539 & 476 & 63 & 486 & 571 & -85 & 4.73 \\
\hline grip & B & 5.07 & 1.68 & 2,611 & 1,260 & 490 & 572 & -82 & 521 & 576 & -55 & 4.06 \\
\hline groom & B & 5.79 & 1.60 & 1,972 & 904 & 527 & 555 & -28 & 588 & 611 & -23 & 3.61 \\
\hline grove & $\mathrm{N}$ & 5.71 & 1.05 & 3,119 & 1,783 & 608 & 722 & -114 & 608 & 716 & -108 & 3.66 \\
\hline grovel & $\mathrm{V}$ & 4.22 & 2.22 & 2,176 & 1,199 & 656 & 534 & 122 & 656 & 534 & 122 & 2.74 \\
\hline grow & $\mathrm{V}$ & 5.11 & 1.83 & 2,161 & 939 & 588 & 430 & 158 & 541 & 532 & 9 & 4.87 \\
\hline growl & B & 5.89 & 1.71 & 1,867 & 1,093 & 597 & 595 & 2 & 644 & 646 & -2 & 3.25 \\
\hline growth & $\mathrm{N}$ & 3.79 & 2.08 & 2,891 & 1,700 & 519 & 607 & -88 & 520 & 608 & -88 & 4.57 \\
\hline guilt & $\mathrm{N}$ & 4.04 & 2,12 & 2,798 & 1,789 & 521 & 532 & -11 & 521 & 532 & -11 & 3.70 \\
\hline guitar & $\mathbf{N}$ & 6.86 & 0.36 & 1,701 & 659 & 445 & 559 & -114 & 460 & 564 & -104 & 4.47 \\
\hline gulf & $\mathbf{N}$ & 5.04 & 1.88 & 2,945 & 2,084 & 541 & 676 & -135 & 541 & 676 & -135 & 3.81 \\
\hline gulp & B & 5.54 & 1.55 & 2,363 & 1,153 & 598 & 605 & -7 & 643 & 638 & 5 & 2.98 \\
\hline guzzle & V & 4.43 & 1.87 & 2,557 & 1,387 & & & & & & & 1.98 \\
\hline habit & $\mathrm{N}$ & 2.68 & 1.66 & 2,884 & 1,696 & 526 & 581 & -55 & 551 & 583 & -32 & 4.04 \\
\hline hammer & B & 6.96 & 0.19 & 1,798 & 1,455 & 457 & 570 & -113 & 481 & 576 & -95 & 3.94 \\
\hline hang & V & 5.54 & 1.55 & 1,875 & 983 & 544 & 436 & 108 & 537 & 506 & 31 & 4.65 \\
\hline happen & V & 1.96 & 1.67 & 2,863 & 1,735 & 676 & 535 & 141 & 652 & 581 & 71 & 5.28 \\
\hline harass & $\mathrm{V}$ & 5.11 & 1.76 & 2,534 & 1,673 & 753 & 634 & 119 & 693 & 634 & 59 & 3.80 \\
\hline harp & B & 6.39 & 1.37 & 2,019 & 1,054 & 494 & 554 & -60 & 536 & 581 & -45 & 3.35 \\
\hline haste & $\mathrm{N}$ & 3.75 & 1.88 & 2,456 & 1,524 & 613 & 628 & -15 & 613 & 628 & -15 & 2.89 \\
\hline hasten & V & 3.21 & 1.97 & 2,438 & 1,151 & 677 & 563 & 114 & 677 & 563 & 114 & 2.73 \\
\hline haven & $\mathrm{N}$ & 3.59 & 1.82 & 2,882 & 939 & 624 & 750 & -126 & 629 & 748 & -119 & 3.77 \\
\hline heal & V & 4.07 & 1.88 & 2,937 & 1,686 & 580 & 488 & 92 & 545 & 575 & -30 & 4.20 \\
\hline health & $\mathrm{N}$ & 4.96 & 2.05 & 2,149 & 948 & 493 & 567 & -74 & 493 & 567 & -74 & 4.78 \\
\hline hear & V & 4.93 & 2.09 & 2,733 & 1,426 & 663 & 493 & 170 & 645 & 559 & 86 & 5.41 \\
\hline heart & $\mathrm{N}$ & 6.86 & 0.45 & 1,422 & 564 & 461 & 573 & -112 & 476 & 577 & -101 & 4.74 \\
\hline hearth & $\mathrm{N}$ & 3.96 & 2.15 & 2,498 & 1,730 & 625 & 728 & -103 & 625 & 728 & -103 & 2.62 \\
\hline heaven & $\mathrm{N}$ & 6.39 & 1.31 & 2,307 & 1,641 & 529 & 551 & -22 & 563 & 599 & -36 & 4.31 \\
\hline height & $\mathrm{N}$ & 5.04 & 2.01 & 2,472 & 1,282 & 462 & 578 & -116 & 483 & 585 & -102 & 4.21 \\
\hline heir & $N$ & 3.39 & 1.99 & 3,043 & 1,407 & 554 & 670 & -116 & 574 & 651 & -77 & 3.34 \\
\hline hem & B & 5.00 & 1.68 & 2,656 & 1,359 & 599 & 664 & -65 & 599 & 664 & -65 & 3.25 \\
\hline hen & $\mathbf{N}$ & 6.54 & 0.96 & 1,743 & 1,014 & 538 & 586 & -48 & 552 & 601 & -49 & 3.22 \\
\hline hero & $\mathrm{N}$ & 5.54 & 1.40 & 2,433 & 1,404 & 575 & 706 & -131 & 557 & 679 & -122 & 4.40 \\
\hline hill & $\mathrm{N}$ & 6.64 & 0.68 & 1,741 & 668 & 519 & 657 & -138 & 520 & 657 & -137 & 4.63 \\
\hline hinder & V & 3.30 & 1.79 & 2,769 & 1,952 & 704 & 560 & 144 & 696 & 622 & 74 & 3.23 \\
\hline hint & B & 4.30 & 1.90 & 2,104 & 767 & 524 & 558 & -34 & 558 & 571 & -13 & 4.34 \\
\hline hire & V & 3.39 & 1.73 & 2,735 & 1,346 & 637 & 489 & 148 & 592 & 526 & 66 & 4.40 \\
\hline hitch & B & 4.78 & 1.89 & 2,614 & 1,099 & 570 & 646 & -76 & 612 & 676 & -64 & 3.28 \\
\hline hobby & $\mathrm{N}$ & 4.04 & 2.05 & 2,611 & 1,462 & 492 & 599 & -107 & 511 & 602 & -91 & 4.00 \\
\hline
\end{tabular}


APPENDIX B (Continued)

\begin{tabular}{|c|c|c|c|c|c|c|c|c|c|c|c|c|}
\hline \multirow[b]{2}{*}{ Word } & \multirow{2}{*}{$\begin{array}{c}\text { FK } \\
\text { Code }\end{array}$} & \multicolumn{2}{|c|}{ Image Rate } & \multicolumn{2}{|c|}{ Image RT } & \multicolumn{3}{|c|}{ HAL Uninflected $\dagger$} & \multicolumn{3}{|c|}{ HAL Inflected $\ddagger$} & \multirow{2}{*}{$\begin{array}{c}\text { Usenet } \\
\text { Log Frequency }\end{array}$} \\
\hline & & $M$ & $S D$ & $M$ & $S D$ & NDist & VDist & NVDD & NDist & VDist & NVDD & \\
\hline holler & $\mathrm{V}$ & 5.04 & 2.12 & 2,389 & 795 & 681 & 683 & -2 & 683 & 681 & 2 & 2.73 \\
\hline honor & B & 3.36 & 2.04 & 3,211 & 2,115 & 484 & 507 & -23 & 520 & 541 & -21 & 4.23 \\
\hline hoot & B & 4.32 & 2.13 & 3,426 & 1,982 & 693 & 697 & -4 & 693 & 697 & -4 & 2.98 \\
\hline hope & B & 3.68 & 2.13 & 2,603 & 1,199 & 563 & 530 & 33 & 568 & 538 & 30 & 5.26 \\
\hline horror & $\mathrm{N}$ & 5.04 & 1.79 & 2,727 & 1,658 & 495 & 626 & -131 & 530 & 659 & -129 & 4.21 \\
\hline hour & $\mathrm{N}$ & 5.07 & 2.21 & 2,321 & 1,653 & 563 & 653 & -90 & 563 & 639 & -76 & 5.09 \\
\hline howl & B & 6.21 & 1.20 & 1,763 & 993 & 783 & 873 & -90 & 762 & 852 & -90 & 3.92 \\
\hline hub & $\mathrm{N}$ & 3.04 & 1.79 & 2,575 & 1,069 & 491 & 610 & -119 & 527 & 623 & -96 & 3.85 \\
\hline hue & $\mathrm{N}$ & 2.93 & 2.29 & 2,312 & 1,072 & 518 & 631 & -113 & 547 & 659 & -112 & 3.20 \\
\hline hum & B & 5.36 & 2.06 & 1,978 & 961 & 488 & 534 & -46 & 527 & 562 & -35 & 3.62 \\
\hline hunk & $\mathbf{N}$ & 5.43 & 1.77 & 1,846 & 743 & 590 & 637 & -47 & 603 & 645 & -42 & 3.05 \\
\hline hurl & V & 5.79 & 1.52 & 2,484 & 1,722 & 642 & 519 & 123 & 640 & 589 & 51 & 3.16 \\
\hline hush & B & 4.43 & 1.85 & 2,236 & 1,059 & 569 & 572 & -3 & 599 & 613 & -14 & 2.88 \\
\hline hustle & V & 4.14 & 2.14 & 2,850 & 2,269 & 573 & 548 & 25 & 584 & 571 & 13 & 2.95 \\
\hline hymn & $N$ & 5.39 & 1.64 & 2,337 & 1,061 & 840 & 927 & -87 & 785 & 873 & -88 & 3.46 \\
\hline idea & $\mathrm{N}$ & 4.86 & 2.14 & 2,146 & 1,044 & 557 & 599 & -42 & 558 & 586 & -28 & 5.31 \\
\hline idiot & $\mathrm{N}$ & 5.68 & 1.61 & 2,111 & 964 & 594 & 588 & 6 & 580 & 581 & -1 & 4.26 \\
\hline ignite & V & 5.57 & 1.29 & 2,825 & 2,919 & 657 & 525 & 132 & 645 & 588 & 57 & 3.13 \\
\hline ignore & V & 3.25 & 1.78 & 2,749 & 1,149 & 593 & 438 & 155 & 590 & 490 & 100 & 4.73 \\
\hline impair & V & 3.29 & 1.70 & 2,521 & 1,517 & 800 & 670 & 130 & 607 & 616 & -9 & 3.38 \\
\hline impale & V & 2.75 & 2.24 & 3,041 & 1,957 & & & & 689 & 708 & -19 & 2.82 \\
\hline impart & V & 2.29 & 1.51 & 2,381 & 1,057 & 709 & 555 & 154 & 685 & 629 & 56 & 3.04 \\
\hline impede & V & 2.93 & 1.86 & 2,469 & 1,469 & 724 & 588 & 136 & 728 & 636 & 92 & 2.93 \\
\hline imply & V & 1.75 & 1.29 & 2,518 & 1,409 & 665 & 525 & 140 & 613 & 572 & 41 & 4.44 \\
\hline impose & V & 3.39 & 2.01 & 2,753 & 1,457 & 653 & 488 & 165 & 600 & 559 & 41 & 4.12 \\
\hline incite & V & 2.96 & 1.69 & 2,416 & 1,291 & 711 & 566 & 145 & 741 & 674 & 67 & 3.04 \\
\hline incur & V & 2.25 & 1.35 & 1,989 & 711 & 763 & 689 & 74 & 705 & 671 & 34 & 3.50 \\
\hline indict & V & 2.82 & 1.79 & 3,139 & 1,427 & & & & 700 & 697 & 3 & 3.18 \\
\hline induce & V & 3.14 & 1.88 & 2,367 & 1,839 & 662 & 514 & 148 & 586 & 582 & 4 & 3.73 \\
\hline infect & V & 4.39 & 1.75 & 2,889 & 1,514 & 626 & 512 & 114 & 586 & 586 & 0 & 3.83 \\
\hline infer & V & 2.43 & 1.60 & 2,098 & 1,106 & 699 & 529 & 170 & 694 & 570 & 124 & 3.40 \\
\hline infest & V & 3.93 & 1.88 & 3,361 & 2,434 & & & & 606 & 611 & -5 & 2.86 \\
\hline inform & V & 4.04 & 2.01 & 2,595 & 1,286 & 602 & 456 & 146 & 597 & 510 & 87 & 4.44 \\
\hline ingest & V & 4.04 & 1.91 & 2,516 & 1,312 & 720 & 560 & 160 & 688 & 609 & 79 & 3.19 \\
\hline inject & V & 5.71 & 1.36 & 2,360 & 1,245 & 622 & 473 & 149 & 593 & 566 & 27 & 3.51 \\
\hline injure & V & 4.82 & 1.83 & 3,575 & 3.043 & 702 & 550 & 152 & 602 & 595 & 7 & 3.89 \\
\hline injury & $\mathrm{N}$ & 5.07 & 1.94 & 2,807 & 1,515 & 516 & 551 & -35 & 529 & 561 & -32 & 4.12 \\
\hline insect & $\mathrm{N}$ & 6.57 & 0.79 & 1,505 & 611 & 618 & 732 & -114 & 596 & 662 & -66 & 3.69 \\
\hline insist & V & 4.14 & 1.90 & 2,251 & 1,129 & 630 & 502 & 128 & 600 & 537 & 63 & 4.23 \\
\hline insure & V & 2.96 & 1.77 & 3,092 & 1,860 & 654 & 556 & 98 & 665 & 601 & 64 & 3.91 \\
\hline intend & $\mathrm{V}$ & 2.04 & 1.10 & 2,574 & 1,298 & 676 & 580 & 96 & 606 & 588 & 18 & 4.68 \\
\hline intent & $\mathrm{N}$ & 3.11 & 1.59 & 2,625 & 1,847 & 517 & 569 & -52 & 527 & 576 & -49 & 4.14 \\
\hline invade & V & 4.64 & 1.68 & 2,611 & 1,271 & 665 & 520 & 145 & 612 & 578 & 34 & 3.76 \\
\hline invent & V & 3.11 & 1.95 & 3,109 & 1,635 & 658 & 495 & 163 & 613 & 564 & 49 & 4.04 \\
\hline invert & V & 3.32 & 1.91 & 2,945 & 1,708 & 592 & 568 & 24 & 555 & 610 & -55 & 3.43 \\
\hline invest & V & 3.93 & 1.90 & 2,612 & 1,760 & 651 & 481 & 170 & 621 & 524 & 97 & 4.19 \\
\hline ion & $\mathbf{N}$ & 3.61 & 2.18 & 3,181 & 2,176 & 530 & 629 & -99 & 551 & 637 & -86 & 3.63 \\
\hline irony & $\mathrm{N}$ & 1.79 & 1.10 & 2,796 & 1,683 & 518 & 574 & -56 & 530 & 586 & -56 & 3.51 \\
\hline item & $N$ & 4.93 & 2.16 & 3,048 & 3,124 & 517 & 604 & -87 & 529 & 592 & -63 & 4.93 \\
\hline join & V & 4.75 & 1.73 & 2,564 & 1,469 & 605 & 462 & 143 & 592 & 493 & 99 & 4.81 \\
\hline jolt & B & 4.85 & 1.73 & 2,522 & 1,673 & 600 & 655 & -55 & 618 & 664 & -46 & 2.99 \\
\hline joy & $\mathrm{N}$ & 5.61 & 1.91 & 1,761 & 786 & 485 & 558 & -73 & 491 & 562 & -71 & 4.10 \\
\hline juggle & V & 6.25 & 1.21 & 2,155 & 1,004 & 641 & 560 & 81 & 561 & 560 & 1 & 3.42 \\
\hline jumble & B & 4.18 & 2.06 & 2,422 & 1,311 & 645 & 718 & -73 & 643 & 700 & -57 & 2.75 \\
\hline jungle & $\mathrm{N}$ & 6.89 & 0.31 & 1,471 & 623 & 498 & 662 & -164 & 508 & 667 & -159 & 3.77 \\
\hline keg & $\mathrm{N}$ & 6.32 & 1.02 & 2,183 & 1,174 & 522 & 632 & -110 & 530 & 622 & -92 & 3.21 \\
\hline kelp & $\mathrm{N}$ & 5.61 & 2.04 & 2,388 & 1,572 & 979 & 1069 & -90 & 979 & 1069 & -90 & 3.28 \\
\hline kettle & $\mathrm{N}$ & 6.54 & 0.88 & 1,767 & 859 & 547 & 673 & -126 & 547 & 673 & -126 & 3.18 \\
\hline kidnap & V & 5.14 & 1.94 & 2,287 & 772 & 612 & 546 & 66 & 578 & 605 & -27 & 3.49 \\
\hline kit & $\mathrm{N}$ & 4.93 & 1.76 & 2,520 & 1,065 & 489 & 624 & -135 & 499 & 617 & -118 & 4.51 \\
\hline knack & $\mathrm{N}$ & 2.48 & 1.63 & 2,798 & 1,264 & 639 & 687 & -48 & 639 & 687 & -48 & 2.80 \\
\hline kneel & V & 6.14 & 1.15 & 2,103 & 961 & 692 & 562 & 130 & 668 & 639 & 29 & 3.33 \\
\hline knob & $\mathrm{N}$ & 6.57 & 1.07 & 1,790 & 840 & 513 & 624 & -111 & 531 & 629 & -98 & 3.50 \\
\hline
\end{tabular}


APPENDIX B (Continued)

\begin{tabular}{|c|c|c|c|c|c|c|c|c|c|c|c|c|}
\hline \multirow[b]{2}{*}{ Word } & \multirow{2}{*}{$\begin{array}{c}\text { FK } \\
\text { Code }\end{array}$} & \multicolumn{2}{|c|}{ Image Rate } & \multicolumn{2}{|c|}{ Image RT } & \multicolumn{3}{|c|}{ HAL Uninflected $\dagger$} & \multicolumn{3}{|c|}{ HAL Inflected $\ddagger$} & \multirow{2}{*}{$\begin{array}{c}\text { Usenet } \\
\text { Log Frequency }\end{array}$} \\
\hline & & $M$ & $S D$ & $M$ & $S D$ & NDist & VDist & NVDD & NDist & VDist & NVDD & \\
\hline label & $\mathrm{B}$ & 5.57 & 1.75 & 2,384 & 1,357 & 472 & 568 & -96 & 497 & 567 & -70 & 4.60 \\
\hline lack & $\mathrm{B}$ & 1.93 & 1.12 & 2,976 & 1,640 & 479 & 531 & -52 & 504 & 542 & -38 & 4.72 \\
\hline lad & $\mathrm{N}$ & 5.14 & 1.78 & 2,579 & 2,769 & 538 & 614 & -76 & 543 & 620 & -77 & 3.47 \\
\hline lake & $\mathrm{N}$ & 6.82 & 0.55 & 2,281 & 3,855 & 500 & 655 & -155 & 507 & 656 & -149 & 4.40 \\
\hline lamp & $\mathrm{N}$ & 6.74 & 0.53 & 1,741 & 986 & 595 & 754 & -159 & 579 & 724 & -145 & 3.92 \\
\hline lane & $\mathrm{N}$ & 5.43 & 1.83 & 2,490 & 1,745 & 560 & 677 & -117 & 561 & 672 & -111 & 4.21 \\
\hline lapel & $\mathrm{N}$ & 4.75 & 2.27 & 2,188 & 1,060 & 630 & 743 & -113 & 630 & 743 & -113 & 2.38 \\
\hline lapse & B & 3.29 & 1.92 & 2,854 & 1,437 & 682 & 751 & -69 & 683 & 730 & -47 & 3.33 \\
\hline lasso & B & 6.33 & 1.49 & 1,796 & 720 & 695 & 725 & -30 & 695 & 725 & -30 & 2.26 \\
\hline lather & B & 4.82 & 2.07 & 2,273 & 824 & 645 & 716 & -71 & 645 & 716 & -71 & 2.58 \\
\hline law & $\mathrm{N}$ & 4.36 & 2.09 & 2,721 & 1,522 & 481 & 580 & -99 & 491 & 572 & -81 & 5.24 \\
\hline lawn & $\mathrm{N}$ & 6.57 & 0.84 & 1,696 & 854 & 526 & 629 & -103 & 537 & 634 & -97 & 3.49 \\
\hline lawyer & $\mathrm{N}$ & 6.36 & 1.03 & 2,069 & 1,044 & 544 & 578 & -34 & 530 & 565 & -35 & 4.38 \\
\hline leak & B & 5.75 & 1.38 & 2,582 & 1,388 & 611 & 679 & -68 & 588 & 635 & -47 & 4.01 \\
\hline learn & V & 3.93 & 2.11 & 2,765 & 1,428 & 619 & 439 & 180 & 582 & 485 & 97 & 5.14 \\
\hline lease & B & 3.57 & 2.08 & 3,435 & 2,153 & 538 & 587 & -49 & 580 & 619 & -39 & 3.86 \\
\hline ledge & $\mathrm{N}$ & 5.82 & 1.36 & 2,059 & 860 & 640 & 701 & -61 & 640 & 703 & -63 & 3.29 \\
\hline leg & $\mathrm{N}$ & 6.79 & 0.63 & 1,544 & 543 & 510 & 640 & -130 & 570 & 649 & -79 & 4.65 \\
\hline legend & $\mathrm{N}$ & 4.43 & 1.81 & 2,708 & 1,098 & 554 & 705 & -151 & 672 & 795 & -123 & 4.52 \\
\hline lend & $\mathrm{V}$ & 3.75 & 1.69 & 2,633 & 1,165 & 628 & 468 & 160 & 605 & 553 & 52 & 3.83 \\
\hline length & $\mathrm{N}$ & 4.18 & 2.09 & 3,515 & 2,169 & 625 & 718 & -93 & 622 & 709 & -87 & 4.73 \\
\hline lesson & $\mathrm{N}$ & 4.43 & 1.77 & 2,323 & 1,214 & 510 & 565 & -55 & 513 & 549 & -36 & 4.18 \\
\hline lever & $\mathrm{N}$ & 5.79 & 1.57 & 3,013 & 2,239 & 498 & 606 & -108 & 514 & 610 & -96 & 3.47 \\
\hline liar & $\mathrm{N}$ & 4.82 & 2.06 & 2,810 & 1,584 & 663 & 672 & -9 & 658 & 661 & -3 & 3.89 \\
\hline lick & V & 6.43 & 1.17 & 1,894 & 752 & 646 & 530 & 116 & 653 & 605 & 48 & 4.05 \\
\hline lid & $\mathrm{N}$ & 6.36 & 1.13 & 1,965 & 1,091 & 518 & 626 & -108 & 529 & 631 & -102 & 3.53 \\
\hline life & $\mathbf{N}$ & 4.71 & 2.14 & 2,702 & 1,470 & 487 & 562 & -75 & 498 & 564 & -66 & 5.42 \\
\hline limb & $\mathrm{N}$ & 6.14 & 1.27 & 1,797 & 784 & 638 & 691 & -53 & 598 & 658 & -60 & 3.59 \\
\hline linger & $\mathrm{V}$ & 3.25 & 1.71 & 2,720 & 1,256 & 656 & 550 & 106 & 629 & 622 & 7 & 3.24 \\
\hline link & B & 4.61 & 1.77 & 2,757 & 1,327 & 490 & 549 & -59 & 517 & 564 & -47 & 4.90 \\
\hline lint & $\mathrm{N}$ & 5.96 & 1.72 & 2,082 & 1,133 & 628 & 668 & -40 & 628 & 668 & -40 & 3.00 \\
\hline lion & $\mathrm{N}$ & 6.93 & 0.26 & 1,447 & 573 & 509 & 647 & -138 & 537 & 664 & -127 & 4.13 \\
\hline listen & V & 4.93 & 2.11 & 2,200 & 1,405 & 597 & 440 & 157 & 587 & 483 & 104 & 4.78 \\
\hline liter & $\mathrm{N}$ & 5.79 & 1.42 & 2,740 & 1,411 & 589 & 730 & -141 & 615 & 743 & -128 & 3.33 \\
\hline litter & B & 5.82 & 1.33 & 2,775 & 1,317 & 476 & 569 & -93 & 518 & 596 & -78 & 3.63 \\
\hline lizard & $\mathrm{N}$ & 6.89 & 0.42 & 1,513 & 629 & 601 & 681 & -80 & 592 & 670 & -78 & 3.85 \\
\hline locate & V & 2.93 & 1.49 & 3,378 & 1,777 & 688 & 535 & 153 & 612 & 608 & 4 & 4.71 \\
\hline loosen & V & 4.63 & 1.42 & 3,561 & 2,005 & 606 & 487 & 119 & 615 & 553 & 62 & 3.36 \\
\hline lose & V & 3.96 & 1.77 & 4,186 & 3,866 & 636 & 459 & 177 & 552 & 501 & 51 & 5.14 \\
\hline loss & $\mathrm{N}$ & 4.21 & 1.75 & 2,852 & 1,667 & 458 & 552 & -94 & 472 & 552 & -80 & 4.56 \\
\hline lotion & $\mathrm{N}$ & 6.54 & 1.04 & 1,790 & 1,006 & 559 & 666 & -107 & 586 & 679 & -93 & 3.11 \\
\hline lounge & B & 5.25 & 2.08 & 2,511 & 1,197 & 494 & 634 & -140 & 505 & 641 & -136 & 3.40 \\
\hline love & B & 6.25 & 1.43 & 2,480 & 1,784 & 536 & 502 & 34 & 543 & 512 & 31 & 5.31 \\
\hline lull & B & 3.36 & 2.06 & 2,590 & 1,400 & 673 & 712 & -39 & 690 & 699 & -9 & 2.81 \\
\hline lung & $\mathrm{N}$ & 6.50 & 0.96 & 1,793 & 1,178 & 994 & 1013 & -19 & 926 & 955 & -29 & 4.21 \\
\hline lurk & $\mathrm{V}$ & 4.18 & 2.02 & 2,365 & 1,316 & 623 & 535 & 88 & 632 & 593 & 39 & 3.80 \\
\hline luxury & $\mathbf{N}$ & 5.14 & 1.99 & 2,459 & 1,419 & 490 & 558 & -68 & 508 & 569 & -61 & 3.59 \\
\hline magnet & $\mathrm{N}$ & 6.64 & 0.68 & 2,048 & 2,019 & 488 & 597 & -109 & 505 & 604 & -99 & 3.51 \\
\hline malt & B & 5.93 & 1.33 & 2,363 & 1,572 & 510 & 614 & -104 & 523 & 620 & -97 & 3.32 \\
\hline manage & V & 2.93 & 1.80 & 3,547 & 2,680 & 634 & 476 & 158 & 589 & 528 & 61 & 4.72 \\
\hline mane & $\mathrm{N}$ & 5.82 & 1.91 & 2,041 & 969 & 538 & 647 & -109 & 654 & 715 & -61 & 2.98 \\
\hline manner & $\mathrm{N}$ & 2.11 & 1.45 & 2,470 & 900 & 619 & 687 & -68 & 612 & 673 & -61 & 4.40 \\
\hline manor & $\mathrm{N}$ & 4.78 & 1.80 & 2,590 & 1,101 & 610 & 742 & -132 & 610 & 742 & -132 & 3.21 \\
\hline mantel & $\mathrm{N}$ & 6.04 & 1.37 & 2,233 & 988 & 621 & 702 & -81 & 621 & 702 & -81 & 2.31 \\
\hline mar & V & 2.43 & 1.50 & 2,384 & 1,261 & 742 & 827 & -85 & 699 & 787 & -88 & 4.69 \\
\hline marrow & $\mathrm{N}$ & 3.29 & 2.02 & 2,724 & 1,491 & 529 & 626 & -97 & 529 & 626 & -97 & 3.02 \\
\hline marry & V & 6.30 & 0.95 & 2,003 & 1,008 & 672 & 506 & 166 & 599 & 541 & 58 & 4.56 \\
\hline marsh & $\mathrm{N}$ & 5.39 & 1.57 & 2,340 & 1,347 & 831 & 959 & -128 & 828 & 956 & -128 & 3.73 \\
\hline marvel & B & 3.07 & 1.66 & 2,954 & 1,630 & 740 & 826 & -86 & 739 & 824 & -85 & 4.32 \\
\hline math & $\mathrm{N}$ & 5.14 & 2.07 & 2,673 & 1,380 & 471 & 540 & -69 & 477 & 546 & -69 & 4.30 \\
\hline meal & $\mathrm{N}$ & 6.54 & 0.79 & 2,267 & 1,258 & 511 & 600 & -89 & 529 & 594 & -65 & 4.02 \\
\hline meat & $\mathrm{N}$ & 6.68 & 0.72 & 1,601 & 575 & 455 & 513 & -58 & 462 & 519 & -57 & 4.19 \\
\hline meddle & V & 2.29 & 1.24 & 3,128 & 1,254 & 751 & 645 & 106 & 769 & 736 & 33 & 3.19 \\
\hline
\end{tabular}


APPENDIX B (Continued)

\begin{tabular}{|c|c|c|c|c|c|c|c|c|c|c|c|c|}
\hline \multirow[b]{2}{*}{ Word } & \multirow{2}{*}{$\begin{array}{c}\text { FK } \\
\text { Code }\end{array}$} & \multicolumn{2}{|c|}{ Image Rate } & \multicolumn{2}{|c|}{ Image RT } & \multicolumn{3}{|c|}{ HAL Uninflected $\dagger$} & \multicolumn{3}{|c|}{ HAL Inflected +} & \multirow{2}{*}{$\begin{array}{c}\text { Usenet } \\
\text { Log Frequency }\end{array}$} \\
\hline & & $M$ & $S D$ & $M$ & $S D$ & NDist & VDist & NVDD & NDist & VDist & NVDD & \\
\hline melody & $\mathrm{N}$ & 4.43 & 1.89 & 3,219 & 1,368 & 466 & 581 & -115 & 491 & 591 & -100 & 3.57 \\
\hline melt & $\mathrm{V}$ & 5.71 & 1.49 & 2,357 & 1,553 & 558 & 475 & 83 & 559 & 587 & -28 & 3.89 \\
\hline member & $\mathrm{N}$ & 3.61 & 2.13 & 2,932 & 1,261 & 541 & 611 & -70 & 527 & 589 & -62 & 5.16 \\
\hline memo & $\mathrm{N}$ & 5.61 & 1.66 & 2,664 & 1,837 & 513 & 630 & -117 & 532 & 635 & -103 & 3.59 \\
\hline mend & V & 4.64 & 1.57 & 2,873 & 1,591 & 701 & 561 & 140 & 712 & 620 & 92 & 2.75 \\
\hline menu & $\mathrm{N}$ & 6.67 & 0.78 & 3,018 & 7,852 & 546 & 644 & -98 & 543 & 632 & -89 & 4.54 \\
\hline mercy. & $\mathrm{N}$ & 2.71 & 1.96 & 3,366 & 1,661 & 577 & 628 & -51 & 580 & 630 & -50 & 3.79 \\
\hline merger & $N$ & 2.64 & 1.28 & 3,068 & 1,633 & 501 & 620 & -119 & 551 & 658 & -107 & 3.34 \\
\hline mesh & B & 3.68 & 1.83 & 3,241 & 2,526 & 473 & 558 & -85 & 498 & 570 & -72 & 3.35 \\
\hline meteor & $\mathrm{N}$ & 6.25 & 1.48 & 2,354 & 1,981 & 657 & 791 & -134 & 656 & 771 & -115 & 3.18 \\
\hline method & $\mathrm{N}$ & 2.44 & 1.63 & 2,802 & 1,881 & 486 & 576 & -90 & 506 & 579 & -73 & 4.92 \\
\hline mile & $\mathrm{N}$ & 4.64 & 2.15 & 3,097 & 1,965 & 561 & 680 & -119 & 532 & 631 & -99 & 4.66 \\
\hline mince & V & 4.14 & 1.78 & 2,780 & 1,480 & 668 & 626 & 42 & 754 & 789 & -35 & 3.06 \\
\hline mingle & V & 4.11 & 1.69 & 3,066 & 1,557 & 690 & 558 & 132 & 671 & 646 & 25 & 2.94 \\
\hline misery & $\mathrm{N}$ & 5.36 & 1.87 & 2,723 & 2,312 & 553 & 593 & -40 & 594 & 630 & -36 & 3.50 \\
\hline mitten & $\mathrm{N}$ & 6.39 & 1.29 & 2,402 & 1,442 & 751 & 868 & -117 & 697 & 758 & -61 & 2.61 \\
\hline modify & V & 2.79 & 1.50 & 3,211 & 1,776 & 631 & 459 & 172 & 558 & 533 & 25 & 4.64 \\
\hline molest & V & 4.54 & 1.79 & 2,998 & 1,632 & 742 & 626 & 116 & 724 & 665 & 59 & 3.14 \\
\hline moment & $N$ & 3.18 & 2.16 & 3,104 & 2,250 & 538 & 642 & -104 & 540 & 639 & -99 & 4.71 \\
\hline monk & $\mathrm{N}$ & 6.14 & 1.46 & 2,044 & 1,079 & 544 & 691 & -147 & 536 & 663 & -127 & 3.78 \\
\hline mood & $\mathrm{N}$ & 4.68 & 1.98 & 2,961 & 2,053 & 520 & 612 & -92 & 530 & 613 & -83 & 3.91 \\
\hline morale & $\mathrm{N}$ & 3.00 & 1.72 & 2,685 & 1,262 & 700 & 812 & -112 & 700 & 812 & -112 & 3.49 \\
\hline morsel & $\mathrm{N}$ & 4.25 & 1.69 & 2,771 & 1,458 & 681 & 709 & -28 & 681 & 709 & -28 & 2.21 \\
\hline moss & $\mathrm{N}$ & 5.89 & 1.42 & 1,812 & 880 & 608 & 724 & -116 & 608 & 724 & -116 & 3.57 \\
\hline motel & $N$ & 6.64 & 0.68 & 1,553 & 597 & 492 & 618 & -126 & 516 & 633 & -117 & 3.37 \\
\hline moth & $\mathrm{N}$ & 6.68 & 0.55 & 1,961 & 1,452 & 560 & 663 & -103 & 563 & 650 & -87 & 2.96 \\
\hline mourn & V & 5.57 & 1.77 & 2,121 & 1,330 & 679 & 547 & 132 & 623 & 668 & -45 & 3.42 \\
\hline movie & $\mathrm{N}$ & 6.86 & 0.45 & 1,581 & 732 & 460 & 596 & -136 & 474 & 588 & -114 & 4.96 \\
\hline mud & $\mathrm{N}$ & 6.82 & 0.55 & 1,574 & 656 & 451 & 567 & -116 & 475 & 571 & -96 & 4.15 \\
\hline muffle & V & 4.64 & 1.79 & 2,361 & 1,026 & & & & 624 & 674 & -50 & 2.90 \\
\hline munch & V & 6.04 & 1.10 & 2,333 & 1,971 & 588 & 588 & 0 & 629 & 647 & -18 & 3.28 \\
\hline museum & $\mathrm{N}$ & 6.82 & 0.55 & 1,535 & 624 & 492 & 643 & -151 & 511 & 647 & -136 & 4.09 \\
\hline mutter & V & 4.75 & 1.65 & 2,484 & 1,589 & 690 & 616 & 74 & 673 & 653 & 20 & 3.25 \\
\hline myth & $\mathrm{N}$ & 4.18 & 1.94 & 2,731 & 1,747 & 510 & 627 & -117 & 521 & 623 & -102 & 4.07 \\
\hline nab & V & 3.54 & 2.28 & 2,464 & 1,472 & 650 & 588 & 62 & 675 & 615 & 60 & 2.67 \\
\hline nag & V & 5.25 & 1.80 & 2,258 & 1,375 & 538 & 610 & -72 & 561 & 609 & -48 & 3.21 \\
\hline napkin & $\mathrm{N}$ & 6.46 & 1.26 & 1,746 & 947 & 638 & 722 & -84 & 658 & 714 & -56 & 2.85 \\
\hline nation & $\mathrm{N}$ & 5.89 & 1.57 & 2,095 & 1,120 & 509 & 621 & -112 & 541 & 649 & -108 & 4.75 \\
\hline nature & $\mathrm{N}$ & 5.61 & 1.50 & 2,379 & 1,010 & 501 & 601 & -100 & 507 & 606 & -99 & 4.73 \\
\hline nectar & $\mathrm{N}$ & 5.32 & 1.28 & 2,704 & 1,076 & 564 & 657 & -93 & 564 & 657 & -93 & 2.71 \\
\hline neon & $\mathrm{N}$ & 5.85 & 1.61 & 2,383 & 1,032 & 492 & 618 & -126 & 492 & 618 & -126 & 3.56 \\
\hline nerve & $\mathrm{N}$ & 4.46 & 1.95 & 2,881 & 1,696 & 501 & 575 & -74 & 528 & 590 & -62 & 3.82 \\
\hline nestle & V & 4.25 & 1.94 & 2,535 & 1,516 & 705 & 734 & -29 & 680 & 715 & -35 & 2.86 \\
\hline news & $\mathrm{N}$ & 5.96 & 1.23 & 1,983 & 814 & 478 & 555 & -77 & 478 & 555 & -77 & 5.17 \\
\hline nickel & $\mathrm{N}$ & 6.68 & 0.90 & 1,730 & 805 & 492 & 573 & -81 & 507 & 583 & -76 & 3.34 \\
\hline niece & $\mathrm{N}$ & 5.82 & 1.83 & 2,322 & 1,287 & 622 & 626 & -4 & 639 & 641 & -2 & 2.93 \\
\hline night & $\mathrm{N}$ & 6.57 & 0.96 & 1,733 & 1,029 & 499 & 604 & -105 & 505 & 609 & -104 & 5.05 \\
\hline nip & B & 4.00 & 2.05 & 2,485 & 1,188 & 638 & 572 & 66 & 668 & 640 & 28 & 3.19 \\
\hline noon & $N$ & 4.21 & 2.42 & 2,798 & 1,656 & 624 & 679 & -55 & 624 & 679 & -55 & 3.69 \\
\hline note & $\mathrm{B}$ & 6.33 & 0.78 & 2,115 & 976 & 524 & 571 & -47 & 529 & 577 & -48 & 5.30 \\
\hline notify & $\mathrm{V}$ & 3.11 & 1.79 & 3,179 & 2,539 & 699 & 560 & 139 & 703 & 632 & 71 & 4.03 \\
\hline notion & $\mathrm{N}$ & 1.46 & 0.74 & 2,901 & 1,679 & 514 & 566 & -52 & 539 & 570 & -31 & 4.13 \\
\hline noun & $\mathrm{N}$ & 3.64 & 2.48 & 3,288 & 1,939 & 567 & 653 & -86 & 586 & 654 & -68 & 3.35 \\
\hline nozzle & $\mathrm{N}$ & 5.46 & 1.69 & 2,335 & 954 & 596 & 709 & -113 & 604 & 706 & -102 & 2.95 \\
\hline nurse & B & 6.79 & 0.50 & 1,792 & 1,044 & 520 & 495 & 25 & 529 & 541 & -12 & 4.25 \\
\hline oasis & $\mathrm{N}$ & 5.59 & 1.65 & 2,073 & 1,125 & 708 & 811 & -103 & 708 & 811 & -103 & 3.61 \\
\hline oath & $\mathrm{N}$ & 4.89 & 1.89 & 2,079 & 980 & 598 & 663 & -65 & 603 & 661 & -58 & 3.60 \\
\hline obey & V & 4.21 & 2.10 & 2,968 & 1,843 & 681 & 504 & 177 & 680 & 545 & 135 & 3.80 \\
\hline obtain & V & 4.46 & 2.03 & 2,381 & 1,702 & 661 & 512 & 149 & 656 & 580 & 76 & 4.71 \\
\hline occupy & V & 4.14 & 1.76 & 3,058 & 1,687 & 637 & 512 & 125 & 574 & 584 & -10 & 3.93 \\
\hline occur & V & 3.11 & 1.99 & 2,733 & 1,854 & 637 & 547 & 90 & 605 & 597 & 8 & 4.75 \\
\hline ocean & $\mathrm{N}$ & 6.96 & 0.19 & 1,521 & 559 & 483 & 629 & -146 & 500 & 640 & -140 & 4.11 \\
\hline odor & $\mathrm{N}$ & 4.96 & 1.91 & 3,106 & 1,631 & 539 & 608 & -69 & 557 & 619 & -62 & 3.23 \\
\hline
\end{tabular}


APPENDIX B (Continued)

\begin{tabular}{|c|c|c|c|c|c|c|c|c|c|c|c|c|}
\hline \multirow[b]{2}{*}{ Word } & \multirow{2}{*}{$\begin{array}{c}\text { FK } \\
\text { Code }\end{array}$} & \multicolumn{2}{|c|}{ Image Rate } & \multicolumn{2}{|c|}{ Image RT } & \multicolumn{3}{|c|}{ HAL Uninflected $\dagger$} & \multicolumn{3}{|c|}{ HAL Inflected $\ddagger$} & \multirow{2}{*}{$\begin{array}{c}\text { Usenet } \\
\text { Log Frequency } \\
\end{array}$} \\
\hline & & $M$ & $S D$ & $M$ & $S D$ & NDist & VDist & NVDD & NDist & VDist & NVDD & \\
\hline offend & $\mathrm{V}$ & 3.86 & 1.78 & 2,642 & 1,034 & 731 & 549 & 182 & 675 & 591 & 84 & 4.09 \\
\hline office & $\mathrm{N}$ & 6.71 & 0.53 & 1,789 & 1,401 & 508 & 613 & -105 & 522 & 623 & -101 & 5.01 \\
\hline omelet & $\mathbf{N}$ & 6.64 & 0.73 & 1,526 & 610 & & & & & & & 1.48 \\
\hline omit & V & 2.89 & 1.85 & 3,198 & 1,511 & 645 & 519 & 126 & 625 & 586 & 39 & 3.70 \\
\hline onion & $\mathrm{N}$ & 6.82 & 0.55 & 1,261 & 306 & 586 & 698 & -112 & 584 & 685 & -101 & 3.66 \\
\hline opera & $\mathrm{N}$ & 6.32 & 0.94 & 1,911 & 636 & 454 & 592 & -138 & 466 & 595 & -129 & 3.89 \\
\hline oppose & $\mathrm{V}$ & 3.14 & 1.76 & 2,789 & 1,428 & 634 & 487 & 147 & 579 & 569 & 10 & 4.49 \\
\hline ordeal & $N$ & 1.86 & 1.38 & 3,114 & 1,619 & 627 & 678 & -51 & 627 & 678 & -51 & 3.05 \\
\hline ore & $\mathrm{N}$ & 5.25 & 1.96 & 2,580 & 1,203 & 537 & 641 & -104 & 577 & 676 & -99 & 3.26 \\
\hline organ & $\mathrm{N}$ & 6.36 & 1.10 & 2,364 & 1,371 & 465 & 576 & -111 & 486 & 587 & -101 & 4.36 \\
\hline orphan & B & 5.25 & 1.84 & 2,299 & 725 & 568 & 624 & -56 & 591 & 635 & -44 & 3.26 \\
\hline ounce & $\mathrm{N}$ & 4.04 & 1.82 & 2,931 & 1,313 & 592 & 660 & -68 & 609 & 677 & -68 & 3.56 \\
\hline outlet & $\mathrm{N}$ & 5.89 & 1.71 & 2,011 & 690 & 526 & 621 & -95 & 549 & 619 & -70 & 3.80 \\
\hline oven & $\mathrm{N}$ & 6.82 & 0.48 & 1,476 & 978 & 518 & 662 & -144 & 525 & 658 & -133 & 3.65 \\
\hline owe & V & 4.04 & 1.84 & 2,505 & 951 & 641 & 543 & 98 & 623 & 575 & 48 & 3.96 \\
\hline owl & $\mathrm{N}$ & 6.86 & 0.59 & 1,289 & 414 & 509 & 608 & -99 & 526 & 620 & -94 & 3.67 \\
\hline pacify & V & 3.75 & 1.97 & 2,439 & 1,207 & 750 & 665 & 85 & 750 & 665 & 85 & 2.44 \\
\hline packet & $\mathrm{N}$ & 5.79 & 1.55 & 2,619 & 1,683 & 483 & 582 & -99 & 499 & 568 & -69 & 4.35 \\
\hline pact & $\mathrm{N}$ & 3.11 & 1.72 & 2,472 & 1,106 & 555 & 705 & -150 & 555 & 705 & -150 & 3.14 \\
\hline pad & B & 5.86 & 1.38 & 1,801 & 636 & 477 & 604 & -127 & 531 & 629 & -98 & 4.23 \\
\hline pail & $N$ & 5.86 & 1.67 & 1,961 & 1,072 & 581 & 737 & -156 & 581 & 737 & -156 & 2.70 \\
\hline pane & $\mathrm{N}$ & 4.89 & 1.95 & 2,749 & 1,466 & 546 & 667 & -121 & 557 & 672 & -115 & 3.11 \\
\hline pang & $\mathrm{N}$ & 2.50 & 1.86 & 2,714 & 1,260 & 676 & 755 & -79 & 676 & 755 & -79 & 2.86 \\
\hline pant & B & 5.29 & 1.86 & 2,348 & 1,223 & 642 & 609 & 33 & 581 & 616 & -35 & 4.08 \\
\hline pantry & $\mathrm{N}$ & 6.18 & 1.47 & 1,847 & 1,082 & 625 & 741 & -116 & 625 & 741 & -116 & 2.33 \\
\hline parch & $\mathrm{V}$ & 3.36 & 1.81 & 2,892 & 1,748 & & & & & & & 1.98 \\
\hline pardon & B & 3.39 & 1.71 & 2,921 & 2,010 & 592 & 596 & -4 & 605 & 608 & -3 & 3.73 \\
\hline pare & V & 2.36 & 1.70 & 3,798 & 3,341 & 757 & 699 & 58 & 760 & 718 & 42 & 3.06 \\
\hline parlor & $\mathrm{N}$ & 5.14 & 1.86 & 2,795 & 1,147 & 554 & 674 & -120 & 554 & 674 & -120 & 2.83 \\
\hline paste & B & 5.50 & 1.53 & 2,173 & 1,245 & 631 & 583 & 48 & 628 & 592 & 36 & 3.93 \\
\hline pastry & $\mathrm{N}$ & 6.36 & 1.28 & 2,003 & 1,358 & 524 & 642 & -118 & 556 & 662 & -106 & 2.93 \\
\hline path & $\mathrm{N}$ & 6.39 & 1.03 & 2,088 & 1,321 & 495 & 603 & -108 & 498 & 600 & -102 & 4.70 \\
\hline patio & $\mathrm{N}$ & 6.46 & 0.96 & 1,518 & 594 & 583 & 697 & -114 & 583 & 697 & -114 & 2.84 \\
\hline pave & $\mathrm{V}$ & 4.22 & 1.74 & 2,552 & 1,146 & 598 & 543 & 55 & 568 & 606 & -38 & 3.41 \\
\hline pea & $\mathrm{N}$ & 6.57 & 1.03 & 1,685 & 657 & 512 & 604 & -92 & 552 & 635 & -83 & 3.38 \\
\hline peace & $\mathrm{N}$ & 4.50 & 2.05 & 3,831 & 3,608 & 473 & 525 & -52 & 473 & 525 & -52 & 4.61 \\
\hline pear & $\mathrm{N}$ & 6.71 & 1.15 & 1,655 & 690 & 552 & 654 & -102 & 581 & 672 & -91 & 3.11 \\
\hline pecan & $\mathrm{N}$ & 6.07 & 1.18 & 1,936 & 961 & 601 & 700 & -99 & 601 & 700 & -99 & 2.25 \\
\hline peddle & V & 5.71 & 1.36 & 3,511 & 2,798 & 680 & 586 & 94 & 681 & 623 & 58 & 2.87 \\
\hline peep & B & 5.25 & 1.69 & 2,324 & 1,219 & 615 & 630 & -15 & 629 & 651 & -22 & 3.06 \\
\hline penny & $N$ & 6.71 & 0.98 & 1,415 & 650 & 512 & 583 & -71 & 535 & 592 & -57 & 3.82 \\
\hline period & $\mathrm{N}$ & 5.71 & 2.11 & 2,583 & 1,405 & 495 & 628 & -133 & 509 & 628 & -119 & 4.79 \\
\hline perish & $\mathrm{V}$ & 4.21 & 2.01 & 2,714 & 1,350 & 723 & 651 & 72 & 712 & 662 & 50 & 3.18 \\
\hline person & $\mathrm{N}$ & 6.43 & 1.20 & 1,819 & 804 & 487 & 559 & -72 & 494 & 563 & -69 & 5.30 \\
\hline pest & $\mathrm{N}$ & 5.96 & 1.37 & 2,503 & 1,314 & 549 & 598 & -49 & 589 & 617 & -28 & 3.23 \\
\hline pester & V & 4.54 & 2.12 & 2,243 & 1,269 & 748 & 583 & 165 & 785 & 710 & 75 & 2.77 \\
\hline pickle & B & 6.57 & 1.20 & 2,156 & 1,310 & 514 & 623 & -109 & 549 & 635 & -86 & 3.28 \\
\hline pie & $\mathrm{N}$ & 7.00 & 0.00 & 1,777 & 1,191 & 485 & 600 & -115 & 500 & 607 & -107 & 3.75 \\
\hline pier & $\mathrm{N}$ & 6.50 & 0.88 & 1,788 & 637 & 536 & 685 & -149 & 547 & 668 & -121 & 3.32 \\
\hline pierce & $\mathrm{V}$ & 6.14 & 1.21 & 2,293 & 1,724 & 522 & 579 & -57 & 518 & 598 & -80 & 4.15 \\
\hline pigeon & $\mathrm{N}$ & 6.67 & 0.73 & 1,813 & 1,224 & 660 & 719 & -59 & 615 & 671 & -56 & 3.19 \\
\hline pile & B & 5.89 & 1.57 & 2,460 & 1,778 & 498 & 583 & -85 & 551 & 612 & -61 & 3.92 \\
\hline pillow & $N$ & 6.79 & 0.57 & 1,625 & 1,019 & 570 & 675 & -105 & 572 & 670 & -98 & 3.49 \\
\hline pint & $\mathrm{N}$ & 5.00 & 1.87 & 2,217 & 804 & 554 & 658 & -104 & 565 & 662 & -97 & 3.29 \\
\hline pitch & B & 5.37 & 1.94 & 2,703 & 1,823 & 450 & 522 & -72 & 477 & 541 & -64 & 4.11 \\
\hline pizza & $\mathrm{N}$ & 6.96 & 0.19 & 1,618 & 674 & 469 & 545 & -76 & 478 & 551 & -73 & 3.77 \\
\hline plan & B & 3.46 & 1.75 & 2,490 & 1,498 & 484 & 496 & -12 & 520 & 531 & -11 & 5.15 \\
\hline planet & $\mathrm{N}$ & 6.89 & 0.31 & 2,005 & 949 & 503 & 630 & -127 & 505 & 624 & -119 & 4.55 \\
\hline plaza & $\mathrm{N}$ & 5.93 & 1.24 & 2,277 & 1,276 & 688 & 797 & -109 & 688 & 797 & -109 & 3.76 \\
\hline plea & $\mathrm{N}$ & 4.30 & 1.75 & 2,597 & 1,201 & 548 & 578 & -30 & 568 & 574 & -6 & 3.50 \\
\hline plead & V & 5.04 & 1.91 & 2,267 & 778 & 649 & 506 & 143 & 649 & 621 & 28 & 3.54 \\
\hline pledge & B & 4.86 & 1.69 & 2,288 & 1,020 & 528 & 533 & -5 & 577 & 594 & -17 & 3.65 \\
\hline plod & $\mathrm{V}$ & 2.68 & 1.74 & 3,027 & 1,957 & & & & 640 & 656 & -16 & 2.49 \\
\hline plow & B & 5.67 & 1.47 & 1,844 & 883 & 561 & 522 & 39 & 611 & 604 & 7 & 3.19 \\
\hline
\end{tabular}


APPENDIX B (Continued)

\begin{tabular}{|c|c|c|c|c|c|c|c|c|c|c|c|c|}
\hline \multirow[b]{2}{*}{ Word } & \multirow{2}{*}{$\begin{array}{c}\text { FK } \\
\text { Code }\end{array}$} & \multicolumn{2}{|c|}{ Image Rate } & \multicolumn{2}{|c|}{ Image RT } & \multicolumn{3}{|c|}{ HAL Uninflected $\dagger$} & \multicolumn{3}{|c|}{ HAL Inflected $\ddagger$} & \multirow{2}{*}{$\begin{array}{c}\text { Usenet } \\
\text { Log Frequency }\end{array}$} \\
\hline & & $M$ & $S D$ & $M$ & $S D$ & NDist & VDist & NVDD & NDist & VDist & NVDD & \\
\hline poach & V & 4.18 & 1.96 & 3,178 & 2,268 & & & & 667 & 685 & -18 & 2.32 \\
\hline poem & $\mathrm{N}$ & 5.71 & 1.70 & 1,818 & 1,017 & 499 & 596 & -97 & 513 & 594 & -81 & 3.95 \\
\hline poet & $\mathrm{N}$ & 5.07 & 1.72 & 2,461 & 1,126 & 516 & 643 & -127 & 531 & 643 & -112 & 3.74 \\
\hline poise & $\mathrm{B}$ & 3.39 & 1.55 & 3,001 & 1,619 & 788 & 822 & -34 & 694 & 727 & -33 & 3.14 \\
\hline poison & B & 5.32 & 1.74 & 2,491 & 1,374 & 458 & 518 & -60 & 511 & 560 & -49 & 3.94 \\
\hline poker & $N$ & 6.64 & 0.62 & 1,708 & 733 & 507 & 623 & -116 & 507 & 623 & -116 & 3.66 \\
\hline policy & $\mathrm{N}$ & 2.54 & 2.03 & 2,477 & 1,057 & 481 & 567 & -86 & 498 & 572 & -74 & 4.80 \\
\hline pollen & $\mathrm{N}$ & 5.50 & 1.60 & 2,285 & 1,206 & 733 & 816 & -83 & 733 & 816 & -83 & 2.94 \\
\hline pond & $\mathrm{N}$ & 6.57 & 0.84 & 1,749 & 852 & 496 & 653 & -157 & 514 & 658 & -144 & 3.62 \\
\hline ponder & V & 3.79 & 1.85 & 2,934 & 1,435 & 664 & 522 & 142 & 678 & 613 & 65 & 3.50 \\
\hline poppy & $\mathrm{N}$ & 4.75 & 2.27 & 2,244 & 1,060 & 530 & 650 & -120 & 550 & 661 & -111 & 3.05 \\
\hline porch & $\mathrm{N}$ & 6.29 & 1.27 & 1,910 & 978 & 623 & 727 & -104 & 623 & 727 & -104 & 3.23 \\
\hline poster & $\mathrm{N}$ & 6.48 & 1.28 & 2,050 & 1,355 & 517 & 599 & -82 & 518 & 590 & -72 & 4.58 \\
\hline pour & V & 5.67 & 1.69 & 2,417 & 1,729 & 605 & 611 & -6 & 595 & 610 & -15 & 4.21 \\
\hline pout & B & 4.71 & 2.14 & 2,246 & 840 & 683 & 594 & 89 & 687 & 645 & 42 & 2.75 \\
\hline pray & V & 6.18 & 1.28 & 1,949 & 1,682 & 624 & 509 & 115 & 629 & 534 & 95 & 4.14 \\
\hline prayer & $\mathrm{N}$ & 6.18 & 1.61 & 2,027 & 1,340 & 508 & 574 & -66 & 523 & 577 & -54 & 4.13 \\
\hline preach & V & 5.36 & 1.45 & 2,480 & 1,376 & 667 & 528 & 139 & 640 & 572 & 68 & 3.76 \\
\hline prefer & V & 2.61 & 1.42 & 3,238 & 1,879 & 648 & 572 & 76 & 639 & 606 & 33 & 4.89 \\
\hline press & B & 5.25 & 1.90 & 2,760 & 1,347 & 476 & 564 & -88 & 490 & 563 & -73 & 4.98 \\
\hline priest & $\mathrm{N}$ & 6.71 & 0.66 & 1,762 & 1,286 & 670 & 803 & -133 & 638 & 755 & -117 & 4.26 \\
\hline prince & $\mathrm{N}$ & 6.29 & 1.12 & 2,086 & 1,224 & 446 & 574 & -128 & 456 & 580 & -124 & 4.09 \\
\hline prison & $N$ & 6.68 & 0.61 & 1,612 & 758 & 526 & 591 & -65 & 534 & 596 & -62 & 4.19 \\
\hline prop & B & 4.14 & 1.92 & 2,660 & 1,494 & 460 & 507 & -47 & 504 & 549 & -45 & 3.74 \\
\hline propel & $\mathrm{V}$ & 4.33 & 1.90 & 2,255 & 860 & 688 & 577 & 111 & 650 & 611 & 39 & 2.96 \\
\hline prose & $\mathrm{N}$ & 3.18 & 1.96 & 2,626 & 1,431 & 532 & 596 & -64 & 569 & 631 & -62 & 3.35 \\
\hline prove & V & 2.00 & 1.41 & 2,614 & 1,085 & 631 & 445 & 186 & 604 & 512 & 92 & 4.83 \\
\hline pry & V & 4.32 & 1.85 & 2,481 & 1,097 & 754 & 617 & 137 & 729 & 651 & 78 & 3.31 \\
\hline pub & $\mathrm{N}$ & 5.71 & 1.86 & 2,036 & 901 & 826 & 884 & -58 & 823 & 881 & -58 & 5.02 \\
\hline pulley & $\mathrm{N}$ & 6.00 & 1.44 & 1,962 & 646 & 743 & 858 & -115 & 717 & 824 & -107 & 3.20 \\
\hline pulpit & $\mathrm{N}$ & 4.25 & 2.22 & 2,060 & 939 & 674 & 796 & -122 & 674 & 796 & -122 & 2.57 \\
\hline pump & B & 5.82 & 1.36 & 2,337 & 1,525 & 480 & 511 & -31 & 509 & 534 & -25 & 4.29 \\
\hline pun & B & 3.11 & 1.97 & 3,109 & 1,902 & 522 & 590 & -68 & 532 & 597 & -65 & 3.67 \\
\hline punish & V & 4.85 & 1.59 & 2,701 & 1,426 & 651 & 469 & 182 & 660 & 546 & 114 & 3.93 \\
\hline punt & $\mathrm{B}$ & 5.14 & 1.99 & 2,179 & 884 & 563 & 563 & 0 & 585 & 602 & -17 & 2.80 \\
\hline puppy & $\mathrm{N}$ & 6.96 & 0.19 & 1,402 & 717 & 488 & 551 & -63 & 509 & 559 & -50 & 4.10 \\
\hline purify & V & 4.25 & 1.84 & 2,320 & 1,781 & 672 & 570 & 102 & 630 & 642 & -12 & 3.43 \\
\hline pursue & V & 4.18 & 1.83 & 2,473 & 1,264 & 665 & 489 & 176 & 639 & 539 & 100 & 4.02 \\
\hline put & V & 3.18 & 1.61 & 3,671 & 1,749 & 556 & 419 & 137 & 550 & 437 & 113 & 5.44 \\
\hline quart & $\mathrm{N}$ & 5.11 & 1.87 & 2,058 & 1,255 & 568 & 674 & -106 & 589 & 683 & -94 & 3.18 \\
\hline query & B & 2.50 & 1.53 & 2,641 & 1,059 & 531 & 555 & -24 & 558 & 561 & -3 & 4.22 \\
\hline quip & B & 1.75 & 1.32 & 2,589 & 1,388 & 857 & 889 & -32 & 788 & 814 & -26 & 2.94 \\
\hline quit & $\mathrm{V}$ & 3.64 & 1.93 & 2,877 & 1,369 & 585 & 463 & 122 & 590 & 485 & 105 & 4.29 \\
\hline quota & $\mathrm{N}$ & 2.29 & 1.76 & 2,911 & 1,336 & 512 & 570 & -58 & 542 & 575 & -33 & 3.71 \\
\hline radar & $\mathrm{N}$ & 5.39 & 1.59 & 2,267 & 1,054 & 453 & 556 & -103 & 461 & 561 & -100 & 3.90 \\
\hline rake & B & 6.79 & 0.79 & 1,626 & 829 & 532 & 568 & -36 & 573 & 592 & -19 & 3.16 \\
\hline rally & B & 5.07 & 2.02 & 2,043 & 1,065 & 490 & 594 & -104 & 525 & 611 & -86 & 3.87 \\
\hline ramble & V & 4.75 & 2.03 & 2,188 & 885 & 684 & 549 & 135 & 633 & 604 & 29 & 3.42 \\
\hline ravine & $\mathrm{N}$ & 4.68 & 2.29 & 2,320 & 1,313 & 632 & 786 & -154 & 632 & 786 & -154 & 2.45 \\
\hline razor & $\mathrm{N}$ & 6.82 & 0.39 & 2,503 & 1,728 & 489 & 600 & -111 & 508 & 615 & -107 & 3.56 \\
\hline react & V & 4.54 & 1.84 & 2,273 & 1,125 & 648 & 481 & 167 & 630 & 520 & 110 & 3.99 \\
\hline read & V & 5.68 & 1.44 & 3,049 & 1,953 & 593 & 465 & 128 & 579 & 484 & 95 & 5.61 \\
\hline realm & $\mathrm{N}$ & 3.43 & 2.15 & 1,948 & 940 & 545 & 684 & -139 & 550 & 682 & -132 & 4.02 \\
\hline reap & V & 3.86 & 1.74 & 2,163 & 823 & 700 & 616 & 84 & 704 & 632 & 72 & 3.22 \\
\hline rebuff & B & 2.61 & 1.47 & 3,049 & 2,354 & & & & 782 & 766 & 16 & 2.42 \\
\hline recede & $\mathrm{V}$ & 3.79 & 1.97 & 2,453 & 1,263 & & & & 623 & 699 & -76 & 2.58 \\
\hline recipe & $\mathrm{N}$ & 5.11 & 1.99 & 2,495 & 1,251 & 532 & 603 & -71 & 548 & 612 & -64 & 4.23 \\
\hline recite & V & 4.25 & 2.03 & 2,607 & 1,102 & 655 & 505 & 150 & 646 & 577 & 69 & 3.20 \\
\hline redeem & V & 3.46 & 1.82 & 2,657 & 1,583 & 685 & 549 & 136 & 651 & 612 & 39 & 3.34 \\
\hline reduce & V & 2.86 & 1.33 & 2,840 & 1,438 & 602 & 454 & 148 & 565 & 517 & 48 & 4.68 \\
\hline reef & $\mathrm{N}$ & 5.04 & 1.79 & 2,140 & 838 & 522 & 686 & -164 & 535 & 684 & -149 & 3.55 \\
\hline reel & B & 5.25 & 1.82 & 2,246 & 905 & 461 & 568 & -107 & 504 & 588 & -84 & 3.66 \\
\hline refer & V & 3.46 & 1.88 & 2,613 & 998 & 592 & 480 & 112 & 597 & 551 & 46 & 4.86 \\
\hline refine & V & 2.96 & 1.72 & 3,028 & 1,738 & 699 & 542 & 157 & 608 & 600 & 8 & 3.50 \\
\hline
\end{tabular}


APPENDIX B (Continued)

\begin{tabular}{|c|c|c|c|c|c|c|c|c|c|c|c|c|}
\hline \multirow[b]{2}{*}{ Word } & \multirow{2}{*}{$\begin{array}{c}\text { FK } \\
\text { Code } \\
\end{array}$} & \multicolumn{2}{|c|}{ Image Rate } & \multicolumn{2}{|c|}{ Image RT } & \multicolumn{3}{|c|}{ HAL Uninflected $\dagger$} & \multicolumn{3}{|c|}{ HAL Inflected $\ddagger$} & \multirow{2}{*}{$\begin{array}{c}\text { Usenet } \\
\text { Log Frequency }\end{array}$} \\
\hline & & $M$ & $S D$ & $M$ & $S D$ & NDist & VDist & NVDD & NDist & VDist & NVDD & \\
\hline refute & $\mathrm{V}$ & 2.14 & 1.48 & 2,784 & 1,845 & 697 & 509 & 188 & 690 & 567 & 123 & 3.61 \\
\hline regain & V & 3.79 & 1.91 & 2,621 & 2,035 & 653 & 496 & 157 & 647 & 566 & 81 & 3.53 \\
\hline regime & $\mathrm{N}$ & 3.39 & 2.08 & 3,130 & 1,692 & 549 & 655 & -106 & 570 & 661 & -91 & 3.82 \\
\hline region & $\mathrm{N}$ & 4.79 & 1.71 & 2,398 & 835 & 528 & 665 & -137 & 537 & 661 & -124 & 4.54 \\
\hline reign & B & 4.00 & 1.89 & 2,701 & 2,243 & 578 & 633 & -55 & 593 & 649 & -56 & 3.60 \\
\hline relate & V & 3.07 & 1.54 & 2,477 & 1,332 & 629 & 492 & 137 & 565 & 587 & -22 & 4.98 \\
\hline relax & V & 5.32 & 1.85 & 2,344 & 1,266 & 616 & 472 & 144 & 595 & 528 & 67 & 4.09 \\
\hline relent & V & 2.61 & 1.55 & 2,105 & 940 & & & & 796 & 806 & -10 & 2.51 \\
\hline relic & $\mathrm{N}$ & 4.54 & 2.03 & 1,831 & 581 & 938 & 1016 & -78 & 901 & 978 & -77 & 3.74 \\
\hline relief & $\mathrm{N}$ & 3.96 & 1.82 & 3,429 & 1,906 & 468 & 557 & -89 & 468 & 557 & -89 & 3.96 \\
\hline rely & V & 3.61 & 2.06 & 2,913 & 1,305 & 641 & 473 & 168 & 623 & 523 & 100 & 4.17 \\
\hline remain & V & 2.36 & 1.28 & 3,473 & 2,048 & 577 & 456 & 121 & 555 & 544 & 11 & 4.81 \\
\hline remind & V & 2.61 & 1.57 & 3,155 & 1,547 & 620 & 464 & 156 & 607 & 546 & 61 & 4.32 \\
\hline remove & V & 3.64 & 1.91 & 2,667 & 1,180 & 566 & 447 & 119 & 579 & 510 & 69 & 4.96 \\
\hline render & V & 2.50 & 1.67 & 2,491 & 1,168 & 592 & 453 & 139 & 543 & 535 & 8 & 4.17 \\
\hline repair & B & 5.39 & 1.47 & 2,578 & 1,492 & 503 & 489 & 14 & 528 & 515 & 13 & 4.29 \\
\hline repay & V & 3.89 & 2.01 & 2,742 & 1,400 & 685 & 541 & 144 & 690 & 579 & 111 & 3.12 \\
\hline repent & V & 2.93 & 1.59 & 3,453 & 2,836 & 721 & 560 & 161 & 721 & 560 & 161 & 3.17 \\
\hline report & B & 5.18 & 1.81 & 2,882 & 1,799 & 538 & 581 & -43 & 531 & 577 & -46 & 5.26 \\
\hline rescue & B & 5.89 & 1.42 & 2,500 & 1,704 & 503 & 557 & -54 & 521 & 564 & -43 & 4.14 \\
\hline resent & V & 2.79 & 1.45 & 3,279 & 2,092 & 646 & 541 & 105 & 654 & 558 & 96 & 3.34 \\
\hline reside & V & 3.54 & 1.69 & 2,489 & 899 & 646 & 561 & 85 & 625 & 616 & 9 & 3.86 \\
\hline resign & V & 3.86 & 1.78 & 2,709 & 1,152 & 645 & 507 & 138 & 640 & 578 & 62 & 3.58 \\
\hline resin & $\mathbf{N}$ & 3.07 & 2.21 & 2,640 & 1,313 & 482 & 589 & -107 & 514 & 611 & -97 & 3.23 \\
\hline resist & V & 3.79 & 1.71 & 2,818 & 1,398 & 621 & 467 & 154 & 619 & 500 & 119 & 4.03 \\
\hline retain & V & 2.75 & 1.65 & 2,899 & 1,534 & 610 & 470 & 140 & 620 & 563 & 57 & 4.07 \\
\hline retire & V & 4.57 & 1.93 & 2,337 & 1,132 & 650 & 501 & 149 & 565 & 568 & -3 & 3.97 \\
\hline reveal & V & 4.21 & 1.87 & 3,339 & 2,147 & 562 & 462 & 100 & 547 & 543 & 4 & 4.38 \\
\hline revere & V & 2.71 & 1.63 & 2,666 & 1,551 & 638 & 628 & 10 & 722 & 719 & 3 & 3.14 \\
\hline revert & V & 2.32 & 1.44 & 2,639 & 2,094 & 643 & 535 & 108 & 645 & 588 & 57 & 3.38 \\
\hline review & B & 3.73 & 1.51 & 3,294 & 2,124 & 483 & 548 & -65 & 510 & 562 & -52 & 4.83 \\
\hline revise & V & 3.75 & 1.73 & 2,179 & 838 & 689 & 644 & 45 & 683 & 768 & -85 & 4.46 \\
\hline revive & V & 3.93 & 1.68 & 2,809 & 1,229 & 651 & 513 & 138 & 628 & 581 & 47 & 3.43 \\
\hline rhyme & B & 4.79 & 1.79 & 2,736 & 1,897 & 584 & 585 & -1 & 583 & 595 & -12 & 3.49 \\
\hline rhythm & $\mathrm{N}$ & 4.89 & 2.06 & 2,873 & 1,872 & 466 & 573 & -107 & 484 & 585 & -101 & 3.77 \\
\hline riddle & B & 4.79 & 1.95 & 2,156 & 794 & 517 & 609 & -92 & 557 & 630 & -73 & 3.33 \\
\hline ridge & $\mathrm{N}$ & 4.75 & 1.82 & 2,648 & 1,254 & 524 & 656 & -132 & 626 & 747 & -121 & 3.99 \\
\hline rigor & $\mathrm{N}$ & 3.14 & 1.76 & 2,031 & 799 & 602 & 637 & -35 & 634 & 665 & -31 & 2.86 \\
\hline ring & B & 6.79 & 0.79 & 1,762 & 700 & 500 & 657 & -157 & 496 & 641 & -145 & 4.74 \\
\hline rink & $\mathrm{N}$ & 4.89 & 2.06 & 2,735 & 1,179 & 536 & 673 & -137 & 555 & 681 & -126 & 3.40 \\
\hline rinse & B & 5.00 & 1.81 & 2,867 & 1,486 & 583 & 558 & 25 & 604 & 581 & 23 & 3.38 \\
\hline ripen & V & 4.79 & 1.87 & 2,968 & 3,344 & & & & & & & 2.32 \\
\hline river & $N$ & 6.93 & 0.26 & 1,450 & 841 & 509 & 685 & -176 & 511 & 679 & -168 & 4.50 \\
\hline road & $\mathrm{N}$ & 6.61 & 1.10 & 1,631 & 876 & 513 & 652 & -139 & 512 & 642 & -130 & 4.88 \\
\hline roam & V & 4.18 & 1.63 & 2,931 & 1,179 & 637 & 510 & 127 & 624 & 568 & 56 & 3.34 \\
\hline roast & B & 6.11 & 1.10 & 2,219 & 1,304 & 513 & 537 & -24 & 534 & 571 & -37 & 3.43 \\
\hline rob & V & 5.71 & 1.51 & 2,305 & 1,717 & 543 & 585 & -42 & 550 & 587 & -37 & 4.39 \\
\hline robot & $\mathrm{N}$ & 6.82 & 0.39 & 1,787 & 930 & 459 & 594 & -135 & 493 & 606 & -113 & 4.23 \\
\hline rodeo & $\mathrm{N}$ & 6.18 & 0.98 & 2,000 & 781 & 490 & 581 & -91 & 490 & 581 & -91 & 3.01 \\
\hline role & $\mathrm{N}$ & 2.93 & 1.68 & 3,500 & 1,835 & 490 & 592 & -102 & 498 & 592 & -94 & 4.59 \\
\hline rot & B & 4.75 & 1.86 & 2,568 & 970 & 553 & 505 & 48 & 562 & 548 & 14 & 3.58 \\
\hline rotate & V & 5.11 & 1.79 & 2,264 & 1,173 & 570 & 463 & 107 & 538 & 536 & 2 & 3.91 \\
\hline rouse & V & 3.29 & 1.78 & 3,148 & 3,913 & 645 & 634 & 11 & 645 & 649 & -4 & 2.99 \\
\hline rug & $\mathrm{N}$ & 6.64 & 1.03 & 1,462 & 605 & 538 & 634 & -96 & 575 & 640 & -65 & 3.30 \\
\hline ruin & $\mathrm{B}$ & 4.46 & 2.17 & 2,877 & 1,636 & 641 & 614 & 27 & 644 & 665 & -21 & 4.24 \\
\hline rum & $N$ & 5.89 & 1.55 & 1,738 & 634 & 518 & 635 & -117 & 518 & 635 & -117 & 2.98 \\
\hline rumple & V & 3.39 & 1.83 & 2,784 & 1,700 & & & & & & & 2.05 \\
\hline rye & $\mathrm{N}$ & 4.82 & 2.11 & 2,670 & 1,563 & 552 & 683 & -131 & 552 & 683 & -131 & 3.10 \\
\hline safety & $\mathbf{N}$ & 5.04 & 1.69 & 2,636 & 1,196 & 470 & 543 & -73 & 470 & 543 & -73 & 4.38 \\
\hline salad & $\mathbf{N}$ & 6.64 & 1.34 & 1,579 & 504 & 483 & 586 & -103 & 521 & 612 & -91 & 3.47 \\
\hline salary & $\mathrm{N}$ & 4.07 & 2.34 & 2,851 & 1,297 & 693 & 728 & -35 & 688 & 717 & -29 & 4.56 \\
\hline sale & $\mathrm{N}$ & 4.71 & 2.02 & 2,795 & 1,528 & 685 & 755 & -70 & 620 & 689 & -69 & 5.18 \\
\hline salon & $\mathrm{N}$ & 5.46 & 1.77 & 2,923 & 1,689 & 543 & 667 & -124 & 543 & 667 & -124 & 2.87 \\
\hline satire & $\mathrm{N}$ & 3.21 & 2.04 & 2,294 & 1,108 & 536 & 597 & -61 & 536 & 597 & -61 & 3.22 \\
\hline
\end{tabular}


APPENDIX B (Continued)

\begin{tabular}{|c|c|c|c|c|c|c|c|c|c|c|c|c|}
\hline \multirow[b]{2}{*}{ Word } & \multirow{2}{*}{$\begin{array}{c}\text { FK } \\
\text { Code }\end{array}$} & \multicolumn{2}{|c|}{ Image Rate } & \multicolumn{2}{|c|}{ Image RT } & \multicolumn{3}{|c|}{ HAL Uninflected $\dagger$} & \multicolumn{3}{|c|}{ HAL Inflected $\ddagger$} & \multirow{2}{*}{$\begin{array}{c}\text { Usenet } \\
\text { Log Frequency }\end{array}$} \\
\hline & & $M$ & $S D$ & $M$ & $S D$ & NDist & VDist & NVDD & NDist & VDist & NVDD & \\
\hline saucer & $\mathrm{N}$ & 6.00 & 1.52 & 2,057 & 876 & 505 & 641 & -136 & 537 & 655 & -118 & 3.28 \\
\hline save & V & 3.75 & 2.05 & 2,797 & 1,532 & 564 & 425 & 139 & 557 & 462 & 95 & 5.00 \\
\hline scene & $\mathrm{N}$ & 4.50 & 2.13 & 2,896 & 1,999 & 474 & 594 & -120 & 482 & 593 & -111 & 4.64 \\
\hline scent & B & 5.14 & 1.78 & 3,041 & 2,721 & 486 & 594 & -108 & 510 & 604 & -94 & 3.48 \\
\hline scoff & $\mathrm{V}$ & 3.68 & 1.91 & 2,376 & 1,243 & 683 & 617 & 66 & 677 & 646 & 31 & 2.81 \\
\hline scold & V & 5.07 & 1.82 & 1,997 & 704 & 756 & 597 & 159 & 717 & 654 & 63 & 2.78 \\
\hline scoop & B & 5.64 & 1.57 & 2,541 & 1,158 & 551 & 588 & -37 & 576 & 608 & -32 & 3.54 \\
\hline scorch & V & 5.36 & 1.50 & 2,937 & 1,916 & & & & 601 & 645 & -44 & 2.91 \\
\hline scour & V & 3.67 & 2.15 & 2,761 & 1,514 & & & & 627 & 664 & -37 & 2.59 \\
\hline scuff & B & 4.46 & 1.79 & 2,407 & 936 & 899 & 908 & -9 & 851 & 883 & -32 & 3.03 \\
\hline sea & $\mathrm{N}$ & 6.93 & 0.38 & 1,371 & 426 & 554 & 730 & -176 & 553 & 726 & -173 & 4.60 \\
\hline seal & B & 6.32 & 1.22 & 1,868 & 1,332 & 456 & 539 & -83 & 526 & 608 & -82 & 4.30 \\
\hline sear & $\mathrm{V}$ & 3.32 & 1.87 & 3,244 & 1,766 & 605 & 656 & -51 & 571 & 647 & -76 & 3.64 \\
\hline search & B & 3.82 & 1.52 & 3,083 & 1,565 & 506 & 514 & -8 & 529 & 530 & -1 & 5.00 \\
\hline see & V & 4.68 & 2.21 & 2,630 & 1,332 & 585 & 441 & 144 & 597 & 488 & 109 & 5.94 \\
\hline seek & $\mathrm{V}$ & 4.11 & 1.89 & 2,904 & 1,828 & 569 & 451 & 118 & 605 & 574 & 31 & 4.78 \\
\hline seep & V & 3.68 & 1.74 & 2,995 & 1,636 & 689 & 605 & 84 & 682 & 682 & 0 & 2.79 \\
\hline seize & V & 4.21 & 1.87 & 2,577 & 1,406 & 611 & 514 & 97 & 613 & 588 & 25 & 3.73 \\
\hline send & V & 4.64 & 1.97 & 3,660 & 3,075 & 614 & 521 & 93 & 605 & 528 & 77 & 5.67 \\
\hline sentry & $\mathrm{N}$ & 2.64 & 2.02 & 2,504 & 1,283 & 872 & 948 & -76 & 872 & 948 & -76 & 2.98 \\
\hline sermon & $\mathrm{N}$ & 5.21 & 1.69 & 2,725 & 1,273 & 530 & 644 & -114 & 569 & 647 & -78 & 3.13 \\
\hline settle & V & 3.50 & 1.75 & 2,935 & 1,650 & 627 & 457 & 170 & 596 & 513 & 83 & 4.23 \\
\hline sever & V & 4.43 & 2.10 & 2,987 & 1,964 & 571 & 543 & 28 & 564 & 593 & -29 & 3.33 \\
\hline sew & V & 6.22 & 1.01 & 1,994 & 809 & 589 & 476 & 113 & 532 & 536 & -4 & 3.69 \\
\hline sewage & $\mathrm{N}$ & 6.18 & 0.94 & 2,506 & 1,315 & 577 & 652 & -75 & 577 & 652 & -75 & 2.90 \\
\hline shanty & $N$ & 3.82 & 2.21 & 2,613 & 1,537 & 687 & 819 & -132 & 687 & 819 & -132 & 2.35 \\
\hline shawl & $N$ & 5.71 & 1.84 & 2,177 & 1,011 & & & & & & & 1.52 \\
\hline shelf & $\mathrm{N}$ & 6.50 & 0.96 & 2,198 & 1,025 & 565 & 677 & -112 & 582 & 677 & -95 & 3.94 \\
\hline shield & B & 5.96 & 1.40 & 2.570 & 1,739 & 673 & 814 & -141 & 629 & 750 & -121 & 4.34 \\
\hline shift & B & 3.82 & 1.54 & 3,367 & 1,797 & 472 & 502 & -30 & 490 & 520 & -30 & 4.38 \\
\hline shirk & V & 2.96 & 2.13 & 3,038 & 2,017 & & & & & & & 2.44 \\
\hline shock & B & 5.07 & 1.74 & 3,055 & 2,189 & 461 & 543 & -82 & 515 & 557 & -42 & 4.29 \\
\hline shred & B & 5.21 & 1.60 & 2,940 & 1,638 & 614 & 576 & 38 & 619 & 601 & 18 & 3.52 \\
\hline shriek & B & 5.93 & 1.49 & 3,136 & 3,019 & 586 & 660 & -74 & 655 & 698 & -43 & 2.99 \\
\hline shrimp & $N$ & 6.79 & 0.50 & 1,538 & 586 & 558 & 630 & -72 & 558 & 630 & -72 & 3.30 \\
\hline shrink & V & 5.96 & 1.60 & 2,157 & 930 & 530 & 536 & -6 & 544 & 560 & -16 & 3.79 \\
\hline shrub & $\mathrm{N}$ & 6.04 & 1.55 & 2,280 & 1,481 & 634 & 729 & -95 & 640 & 714 & -74 & 2.79 \\
\hline shun & V & 2.79 & 1.85 & 2,563 & 1,054 & 573 & 522 & 51 & 611 & 561 & 50 & 3.13 \\
\hline shut & V & 5.07 & 1.78 & 2,407 & 1,154 & 570 & 459 & 111 & 571 & 476 & 95 & 4.36 \\
\hline sidle & $\mathrm{V}$ & 2.04 & 1.17 & 4,423 & 5,646 & & & & & & & 0.70 \\
\hline sift & V & 4.29 & 1.82 & 2,736 & 893 & 675 & 562 & 113 & 677 & 617 & 60 & 3.11 \\
\hline simmer & V & 5.11 & 1.48 & 2,572 & 1,339 & 738 & 723 & 15 & 719 & 725 & -6 & 3.15 \\
\hline sing & V & 6.18 & 1.09 & 2.971 & 2,468 & 572 & 448 & 124 & 540 & 539 & 1 & 4.55 \\
\hline sit & V & 6.37 & 1.15 & 2,216 & 2,241 & 591 & 436 & 155 & 565 & 535 & 30 & 4.95 \\
\hline sizzle & V & 6.21 & 0.83 & 2,102 & 1,198 & 634 & 644 & -10 & 622 & 677 & -55 & 2.66 \\
\hline ski & $\mathrm{Ba}$ & 6.70 & 0.72 & 1,464 & 493 & 485 & 564 & -79 & 504 & 564 & -60 & 4.33 \\
\hline skid & $\mathrm{B}$ & 5.29 & 1.76 & 2,113 & 1,528 & 536 & 590 & -54 & 553 & 606 & -53 & 3.01 \\
\hline skill & $\mathrm{N}$ & 2.64 & 1.25 & 3.573 & 1,865 & 545 & 598 & -53 & 687 & 719 & -32 & 5.00 \\
\hline skim & V & 3.89 & 1.77 & 3,040 & 1,085 & 580 & 526 & 54 & 608 & 571 & 37 & 3.28 \\
\hline skip & $\mathrm{V}$ & 5.00 & 1.96 & 2,692 & 1,396 & 577 & 456 & 121 & 580 & 487 & 93 & 4.10 \\
\hline skit & $\mathrm{N}$ & 4.96 & 1.84 & 2,265 & 833 & 582 & 671 & -89 & 587 & 673 & -86 & 3.27 \\
\hline skull & $\mathrm{N}$ & 6.82 & 0.61 & 1,484 & 706 & 576 & 750 & -174 & 573 & 733 & -160 & 3.93 \\
\hline sky & $\mathrm{N}$ & 6.93 & 0.38 & 1,527 & 575 & 516 & 669 & -153 & 521 & 666 & -145 & 4.36 \\
\hline slang & $\mathrm{N}$ & 3.89 & 2.28 & 2,780 & 1,669 & 529 & 607 & -78 & 529 & 607 & -78 & 3.29 \\
\hline sling & $\mathrm{B}$ & 5.32 & 1.61 & 2,738 & 1,456 & 550 & 545 & 5 & 575 & 592 & -17 & 3.10 \\
\hline slob & $\mathrm{N}$ & 5.68 & 1.63 & 2,195 & 935 & 614 & 684 & -70 & 649 & 698 & -49 & 2.75 \\
\hline slogan & $\mathrm{N}$ & 5.11 & 1.87 & 2,482 & 1,117 & 524 & 627 & -103 & 612 & 696 & -84 & 3.46 \\
\hline slouch & B & 5.82 & 1.33 & 2,415 & 1,110 & 739 & 739 & 0 & 739 & 739 & 0 & 2.29 \\
\hline sludge & $\mathrm{N}$ & 4.29 & 2.00 & 2,409 & 1,364 & 536 & 629 & -93 & 536 & 629 & -93 & 2.81 \\
\hline slug & B & 6.43 & 1.20 & 1,676 & 651 & 788 & 941 & -153 & 753 & 895 & -142 & 3.73 \\
\hline smack & V & 6.07 & 1.25 & 2,730 & 2,307 & 557 & 512 & 45 & 582 & 554 & 28 & 3.60 \\
\hline smear & B & 5.29 & 1.38 & 2,035 & 811 & 550 & 516 & 34 & 576 & 565 & 11 & 3.51 \\
\hline smell & B & 5.07 & 1.82 & 2,903 & 1,382 & 537 & 510 & 27 & 554 & 538 & 16 & 4.17 \\
\hline smirk & B & 5.79 & 1.42 & 2,179 & 1,082 & 596 & 604 & -8 & 632 & 634 & -2 & 2.94 \\
\hline
\end{tabular}


APPENDIX B (Continued)

\begin{tabular}{|c|c|c|c|c|c|c|c|c|c|c|c|c|}
\hline \multirow[b]{2}{*}{ Word } & \multirow{2}{*}{$\begin{array}{c}\text { FK } \\
\text { Code }\end{array}$} & \multicolumn{2}{|c|}{ Image Rate } & \multicolumn{2}{|c|}{ Image RT } & \multicolumn{3}{|c|}{ HAL Uninflected $\dagger$} & \multicolumn{3}{|c|}{ HAL Inflected $\ddagger$} & \multirow{2}{*}{$\begin{array}{c}\text { Usenet } \\
\text { Log Frequency }\end{array}$} \\
\hline & & $M$ & $S D$ & $M$ & $S D$ & NDist & VDist & NVDD & NDist & VDist & NVDD & \\
\hline smoke & $\mathrm{B}$ & 6.50 & 1.14 & 1,518 & 579 & 488 & 502 & -14 & 506 & 510 & -4 & 4.46 \\
\hline smudge & B & 5.64 & 1.25 & 2,191 & 1,008 & 625 & 723 & -98 & 625 & 723 & -98 & 2.56 \\
\hline snail & $\mathrm{N}$ & 6.68 & 1.02 & 1,786 & 1,327 & 715 & 722 & -7 & 707 & 716 & -9 & 4.03 \\
\hline snare & $\mathrm{B}$ & 4.46 & 1.71 & 2,395 & 763 & 485 & 604 & -119 & 504 & 614 & -110 & 3.10 \\
\hline sneer & B & 4.36 & 2.20 & 2,016 & 1,055 & 621 & 579 & 42 & 644 & 620 & 24 & 2.99 \\
\hline sniff & V & 5.71 & 1.49 & 2,231 & 1,317 & 672 & 620 & 52 & 654 & 622 & 32 & 3.49 \\
\hline soak & V & 5.32 & 1.66 & 2,236 & 934 & 578 & 481 & 97 & 570 & 547 & 23 & 3.74 \\
\hline soar & V & 5.54 & 1.67 & 2,315 & 1,076 & 588 & 565 & 23 & 571 & 617 & -46 & 3.44 \\
\hline sob & B & 6.00 & 1.44 & 2,042 & 745 & 542 & 533 & 9 & 617 & 609 & 8 & 3.50 \\
\hline soccer & $\mathrm{N}$ & 6.68 & 0.67 & 1,877 & 934 & 494 & 597 & -103 & 494 & 597 & -103 & 3.88 \\
\hline soda & $\mathrm{N}$ & 6.79 & 0.57 & 1,661 & 650 & 494 & 588 & -94 & 510 & 597 & -87 & 3.56 \\
\hline sodium & $\mathrm{N}$ & 4.37 & 2.10 & 2,979 & 1,917 & 567 & 624 & -57 & 567 & 624 & -57 & 3.34 \\
\hline sofa & $\mathrm{N}$ & 6.71 & 0.66 & 1,685 & 1,091 & 601 & 706 & -105 & 601 & 706 & -105 & 3.18 \\
\hline solve & V & 4.46 & 1.99 & 2,120 & 947 & 657 & 477 & 180 & 637 & 532 & 105 & 4.58 \\
\hline son & $\mathrm{N}$ & 6.54 & 0.92 & 2,159 & 1,099 & 503 & 578 & -75 & 514 & 585 & -71 & 4.72 \\
\hline sonar & $\mathrm{N}$ & 3.68 & 1.93 & 2,965 & 1,397 & 593 & 654 & -61 & 593 & 654 & -61 & 2.70 \\
\hline song & $\mathrm{N}$ & 5.89 & 1.29 & 2,795 & 2,031 & 458 & 595 & -137 & 472 & 590 & -118 & 4.97 \\
\hline soothe & V & 4.61 & 1.95 & 2,035 & 812 & 722 & 597 & 125 & 625 & 625 & 0 & 3.00 \\
\hline sorrow & $\mathrm{N}$ & 4.89 & 1.75 & 2,320 & 1,347 & 563 & 587 & -24 & 744 & 799 & -55 & 3.51 \\
\hline soul & $\mathrm{N}$ & 4.68 & 2.09 & 3,067 & 1,576 & 559 & 676 & -117 & 558 & 663 & -105 & 4.58 \\
\hline soup & $\mathrm{N}$ & 6.75 & 0.84 & 1,512 & 709 & 466 & 573 & -107 & 476 & 577 & -101 & 3.81 \\
\hline source & $\mathrm{N}$ & 2.96 & 1.71 & 3,291 & 1,446 & 590 & 663 & -73 & 580 & 646 & -66 & 5.37 \\
\hline spa & $\mathrm{N}$ & 6.86 & 0.45 & 1,767 & 887 & 551 & 642 & -91 & 551 & 642 & -91 & 3.01 \\
\hline speak & V & 5.75 & 1.60 & 2,009 & 957 & 614 & 455 & 159 & 577 & 500 & 77 & 5.06 \\
\hline speck & $\mathrm{N}$ & 4.93 & 1.78 & 2,069 & 695 & 654 & 696 & -42 & 663 & 697 & -34 & 2.86 \\
\hline speech & $\mathrm{N}$ & 4.57 & 2.06 & 3,041 & 1,723 & 512 & 582 & -70 & 516 & 585 & -69 & 4.59 \\
\hline spell & B & 4.71 & 1.94 & 3,067 & 1,774 & 499 & 522 & -23 & 512 & 539 & -27 & 4.67 \\
\hline spend & V & 4.57 & 2.01 & 2,490 & 1,033 & 639 & 453 & 186 & 591 & 497 & 94 & 4.99 \\
\hline sphere & $\mathrm{N}$ & 6.36 & 1.22 & 2,231 & 1,401 & 740 & 878 & -138 & 722 & 854 & -132 & 4.14 \\
\hline spice & B & 6.19 & 0.96 & 1,794 & 595 & 515 & 548 & -33 & 547 & 589 & -42 & 3.61 \\
\hline spike & B & 5.89 & 1.42 & 2,310 & 853 & 622 & 714 & -92 & 595 & 683 & -88 & 3.79 \\
\hline spine & $\mathrm{N}$ & 6.21 & 1.26 & 1,918 & 600 & 575 & 689 & -114 & 577 & 687 & -110 & 3.74 \\
\hline splice & B & 4.41 & 2.21 & 2,742 & 1,151 & 597 & 572 & 25 & 631 & 619 & 12 & 3.15 \\
\hline sponge & B & 6.50 & 1.29 & 1,701 & 554 & 505 & 621 & -116 & 535 & 635 & -100 & 3.29 \\
\hline spouse & $\mathrm{N}$ & 6.32 & 1.25 & 2,315 & 975 & 549 & 598 & -49 & 576 & 610 & -34 & 3.78 \\
\hline spray & B & 6.30 & 1.17 & 2,617 & 1,639 & 483 & 506 & -23 & 521 & 539 & -18 & 3.92 \\
\hline spur & B & 4.48 & 2.23 & 2,725 & 1,552 & 569 & 574 & -5 & 547 & 596 & -49 & 3.40 \\
\hline spurn & $\mathrm{V}$ & 2.36 & 1.57 & 2,480 & 1,160 & & & & & & & 2.30 \\
\hline squad & $\mathrm{N}$ & 5.52 & 1.55 & 2,408 & 1,513 & 463 & 624 & -161 & 482 & 626 & -144 & 3.77 \\
\hline squash & B & 5.89 & 1.45 & 1,951 & 1,137 & 540 & 553 & -13 & 563 & 578 & -15 & 3.29 \\
\hline squeal & B & 5.71 & 1.49 & 2,457 & 1,708 & 584 & 576 & 8 & 650 & 645 & 5 & 3.16 \\
\hline squirm & V & 4.96 & 1.77 & 2,658 & 1,237 & 701 & 565 & 136 & 703 & 652 & 51 & 3.30 \\
\hline stack & B & 6.04 & 1.26 & 2,599 & 2,212 & 466 & 567 & -101 & 484 & 568 & -84 & 4.29 \\
\hline stair & $\mathrm{N}$ & 6.50 & 1.11 & 2,107 & 1,106 & 573 & 684 & -111 & 585 & 668 & -83 & 3.81 \\
\hline stalk & V & 4.82 & 1.96 & 2,290 & 1,214 & 557 & 576 & -19 & 582 & 607 & -25 & 3.38 \\
\hline starve & V & 5.26 & 1.65 & 2,860 & 1,905 & 695 & 529 & 166 & 609 & 543 & 66 & 3.63 \\
\hline statue & $N$ & 6.54 & 1.07 & 1,908 & 803 & 650 & 799 & -149 & 635 & 778 & -143 & 3.95 \\
\hline status & $\mathrm{N}$ & 2.11 & 1.47 & 3,258 & 1,495 & 500 & 573 & -73 & 500 & 573 & -73 & 4.64 \\
\hline steak & $\mathrm{N}$ & 6.96 & 0.19 & 1,559 & 434 & 493 & 564 & -71 & 515 & 573 & -58 & 3.30 \\
\hline steal & V & 4.93 & 1.98 & 3,199 & 2,009 & 596 & 525 & 71 & 585 & 554 & 31 & 4.46 \\
\hline steam & B & 6.61 & 0.69 & 1,685 & 680 & 464 & 554 & -90 & 486 & 569 & -83 & 3.82 \\
\hline stick & B & 6.67 & 0.88 & 1,767 & 737 & 512 & 445 & 67 & 510 & 470 & 40 & 4.59 \\
\hline stifle & V & 3.68 & 1.96 & 3,273 & 1,857 & 633 & 537 & 96 & 645 & 609 & 36 & 3.21 \\
\hline sting & B & 6.18 & 1.02 & 2,040 & 1,581 & 469 & 556 & -87 & 520 & 583 & -63 & 3.65 \\
\hline stint & $\mathrm{N}$ & 2.14 & 1.53 & 2,589 & 1,732 & 646 & 703 & -57 & 646 & 703 & -57 & 2.79 \\
\hline story & $\mathrm{N}$ & 5.96 & 1.48 & 2,173 & 929 & 464 & 583 & -119 & 479 & 574 & -95 & 5.14 \\
\hline stow & $\mathrm{V}$ & 3.57 & 2.25 & 2,200 & 1,179 & 681 & 644 & 37 & 681 & 644 & 37 & 2.26 \\
\hline strap & B & 6.04 & 1.32 & 1,983 & 776 & 492 & 581 & -89 & 526 & 596 & -70 & 3.87 \\
\hline street & $\mathrm{N}$ & 6.71 & 0.66 & 2,364 & 2,329 & 541 & 673 & -132 & 544 & 671 & -127 & 4.94 \\
\hline stride & B & 5.07 & 1.86 & 2,160 & 1,064 & 591 & 626 & -35 & 625 & 646 & -21 & 3.20 \\
\hline strive & V & 3.79 & 1.93 & 2,669 & 1,777 & 654 & 557 & 97 & 650 & 592 & 58 & 3.64 \\
\hline studio & $\mathrm{N}$ & 6.18 & 1.06 & 1,840 & 910 & 442 & 585 & -143 & 461 & 595 & -134 & 4.31 \\
\hline stun & V & 4.71 & 1.96 & 2,195 & 1,151 & 585 & 631 & -46 & 569 & 605 & -36 & 3.78 \\
\hline
\end{tabular}


APPENDIX B (Continued)

\begin{tabular}{|c|c|c|c|c|c|c|c|c|c|c|c|c|}
\hline \multirow[b]{2}{*}{ Word } & \multirow{2}{*}{$\begin{array}{c}\text { FK } \\
\text { Code }\end{array}$} & \multicolumn{2}{|c|}{ Image Rate } & \multicolumn{2}{|c|}{ Image RT } & \multicolumn{3}{|c|}{ HAL Uninflected $\dagger$} & \multicolumn{3}{|c|}{ HAL Inflected $\ddagger$} & \multirow{2}{*}{$\begin{array}{c}\text { Usenet } \\
\text { Log Frequency }\end{array}$} \\
\hline & & $M$ & $S D$ & $M$ & $S D$ & NDist & VDist & NVDD & NDist & VDist & NVDD & \\
\hline stupor & $\mathrm{N}$ & 3.04 & 1.69 & 3,006 & 1,433 & 707 & 777 & -70 & 707 & $77 \overline{7}$ & -70 & 2.41 \\
\hline subdue & $\mathrm{V}$ & 3.26 & 1.43 & 3,262 & 2,086 & 899 & 940 & -41 & 840 & 871 & -31 & 3.32 \\
\hline submit & $\mathrm{V}$ & 3.89 & 2.06 & 2,353 & 1,734 & 654 & 536 & 118 & 628 & 562 & 66 & 4.60 \\
\hline suburb & $\mathrm{N}$ & 5.07 & 1.78 & 2,444 & 1,032 & 680 & 781 & -101 & 641 & 744 & -103 & 3.64 \\
\hline subway & $\mathrm{N}$ & 6.68 & 0.55 & 1,918 & 1,070 & 509 & 640 & -131 & 531 & 649 & -118 & 3.35 \\
\hline suffer & V & 4.00 & 2.09 & 2,925 & 1,549 & 614 & 458 & 156 & 570 & 513 & 57 & 4.50 \\
\hline suite & $\mathrm{N}$ & 5.61 & 1.59 & 2,737 & 1,430 & 874 & 937 & -63 & 866 & 930 & -64 & 4.73 \\
\hline sunset & $\mathrm{N}$ & 6.75 & 0.93 & 1,423 & 558 & 494 & 631 & -137 & 506 & 639 & -133 & 3.57 \\
\hline supper & $\mathrm{N}$ & 6.18 & 1.25 & 2,106 & 1,442 & 584 & 609 & -25 & 584 & 609 & -25 & 3.07 \\
\hline supply & B & 4.18 & 1.61 & 2,970 & 2,497 & 504 & 524 & -20 & 519 & 546 & -27 & 4.77 \\
\hline surge & B & 4.11 & 1.89 & 2,939 & 2,316 & 679 & 787 & -108 & 676 & 771 & -95 & 3.73 \\
\hline swan & $\mathrm{N}$ & 6.64 & 1.03 & 2,036 & 1,281 & 540 & 653 & -113 & 549 & 662 & -113 & 3.33 \\
\hline swap & $\mathrm{V}$ & 4.43 & 1.95 & 3,247 & 2,133 & 512 & 510 & 2 & 526 & 522 & 4 & 4.22 \\
\hline swear & $\mathrm{V}$ & 4.32 & 2.02 & 2,725 & 1,358 & 603 & 526 & 77 & 615 & 570 & 45 & 4.01 \\
\hline swipe & B & 5.30 & 1.66 & 2,493 & 1,250 & 619 & 586 & 33 & 639 & 616 & 23 & 3.08 \\
\hline sword & $\mathrm{N}$ & 6.93 & 0.38 & 1,451 & 528 & 510 & 681 & -171 & 612 & 756 & -144 & 4.42 \\
\hline syrup & $\mathrm{N}$ & 6.57 & 0.92 & 1,570 & 704 & 497 & 603 & -106 & 497 & 603 & -106 & 3.28 \\
\hline system & $\mathrm{N}$ & 2.46 & 1.64 & 3,125 & 2,028 & 468 & 581 & -113 & 508 & 602 & -94 & 5.83 \\
\hline tack & B & 6.43 & 1.26 & 2,507 & 1,290 & 517 & 522 & -5 & 565 & 562 & 3 & 3.44 \\
\hline tact & $\mathrm{N}$ & 2.86 & 1.78 & 2,465 & 1,118 & 643 & 681 & -38 & 643 & 681 & -38 & 2.88 \\
\hline $\operatorname{tag}$ & $B$ & 5.57 & 1.45 & 2,403 & 1,266 & 562 & 645 & -83 & 570 & 638 & -68 & 4.45 \\
\hline taint & B & 3.36 & 1.85 & 2,364 & 872 & 577 & 575 & 2 & 598 & 605 & -7 & 3.18 \\
\hline talent & $\mathrm{N}$ & 4.86 & 1.76 & 2,504 & 1,517 & 510 & 576 & $-6 \overline{6}$ & 531 & 589 & -58 & 4.13 \\
\hline tangle & B & 4.50 & 1.82 & 2,723 & 1,549 & 851 & 927 & -76 & 742 & 813 & -71 & 3.48 \\
\hline task & $\mathrm{N}$ & 3.39 & 1.69 & 2,858 & 1,537 & 489 & 556 & -67 & 519 & 564 & -45 & 4.50 \\
\hline tatter & V & 3.32 & 2.39 & 2,360 & 997 & & & & 628 & 737 & -109 & 2.64 \\
\hline taunt & B & 4.04 & 1.83 & 2,785 & 1,586 & 642 & 552 & 90 & 630 & 598 & 32 & 3.29 \\
\hline tavern & $\mathrm{N}$ & 5.68 & 1.68 & 2,445 & 1,195 & 549 & 691 & -142 & 549 & 691 & -142 & 2.99 \\
\hline tea & $\mathrm{N}$ & 6.61 & 0.69 & 1,630 & 1,101 & 458 & 547 & -89 & 469 & 553 & -84 & 3.97 \\
\hline teach & V & 5.54 & 1.57 & 2,200 & 1,210 & 602 & 426 & 176 & 557 & 499 & 58 & 4.83 \\
\hline teem & V & 2.68 & 1.76 & 4,482 & 4,124 & & & & 678 & 764 & -86 & 2.43 \\
\hline teeter & V & 3.25 & 1.96 & 2,497 & 1,309 & 779 & 824 & -45 & 779 & 824 & -45 & 2.18 \\
\hline tell & V & 4.00 & 1.91 & 2,941 & 1,958 & 622 & 477 & 145 & 601 & 506 & 95 & 5.56 \\
\hline tempo & $\mathrm{N}$ & 3.68 & 1.79 & 2,868 & 1,404 & 493 & 598 & -105 & 505 & 606 & -101 & 3.49 \\
\hline tempt & V & 3.57 & 1.48 & 3,034 & 1,420 & 695 & 553 & 142 & 666 & 616 & 50 & 3.71 \\
\hline tenant & $\mathrm{N}$ & 5.25 & 1.67 & 2,309 & 1,021 & 519 & 623 & -104 & 541 & 619 & -78 & 3.21 \\
\hline tend & V & 3.14 & 1.65 & 2,875 & 2,006 & 585 & 524 & 61 & 573 & 539 & 34 & 4.64 \\
\hline tendon & $\mathrm{N}$ & 5.39 & 1.87 & 2,271 & 836 & 580 & 682 & -102 & 590 & 667 & -77 & 3.07 \\
\hline tennis & $\mathrm{N}$ & 6.79 & 0.57 & 1,744 & 1,116 & 476 & 594 & -118 & 476 & 594 & -118 & 3.81 \\
\hline terror & $\mathrm{N}$ & 4.57 & 1.91 & 2,659 & 1,329 & 511 & 650 & -139 & 515 & 651 & -136 & 3.95 \\
\hline text & $\mathrm{N}$ & 5.82 & 1.42 & 2,169 & 1,001 & 519 & 618 & -99 & 520 & 617 & -97 & 5.12 \\
\hline theme & $\mathrm{N}$ & 2.25 & 1.35 & 2,869 & 1,465 & 454 & 584 & -130 & 479 & 595 & -116 & 4.28 \\
\hline theory & $\mathrm{N}$ & 4.00 & 1.92 & 2,287 & 1,669 & 461 & 556 & -95 & 473 & 557 & -84 & 4.77 \\
\hline thief & $\mathrm{N}$ & 6.29 & 1.21 & 1,948 & 1,245 & 519 & 619 & -100 & 525 & 603 & -78 & 3.83 \\
\hline thigh & $\mathrm{N}$ & 6.36 & 1.31 & 1,955 & 1,146 & 642 & 725 & -83 & 697 & 760 & -63 & 3.91 \\
\hline thing & $\mathrm{N}$ & 3.14 & 2.05 & 3,541 & 1,622 & 538 & 603 & -65 & 541 & 560 & -19 & 5.70 \\
\hline think & V & 4.32 & 2.20 & 2,338 & 1,201 & 629 & 547 & 82 & 612 & 545 & 67 & 5.96 \\
\hline thorn & $\mathrm{N}$ & 6.79 & 0.57 & 1,696 & 747 & 745 & 870 & -125 & 723 & 842 & -119 & 3.64 \\
\hline threat & $\mathrm{N}$ & 3.61 & 1.93 & 2,901 & 1,690 & 513 & 597 & -84 & 519 & 583 & -64 & 4.41 \\
\hline thrift & $\mathrm{N}$ & 2.71 & 1.41 & 3,268 & 1,480 & 575 & 651 & -76 & 575 & 651 & -76 & 2.79 \\
\hline thrill & B & 4.68 & 1.94 & 2,600 & 1,315 & 487 & 557 & -70 & 572 & 591 & -19 & 3.75 \\
\hline thrive & V & 2.43 & 1.35 & 2,853 & 1,268 & 685 & 545 & 140 & 669 & 616 & 53 & 3.47 \\
\hline throb & V & 5.07 & 1.65 & 2,656 & 2,094 & 732 & 673 & 59 & 674 & 728 & -54 & 3.41 \\
\hline thud & B & 4.64 & 2.11 & 3,156 & 3,016 & 641 & 710 & -69 & 641 & 710 & -69 & 2.67 \\
\hline thug & $\mathrm{N}$ & 5.64 & 1.79 & 1,828 & 800 & 561 & 611 & -50 & 555 & 611 & -56 & 3.39 \\
\hline tickle & V & 6.29 & 0.94 & 2,148 & 978 & 608 & 510 & 98 & 633 & 601 & 32 & 3.46 \\
\hline tire & B & 6.79 & 0.63 & 1,651 & 1,076 & 462 & 547 & -85 & 573 & 574 & -1 & 4.53 \\
\hline toad & $\mathrm{N}$ & 6.57 & 1.10 & 2,674 & 5,698 & 545 & 642 & -97 & 574 & 653 & -79 & 3.33 \\
\hline toast & B & 6.63 & 0.79 & 1,583 & 576 & 493 & 529 & -36 & 521 & 550 & -29 & 3.63 \\
\hline toil & B & 3.68 & 1.91 & 2,550 & 1,505 & 668 & 627 & 41 & 668 & 627 & 41 & 2.57 \\
\hline tomato & $\mathrm{N}$ & 6.86 & 0.59 & 1,701 & 908 & 514 & 604 & -90 & 529 & 615 & -86 & 3.64 \\
\hline tomb & $\mathrm{N}$ & 6.18 & 1.02 & 2,008 & 1,092 & 692 & 823 & -131 & 692 & 821 & -129 & 3.82 \\
\hline ton & $\mathrm{N}$ & 3.86 & 2.26 & 3,191 & 2,132 & 563 & 626 & -63 & 551 & 592 & -41 & 4.35 \\
\hline
\end{tabular}


APPENDIX B (Continued)

\begin{tabular}{|c|c|c|c|c|c|c|c|c|c|c|c|c|}
\hline \multirow[b]{2}{*}{ Word } & \multirow{2}{*}{$\begin{array}{c}\text { FK } \\
\text { Code }\end{array}$} & \multicolumn{2}{|c|}{ Image Rate } & \multicolumn{2}{|c|}{ Image RT } & \multicolumn{3}{|c|}{ HAL Uninflected $\dagger$} & \multicolumn{3}{|c|}{ HAL Inflected $\ddagger$} & \multirow{2}{*}{$\begin{array}{c}\text { Usenet } \\
\text { Log Frequency }\end{array}$} \\
\hline & & $M$ & $S D$ & $M$ & $S D$ & NDist & VDist & NVDD & NDist & VDist & NVDD & \\
\hline tooth & $\mathrm{N}$ & 6.69 & 0.97 & 1,580 & 678 & 493 & 592 & -99 & 525 & 579 & -54 & 4.15 \\
\hline topic & $\mathrm{N}$ & 2.57 & 1.48 & 3,272 & 1,719 & 536 & 608 & -72 & 561 & 619 & -58 & 4.80 \\
\hline topple & V & 4.96 & 1.50 & 2,505 & 1,334 & 758 & 659 & 99 & 716 & 683 & 33 & 2.80 \\
\hline touch & B & 5.32 & 1.74 & 2,791 & 1,462 & 531 & 516 & 15 & 541 & 528 & 13 & 4.69 \\
\hline tousle & V & 2.71 & 1.86 & 3,093 & 3,843 & & & & & & & 1.04 \\
\hline tow & B & 5.32 & 1.54 & 1,876 & 746 & 495 & 525 & -30 & 526 & 548 & -22 & 3.51 \\
\hline tower & B & 6.96 & 0.19 & 1,983 & 1,363 & 615 & 763 & -148 & 603 & 747 & -144 & 4.44 \\
\hline town & $\mathrm{N}$ & 6.64 & 0.62 & 2,155 & 1,660 & 489 & 629 & -140 & 497 & 630 & -133 & 4.62 \\
\hline trait & $\mathbf{N}$ & 3.89 & 1.81 & 2,403 & 1,033 & 597 & 654 & -57 & 579 & 622 & -43 & 3.75 \\
\hline tray & $\mathbf{N}$ & 6.64 & 1.16 & 1,576 & 688 & 503 & 638 & -135 & 518 & 638 & -120 & 3.64 \\
\hline tread & B & 4.82 & 1.81 & 3,456 & 1,613 & 551 & 545 & 6 & 570 & 564 & 6 & 3.60 \\
\hline treaty & $\mathrm{N}$ & 4.68 & 1.83 & 2,360 & 1,103 & 523 & 669 & -146 & 539 & 663 & -124 & 3.96 \\
\hline tremor & $\mathrm{N}$ & 5.68 & 1.31 & 2,200 & 1,343 & 744 & 851 & -107 & 717 & 807 & -90 & 2.96 \\
\hline tribe & $\mathrm{N}$ & 6.04 & 1.10 & 2,434 & 1,596 & 500 & 647 & -147 & 525 & 653 & -128 & 3.88 \\
\hline trivia & $\mathrm{N}$ & 2.93 & 1.76 & 3,195 & 1,733 & 531 & 628 & -97 & 531 & 628 & -97 & 3.60 \\
\hline trophy & $\mathrm{N}$ & 6.79 & 0.63 & 1,818 & 844 & 556 & 705 & -149 & 573 & 699 & -126 & 3.45 \\
\hline trout & $\mathrm{N}$ & 6.39 & 0.99 & 1,688 & 701 & 492 & 591 & -99 & 492 & 591 & -99 & 3.29 \\
\hline truce & $\mathrm{N}$ & 3.07 & 1.84 & 3,009 & 1,281 & 634 & 759 & -125 & 634 & 759 & -125 & 2.97 \\
\hline trudge & V & 4.04 & 2.10 & 2,627 & 1,358 & & & & & & & 2.10 \\
\hline trunk & $\mathbf{N}$ & 6.50 & 0.96 & 2,232 & 1,017 & 503 & 627 & -124 & 513 & 620 & -107 & 3.63 \\
\hline trust & B & 4.25 & 2.24 & 2,409 & 1,445 & 547 & 459 & 88 & 560 & 484 & 76 & 4.56 \\
\hline truth & $\mathbf{N}$ & 4.07 & 1.92 & 3,110 & 1,778 & 515 & 546 & -31 & 518 & 548 & -30 & 4.74 \\
\hline tube & $\mathrm{N}$ & 6.15 & 1.17 & 1,831 & 874 & 450 & 604 & -154 & 450 & 604 & -154 & 4.16 \\
\hline tuck & V & 4.75 & 1.60 & 2,590 & 1,058 & 574 & 548 & 26 & 587 & 579 & 8 & 3.36 \\
\hline tulip & $\mathrm{N}$ & 6.32 & 1.42 & 1,713 & 893 & 660 & 741 & -81 & 659 & 733 & -74 & 2.90 \\
\hline tumor & $\mathrm{N}$ & 5.21 & 1.83 & 2,719 & 1,539 & 521 & 622 & -101 & 553 & 633 & -80 & 3.39 \\
\hline turf & $\mathrm{N}$ & 4.71 & 2.00 & 2,601 & 1,286 & 568 & 628 & -60 & 568 & 628 & -60 & 3.05 \\
\hline turkey & $\mathrm{N}$ & 6.86 & 0.45 & 1,348 & 327 & 480 & 547 & -67 & 494 & 558 & -64 & 4.19 \\
\hline tyrant & $\mathrm{N}$ & 4.39 & 1.91 & 2,203 & 1,492 & 577 & 647 & -70 & 635 & 702 & -67 & 3.30 \\
\hline ulcer & $\mathrm{N}$ & 4.04 & 2.13 & 2,456 & 960 & 611 & 665 & -54 & 627 & 658 & -31 & 2.98 \\
\hline unify & V & 4.54 & 1.75 & 2,866 & 2,938 & 677 & 651 & 26 & 564 & 631 & -67 & 3.70 \\
\hline union & $\mathrm{N}$ & 3.79 & 1.93 & 3,311 & 1,607 & 482 & 626 & -144 & 491 & 624 & -133 & 4.55 \\
\hline unit & $\mathrm{N}$ & 3.18 & 1.91 & 3,028 & 1,629 & 458 & 590 & -132 & 468 & 580 & -112 & 4.84 \\
\hline unite & V & 4.89 & 1.91 & 2,839 & 3,223 & 622 & 543 & 79 & 553 & 679 & -126 & 4.93 \\
\hline unity & $\mathbf{N}$ & 4.54 & 1.75 & 2,844 & 1,592 & 507 & 625 & -118 & 507 & 625 & -118 & 3.72 \\
\hline usage & $\mathrm{N}$ & 2.64 & 1.64 & 2,866 & 2,126 & 504 & 570 & -66 & 508 & 573 & -65 & 4.20 \\
\hline vacate & V & 4.32 & 1.94 & 3,097 & 3,313 & 775 & 663 & 112 & 717 & 700 & 17 & 2.69 \\
\hline valley & $\mathrm{N}$ & 6.39 & 1.07 & 1,749 & 571 & 543 & 697 & -154 & 544 & 697 & -153 & 4.41 \\
\hline valve & $\mathrm{N}$ & 5.18 & 1.87 & 2,437 & 2,414 & 471 & 599 & -128 & 481 & 596 & -115 & 3.79 \\
\hline van & $\mathrm{N}$ & 6.68 & 0.86 & 1,727 & 814 & 556 & 656 & -100 & 556 & 656 & -100 & 4.67 \\
\hline vanish & V & 5.18 & 1.85 & 2,446 & 2,814 & 602 & 537 & 65 & 591 & 614 & -23 & 3.69 \\
\hline vanity & $\mathbf{N}$ & 3.71 & 2.11 & 3,085 & 1,797 & 505 & 596 & -91 & 505 & 596 & -91 & 3.14 \\
\hline vary & V & 3.11 & 1.62 & 2,705 & 1,452 & 590 & 565 & 25 & 573 & 589 & -16 & 4.43 \\
\hline vase & $\mathrm{N}$ & 6.54 & 0.96 & 2,680 & 4,586 & 554 & 656 & -102 & 554 & 656 & -102 & 2.73 \\
\hline veer & V & 3.46 & 1.97 & 2,686 & 1,553 & 722 & 625 & 97 & 722 & 625 & 97 & 2.28 \\
\hline verb & $\mathrm{N}$ & 3.54 & 2.03 & 3,411 & 2,211 & 525 & 624 & -99 & 554 & 628 & -74 & 3.48 \\
\hline vessel & $\mathrm{N}$ & 5.59 & 1.37 & 2,357 & 1,286 & 528 & 698 & -170 & 527 & 659 & -132 & 3.80 \\
\hline vest & B & 6.64 & 0.78 & 1,826 & 1,092 & 525 & 610 & -85 & 584 & 640 & -56 & 3.54 \\
\hline victim & $\mathbf{N}$ & 5.52 & 1.99 & 1,983 & 1,188 & 482 & 567 & -85 & 515 & 577 & -62 & 4.39 \\
\hline vie & V & 1.89 & 1.42 & 2,947 & 2,016 & 714 & 729 & -15 & 711 & 731 & -20 & 3.20 \\
\hline vigor & $\mathrm{N}$ & 3.29 & 1.86 & 2,662 & 1,808 & 617 & 647 & -30 & 617 & 647 & -30 & 2.85 \\
\hline vine & $\mathrm{N}$ & 6.07 & 1.44 & 2,476 & 1,704 & 504 & 647 & -143 & 520 & 615 & -95 & 3.52 \\
\hline virtue & $\mathrm{N}$ & 2.89 & 1.87 & 3,154 & 2,553 & 548 & 608 & -60 & 553 & 612 & -59 & 3.78 \\
\hline virus & $\mathrm{N}$ & 5.32 & 1.59 & 2,660 & 1,530 & 527 & 636 & -109 & 569 & 660 & -91 & 4.54 \\
\hline vision & $\mathrm{N}$ & 5.04 & 1.88 & 2,535 & 1,410 & 455 & 560 & -105 & 489 & 589 & -100 & 4.41 \\
\hline vista & $\mathbf{N}$ & 3.46 & 2.13 & 2,842 & 1,592 & 634 & 724 & -90 & 641 & 727 & -86 & 3.55 \\
\hline volume & $\mathrm{N}$ & 4.86 & 1.74 & 2,866 & 1,541 & 458 & 580 & -122 & 465 & 580 & -115 & 4.68 \\
\hline vote & B & 5.68 & 1.56 & 2,067 & 999 & 491 & 486 & 5 & 512 & 536 & -24 & 5.01 \\
\hline vow & B & 3.18 & 1.91 & 2,791 & 1,115 & 551 & 575 & -24 & 593 & 607 & -14 & 3.41 \\
\hline vowel & $\mathbf{N}$ & 5.32 & 1.76 & 3,382 & 2,322 & 568 & 687 & -119 & 586 & 673 & -87 & 3.28 \\
\hline voyage & $\mathrm{N}$ & 5.44 & 1.53 & 2,301 & 1,434 & 533 & 685 & -152 & 554 & 699 & -145 & 3.44 \\
\hline wade & V & 4.50 & 1.91 & 2,859 & 1,374 & 602 & 590 & 12 & 619 & 608 & 11 & 3.80 \\
\hline wagon & $\mathrm{N}$ & 6.75 & 0.80 & 1,654 & 595 & 623 & 762 & -139 & 620 & 750 & -130 & 3.63 \\
\hline
\end{tabular}


APPENDIX B (Continued)

\begin{tabular}{|c|c|c|c|c|c|c|c|c|c|c|c|c|}
\hline \multirow[b]{2}{*}{ Word } & \multirow{2}{*}{$\begin{array}{l}\text { FK } \\
\text { Code }\end{array}$} & \multicolumn{2}{|c|}{ Image Rate } & \multicolumn{2}{|c|}{ Image RT } & \multicolumn{3}{|c|}{ HAL Uninflected $\uparrow$} & \multicolumn{3}{|c|}{ HAL Inflected ${ }_{+}^{+}$} & \multirow{2}{*}{$\begin{array}{c}\text { Usenet } \\
\text { Log Frequency }\end{array}$} \\
\hline & & $M$ & $S D$ & $M$ & $S D$ & NDist & VDist & NVDD & NDist & VDist & NVDD & \\
\hline wail & B & 5.04 & 1.79 & 3,224 & 2,765 & 613 & 595 & 18 & 620 & 647 & -27 & 3.14 \\
\hline waive & V & 2.86 & 2.01 & 2,944 & 1,342 & 688 & 554 & 134 & 694 & 621 & 73 & 3.19 \\
\hline wallow & V & 3.89 & 1.97 & 2,595 & 1,344 & 719 & 583 & 136 & 683 & 607 & 76 & 2.76 \\
\hline wander & V & 4.93 & 1.77 & 2,615 & 1,929 & 609 & 459 & 150 & 581 & 543 & 38 & 3.90 \\
\hline wane & V & 2.25 & 1.67 & 2.554 & 1,827 & 747 & 732 & 15 & 646 & 721 & -75 & 2.69 \\
\hline warden & $\mathrm{N}$ & 5.29 & 2.05 & 2,892 & 1,542 & 556 & 635 & -79 & 583 & 649 & -66 & 2.93 \\
\hline warn & V & 4.07 & 1.80 & 2,505 & 1,035 & 621 & 466 & 155 & 693 & 702 & -9 & 4.68 \\
\hline wart & $\mathrm{N}$ & 6.61 & 0.74 & 2,195 & 1,295 & 621 & 680 & -59 & 630 & 657 & -27 & 2.82 \\
\hline wasp & $N$ & 6.21 & 1.62 & 1,714 & 730 & 552 & 664 & -112 & 568 & 669 & -101 & 3.04 \\
\hline waste & B & 5.44 & 1.85 & 2,017 & 847 & 537 & 485 & 52 & 557 & 512 & 45 & 4.63 \\
\hline way & $\mathrm{N}$ & 3.29 & 2.09 & 2,626 & 1,153 & 505 & 576 & -71 & 514 & 580 & -66 & 5.74 \\
\hline wealth & $N$ & 5.71 & 1.41 & 2,225 & 1,362 & 501 & 563 & -62 & 501 & 563 & -62 & 4.08 \\
\hline wean & V & 2.46 & 1.53 & 2,379 & 1,298 & 786 & 609 & 177 & 713 & 646 & 67 & 3.35 \\
\hline weapon & $\mathrm{N}$ & 6.29 & 1.15 & 1,899 & 689 & 488 & 618 & -130 & 484 & 571 & -87 & 4.68 \\
\hline wed & V & 5.07 & 1.72 & 2,905 & 1,241 & 778 & 852 & -74 & 776 & 849 & -73 & 4.19 \\
\hline week & $N$ & 4.00 & 2.05 & 3,159 & 1,546 & 548 & 668 & -120 & 570 & 678 & -108 & 5.26 \\
\hline weep & V & 5.57 & 1.71 & 2,112 & 1,982 & 674 & 570 & 104 & 669 & 639 & 30 & 3.31 \\
\hline weigh & V & 4.46 & 2.05 & 2,864 & 1,845 & 590 & 471 & 119 & 577 & 540 & 37 & 3.96 \\
\hline wheat & $\mathrm{N}$ & 6.50 & 1.04 & 1,828 & 982 & 513 & 619 & -106 & 513 & 619 & -106 & 3.61 \\
\hline whir & B & 2.82 & 1.79 & 2,271 & 1,113 & & & & 661 & 707 & -46 & 2.37 \\
\hline wicker & $N$ & 3.93 & 2.05 & 2,206 & 1,157 & 673 & 755 & -82 & 673 & 755 & -82 & 2.58 \\
\hline width & $N$ & 5.04 & 1.62 & 2,419 & 973 & 496 & 596 & -100 & 506 & 599 & -93 & 3.91 \\
\hline wield & V & 3.71 & 2.03 & 2,360 & 800 & 672 & 524 & 148 & 655 & 626 & 29 & 3.25 \\
\hline wife & $\mathrm{N}$ & 6.68 & 0.77 & 1,888 & 1,205 & 550 & 571 & -21 & 553 & 575 & -22 & 4.66 \\
\hline wince & V & 4.82 & 1.79 & 2,073 & 710 & 650 & 579 & 71 & 683 & 635 & 48 & 2.87 \\
\hline window & $\mathrm{N}$ & 6.64 & 1.03 & 1,562 & 758 & 498 & 618 & -120 & 533 & 593 & -60 & 5.45 \\
\hline wit & $N$ & 3.46 & 1.86 & 1,968 & 820 & 505 & 505 & 0 & 529 & 535 & -6 & 3.72 \\
\hline work & B & 4.89 & 2.17 & 2,102 & 1,287 & 549 & 454 & 95 & 544 & 490 & 54 & 5.90 \\
\hline world & $\mathrm{N}$ & 6.79 & 0.42 & 1,704 & 786 & 505 & 631 & -126 & 508 & 633 & -125 & 5.50 \\
\hline worth & $\mathrm{Na}$ & 2.21 & 1.75 & 3,011 & 1,767 & 602 & 582 & 20 & 602 & 582 & 20 & 4.91 \\
\hline wrath & $\mathrm{N}$ & 4.39 & 2.33 & 2,146 & 975 & 703 & 825 & -122 & 703 & 825 & -122 & 3.75 \\
\hline wreath & $\mathrm{N}$ & 6.21 & 1.40 & 2,055 & 873 & 618 & 739 & -121 & 618 & 739 & -121 & 2.46 \\
\hline wring & V & 4.18 & 1.85 & 3,093 & 1,788 & 682 & 591 & 91 & 682 & 591 & 91 & 2.55 \\
\hline write & V & 5.61 & 1.73 & 1,927 & 808 & 595 & 448 & 147 & 870 & 894 & -24 & 6.26 \\
\hline year & $\mathrm{N}$ & 4.57 & 2.39 & 2,356 & 1,648 & 514 & 651 & -137 & 546 & 663 & -117 & 5.78 \\
\hline yearn & V & 4.07 & 2.02 & 2.512 & 1,372 & 691 & 622 & 69 & 643 & 645 & -2 & 2.96 \\
\hline yelp & B & 5.32 & 1.91 & 1,990 & 952 & 739 & 751 & -12 & 759 & 767 & -8 & 2.59 \\
\hline youth & $\mathrm{N}$ & 5.11 & 1.71 & 2,580 & 1,033 & 492 & 634 & -142 & 498 & 635 & -137 & 4.17 \\
\hline zeal & $\mathrm{N}$ & 2.71 & 1.76 & 2,146 & 834 & 650 & 683 & -33 & 650 & 683 & -33 & 2.85 \\
\hline zip & V & 5.46 & 2.06 & 2,806 & 1,422 & 496 & 573 & -77 & 504 & 575 & -71 & 4.28 \\
\hline zoom & $\mathrm{V}$ & 4.86 & 2.09 & 2,655 & 1,290 & 485 & 554 & -69 & 504 & 570 & -66 & 3.78 \\
\hline
\end{tabular}

Note-FK, Francis-Kučera; NDist, noun distance; VDist, verb distance; NVDD, noun-verb distance difference. ${ }^{*}$ Item has adjective usage (Francis \& Kučera, 1982). +No entry indicates the uninflected form is not in the HAL matrix. + No entry indicates that this word (inflected or uninflected) is not in the HAL matrix. 


\section{APPENDIX C \\ Part of Speech Coding of Representative Usenet Contexts for 50 Sample Uninflected Words}

The first author examined each of the randomly selected contexts for all 50 sample target words. Ninety-seven percent of the target word occurrences were classifiable as nouns, adjectives, prepositions, adverbs, or verbs. Proper nouns and nouns used to modify a head noun (e.g., work experience) were coded as nouns; all verb occurrences were used as main verbs (none was used as an auxiliary). In the remaining $3 \%$ of the sample contexts, part of speech could not be determined (\%?). In such cases, the word occurred in a nonsyntactic context (e.g., within a line of computer code), occurred within a foreign phrase, or the context was too brief to permit classification (e.g., bolt, $r$ ).

In the table below, each sample word is listed with its Francis-Kučera (FK; 1982) word class code, HAL NVDD score, and its percentage occurrence in the sample for each part of speech. The column labeled $\% \mathrm{~V}-\% \mathrm{~N}$ is the difference between each word's percentage of verb and percentage of noun occurrences. The final column provides other information relevant to interpreting the part of speech coding.

\begin{tabular}{|c|c|c|c|c|c|c|c|c|c|c|}
\hline Word & FK Code & NVDD & \%Noun & $\%$ Adj & $\%$ Prep & $\%$ Adv & $\%$ Verb & $\% ?$ & $\% \mathrm{~V}-\% \mathrm{~N}$ & Comments \\
\hline sword & $\mathrm{N}$ & -171 & 98.0 & & & & 0.0 & 2.0 & -98.0 & \\
\hline circus & $\mathrm{N}$ & -160 & 97.0 & & & & 0.0 & 3.0 & -97.0 & \\
\hline ring & B & -157 & 83.0 & & & & 10.0 & 7.0 & -73.0 & \\
\hline blade & $\mathrm{N}$ & -156 & 96.0 & & & & 1.0 & 3.0 & -95.0 & \\
\hline slug & B & -153 & 92.0 & & & & 7.0 & 1.7 & -85.0 & \\
\hline demon & $\mathrm{N}$ & -151 & 94.5 & & & & 0.0 & 5.5 & -94.5 & \\
\hline crease & B & -144 & 95.5 & & & & 0.0 & 2.7 & -95.5 & \\
\hline bolt & B & -139 & 82.5 & & & 2.5 & 12.5 & 2.5 & -70.0 & \\
\hline $\operatorname{arch}$ & B & -137 & 80.0 & 6.3 & & & 8.6 & 5.1 & -71.4 & $15 \%$ of $\mathrm{N}$ are abbreviations \\
\hline hammer & B & -113 & 81.5 & & & & 12.8 & 5.9 & -68.7 & \\
\hline daze & $\mathrm{V}$ & -112 & 97.3 & & & & 2.7 & 0.0 & -94.6 & $18 \%$ of $\mathrm{N}$ are misspelled "days" \\
\hline shelf & $\mathrm{N}$ & -112 & 98.5 & & & & 1.0 & 0.5 & -97.5 & \\
\hline mar & $\mathrm{V}$ & -85 & 82.5 & & & & 0.6 & 17.0 & -81.9 & $85 \%$ of $\mathrm{N}$ are abbreviations of March \\
\hline zip & $\mathrm{V}$ & -77 & 89.1 & & & & 7.8 & 3.1 & -81.3 & \\
\hline errand & $\mathrm{N}$ & -74 & 99.5 & & & & 0.0 & 0.5 & -99.5 & \\
\hline shriek & B & -74 & 69.6 & & & & 26.5 & 3.9 & -43.1 & \\
\hline wed & $\mathrm{V}$ & -74 & 95.8 & & & & 4.2 & 0.0 & -91.6 & $98 \%$ of $\mathrm{N}$ are abbreviations of Wednesday \\
\hline nag & $\mathrm{V}$ & -72 & 77.3 & & & & 21.8 & 0.9 & -55.5 & \\
\hline sear & $\mathrm{v}$ & -51 & 59.4 & & & & 29.7 & 10.9 & -29.7 & \\
\hline bout & $\mathrm{N}$ & -9 & 12.1 & & 75.8 & 10.6 & 0.5 & 1.0 & -11.6 & all Prep and Adv are reduced "about" \\
\hline shrink & $\mathrm{v}$ & -6 & 36.9 & & & 0.5 & 56.9 & 5.6 & 20.0 & \\
\hline niece & $\mathrm{N}$ & -4 & 95.8 & 3.4 & & & 0.0 & 0.8 & -95.8 & \\
\hline hush & B & -3 & 53.2 & 3.7 & & & 43.1 & 0.0 & -10.1 & \\
\hline rhyme & B & -1 & 65.7 & & & & 30.7 & 3.6 & -35.0 & \\
\hline wit & $\mathrm{N}$ & 0 & 68.9 & & 19.7 & & 8.8 & 2.5 & -60.1 & all Prep are reduced "with" \\
\hline munch & $\mathrm{V}$ & 0 & 61.1 & & & 1.8 & 29.2 & 10.8 & -31.9 & \\
\hline punt & B & 0 & 43.1 & & & 1.0 & 33.3 & 22.5 & -9.8 & $87 \%$ of ? are in foreign phrases \\
\hline slouch & B & 0 & 69.7 & & & & 28.3 & 2.0 & -41.4 & $89 \%$ of $N$ are "(is) no slouch" \\
\hline cure & B & 1 & 66.2 & & & & 30.8 & 3.0 & -35.4 & \\
\hline swap & $\mathrm{V}$ & 2 & 57.6 & & & & 39.9 & 2.5 & -17.7 & \\
\hline erect & $\mathrm{V}$ & 3 & 0.0 & 90.5 & & & 9.0 & 0.5 & 9.0 & \\
\hline idiot & $\mathrm{N}$ & 6 & 100.0 & & & & 0.0 & 0.0 & -100.0 & $25 \%$ of $N$ are " $X$ is an idiot," $15 \%$ are parenthetic \\
\hline extent & $\mathrm{N}$ & 18 & 99.5 & & & & 0.5 & 0.0 & -99.0 & $76 \%$ of $N$ are "to $X$ extent" or "to extent that" \\
\hline $\operatorname{cod}$ & $\mathrm{N}$ & 18 & 6.4 & & & & 0.0 & 0.0 & -6.4 & additional $93 \%$ abbreviated c.o.d. \\
\hline invert & $\mathrm{V}$ & 24 & 17.3 & & & & 78.8 & 3.8 & 61.5 & \\
\hline rinse & B & 25 & 26.5 & & & & 72.8 & 0.7 & 46.3 & \\
\hline access & $\mathrm{N}$ & 61 & 84.4 & & & & 15.6 & 0.0 & -68.8 & \\
\hline croak & B & 75 & 8.0 & & & & 88.0 & 4.0 & 80.0 & \\
\hline care & B & 84 & 53.3 & & & & 46.2 & 0.5 & -7.1 & $30 \%$ of $N$ "take care (of)" \\
\hline pout & B & 89 & 35.7 & & & & 53.6 & 10.7 & 17.9 & \\
\hline send & V & 93 & 2.0 & & & & 97.5 & 0.5 & 95.5 & \\
\hline work & B & 95 & 35.9 & & & & 62.6 & 1.5 & 26.7 & \\
\hline gain & B & 105 & 30.7 & & & & 69.3 & 0.0 & 38.6 & \\
\hline change & B & 106 & 32.7 & & & & 67.3 & 0.0 & 34.6 & \\
\hline berate & $\mathrm{V}$ & 174 & 0.9 & & & & 99.1 & 0.0 & 98.2 & \\
\hline punish & V & 182 & 0.6 & 1.8 & & & 96.5 & 1.2 & 95.9 & \\
\hline prove & V & 186 & 0.0 & & & & 100.0 & 0.0 & 100.0 & \\
\hline delve & $\mathrm{V}$ & 190 & 0.0 & & & & 100.0 & 0.0 & 100.0 & \\
\hline defend & $\mathrm{V}$ & 191 & 0.0 & & & & 100.0 & 0.0 & 100.0 & \\
\hline
\end{tabular}




\section{APPENDIX D \\ Part-of-Speech Coding of Representative Usenet Contexts for 28 Sample Inflected Words}

The first author examined each of the randomly selected contexts for all inflected forms of the 28 sample words. The sampling procedure was the same as that employed for the uninflected forms, except that now a sample of contexts was selected for each (uninflected and inflected) form of the word. Part of speech usages were coded separately for each form of the word, and these percentages were weighted by the Usenet frequency for that particular inflected form before being combined across all forms of the word. Because samples of the same size were culled regardless of the form's frequency, this weighting ensured that the part of speech percentages were not disproportionally influenced by inflected forms having very low frequencies of occurrence. Thus, the percentages reported in the table below reflect the weighted averages for each part of speech, across all inflected forms of the word.

The sampled context could not completely disambiguate the part of speech occurrence for some forms. Some contexts could be read as either adjective or verb usages (labeled \%Adj/V); others could be read as either noun or verb usages (labeled \%N/V). The frequency of occurrence of these ambiguous forms is listed separately in the table.

In the table below, each sample word is listed with its Francis-Kučera (FK) word class code, inflected noun-verb distance difference (NVDD) score, and its percentage occurrence in the sample for each part of speech. The column labeled $\% \mathrm{~V}-\% \mathrm{~N}$ is the difference between each word's percentage of verb and percentage of noun occurrences. The final column provides other information relevant to interpreting the part of speech coding.

\begin{tabular}{|c|c|c|c|c|c|c|c|c|c|c|c|}
\hline Word & FK Code & Inf NVDD & $\%$ Noun & $\%$ Adj & $\%$ Adj/V & $\% \mathrm{~N} / \mathrm{V}$ & $\%$ Intrj & $\%$ Verb & $\% ?$ & $\% \mathrm{~V}-\% \mathrm{~N}$ & Comments \\
\hline sword & $N$ & -144 & 96.6 & 0 & & & & 0 & 3.4 & -96.6 & \\
\hline wrath & $\mathrm{N}$ & -122 & 96.9 & 0 & & & & 0 & 3.0 & -96.9 & $41 \%$ unmodified \\
\hline clay & $\mathrm{N}$ & -117 & 92.1 & 0 & & & & 2.0 & 5.9 & -90.1 & \\
\hline dwarf & $\mathrm{B}$ & -115 & 90.7 & 0.3 & & & & 3.8 & 5.2 & -86.9 & \\
\hline tatter & V & -109 & 15.2 & 81.4 & & & & 0 & 3.4 & -15.2 & \\
\hline pecan & $\mathrm{N}$ & -99 & 98.0 & 0 & & & & 0 & 2.0 & -98.0 & \\
\hline smudge & $\mathrm{B}$ & -98 & 57.2 & 10.7 & 0.3 & & & 18.0 & 13.7 & -39.2 & \\
\hline elapse & V & -86 & 0.4 & 47.0 & & & & 52.6 & 0 & 52.2 & $61 \%$ with "time" \\
\hline blight & $\mathrm{B}$ & -83 & 76.1 & 2.0 & 0.2 & & & 4.9 & 16.5 & -71.2 & \\
\hline brow & $\mathrm{N}$ & -81 & 100.0 & 0 & & & & 0 & 0 & -100.0 & $39 \%$ with possessive pronoun only \\
\hline daze & V & -77 & 58.5 & 28.2 & & & & 5.4 & 4.6 & -53.1 & \\
\hline cousin & $\mathbf{N}$ & -45 & 99.3 & 0 & & & & 0 & 0.7 & -99.3 & $61 \%$ with possessive pronoun only \\
\hline bind & V & -44 & 29.6 & 38.9 & 4.6 & 1.7 & & 21.1 & 3.9 & -8.5 & \\
\hline apathy & $\mathrm{N}$ & -27 & 99.0 & 0 & & & & 0 & 1.0 & -99.0 & $64 \%$ unmodified \\
\hline deceit & $\mathbf{N}$ & -14 & 98.7 & 1.3 & & & & 0 & 0 & -98.7 & $51 \%$ are unmodified \\
\hline rhyme & B & -12 & 59.5 & 7.7 & & & & 27.8 & 5.0 & -31.7 & \\
\hline occupy & V & -10 & 0 & 23.4 & 0.5 & 0.2 & & 75.6 & 0.2 & 75.6 & \\
\hline focus & B & -6 & 39.0 & 5.2 & & 2.2 & & 53.2 & 0.3 & 14.2 & $70 \%$ with "on" \\
\hline plea & $\mathrm{N}$ & -6 & 75.5 & 0.7 & & & 20.4 & 3.4 & 0 & -72.1 & Intrj "pleas" used for "please" \\
\hline tack & B & 3 & 46.8 & 4.7 & & 0.2 & & 44.4 & 4.0 & -2.4 & $31 \%$ are "tack on" \\
\hline erode & $\mathrm{V}$ & 17 & 0.7 & 12.7 & 6.4 & & & 79.5 & 0.7 & 78.8 & \\
\hline frolic & B & 40 & 39.4 & 5.8 & & & & 51.9 & 3.0 & 12.5 & \\
\hline toil & B & 41 & 26.4 & 1.4 & & 2.1 & & 66.6 & 3.4 & 40.2 & \\
\hline grieve & V & 52 & 16.8 & 16.4 & & & & 64.9 & 1.9 & 48.1 & \\
\hline care & B & 74 & 52.7 & 2.0 & & & & 44.9 & 1.0 & -7.8 & $31 \%$ of $N$ "take care of" \\
\hline delve & $\mathrm{V}$ & 122 & 1.2 & 0 & & & & 98.3 & 0.5 & 97.1 & \\
\hline grovel & $\mathrm{V}$ & 122 & 30.0 & 7.9 & & 1.3 & & 51.4 & 9.4 & 21.4 & \\
\hline \multirow[t]{2}{*}{ repent } & V & 161 & 4.3 & 0 & & 0.3 & & 90.2 & 5.2 & 85.9 & \\
\hline & & & & & & & & & & & $21 \%$ of $V$ "who cares" \\
\hline
\end{tabular}

(Manuscript received December 7, 1998; revision accepted for publication May 28, 1999.) 